$11-1-1982$

\title{
On the Interregional Structure of the U.S. Economy
}

William B. Beyers

University of Washington

Follow this and additional works at: https://researchrepository.wvu.edu/rri_iotheorymethods

\section{Recommended Citation}

Beyers, William B., "On the Interregional Structure of the U.S. Economy" (1982). Theory and Methods. 9. https://researchrepository.wvu.edu/rri_iotheorymethods/9

This Article is brought to you for free and open access by the IIOA Input Output Archive at The Research Repository @ WVU. It has been accepted for inclusion in Theory and Methods by an authorized administrator of The Research Repository@WVU. For more information, please contact ian.harmon@mail.wvu.edu. 
ON THE INTERREGIONAL STRUCTURE

OF THE U.S. ECONOMY

William B. Beyers

Regional Science Association

North American Meetings

Session in Honor of William H. Miernyk

'Pittsburgh, November 12-14, 1982 
ON THE INTERREGIONAL STRUCTURE OF THE U.S. ECONOMY

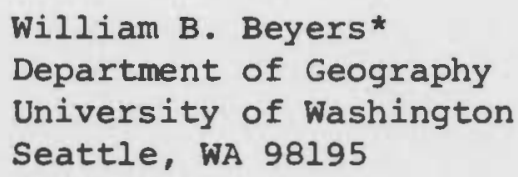

William Miernyk has provided learning tools for a legion of scholars and students of regional science and regional economic structure over the course of his long career. His seminal contributions to measurement of regional economic structure and development are cited almost as frequently as those of his mentor, Professor Leontief. Thus, it is with some humility that I approach this paper, not only knowing that these giants in our field are with us at these sessions, but also realizing that my own contribution in this paper is a modest attempt at extension of our knowledge of spatial interdependence in economic systems.

Leontief and Miernyk have in common the grand distinction of providing us with tantilizing measurements of the models which they have articulated over time, models which in their own right were pioneering from both a theoretical and an empirical standpoint. These accomplishments cannot escape our view in the present era, when much of the written record of "theory" in regional science, economics and geography is totally irreducable to measurement or application, and a period when (possibly not unjustified) we are faced as professions with major funding crises for our research. 1 Miernyk has ably demonstrated that as we progress with the development of more and more powerful theories and models of regional economic systems, that we must also be able to measure these frameworks if they are to extend meaning-

\footnotetext{
* The author wishes to acknowledge the support of the National Science Foundation for measurements which lead to the model presented in this paper, Grant No. SES81-09290. The comments of Professor Roger Bolton on an earlier draft of this paper are also gratefully acknowledged, as are the helpful remarks of Mr. Barney Warf and Mr. Tom Kirn, graduate students in geography at the University of Washington.
} 
advanced

fully scholars understandings of /economic systems and attract the financial support of public and private agencies for such research endeavors. ${ }^{2}$ we must continue to progress with the disaggregation of our models, extending in space and time our theoretical frameworks and their measurement, to continue the tradition of excellence displayed by Professor Miernyk.

As a scholar interested in the spatial dimensions of economic systems, it is necessary to wrestle with the measurement difficulties imposed by the modest funds available for ambitious conceptual structures. At the same time it is necessary to present tentative measurements in order to foster the type of ongoing research support which has distinguished the career of Miernyk. This paper is offered in that spirit. It has its roots in very "conservative" accounts, but it proposes their extension to a degree of geographical disaggregation that is yet to be measured with accuracy. To promote such measurement attempts, a lengthy numerical example is offered which is based on a research project in washington state which has been generously supported by the National science Foundation.

The present paper is organized into five sections. Section I discusses a variety of aspects of findings from regional interindustry models, which suggest the need for additional work at the interregional scale. section II 
presents an initial spatially disaggregate model of interregional economic systems, section III describes data sources used in this paper for some exploratory modelling efforts, and section IV presents results of these exploratory modelling efforts for a single time period and then develops some very tentative illustrations of possible evolution of this interregional system over time. The paper concludes in section $\mathrm{V}$ with a statement of research needs.

first

The/mathematical representation of the interregional input-output model was published thirty years ago by Isard and Leontief. ${ }^{3}$ This model is conceptually decomposable for an open system of regions to any degree of spatial and sectoral detail. Most attempts at measurement of these models have been for partitions of nations into multiregional systems, although Richardson and Gordon suggested a similar detailed disaggregation at the metropolitan scale. 4

As evidence has accumulated on the structure of regional economies, through survey work such as that conducted in washington, West Virginia, Georgia, and Hawaii, it has become evident that regional economic systems in advanced economies are quite open in terms of their interindustry linkage systems.' Consumption and investment distributions within the final demand structure also have strong interregional components, while state and local government outlays appear to be more strongly tied to local factors of production than the typical regional outlay structure of the federal government. Unfortunately, relatively little empirical evidence has accumulated regarding the spatial incidence of value added payments, but with the growing fraction of income originating in non-wage sources, we can anticipate considerable interregional income movement. It seems safe to say that regions such as states in the United States exhibit a considerable degree of interdependence for both intermediate and final goods and services, yet only the most meager measurements of the structure of these interdependencies exist. 
This matter is of considerable significance not only to the academic comnunity, but also to those concerned with regional impacts of public policies. As scholars we are interested in the qualities of spatial structure, just as we are interested in aspects of industrial structure. Ideally, we would have a full understanding of both the sectoral and spatial divisions of the economy down to the level proposed in early treatises on activity analysis. ${ }^{6}$ However, such structural measurement is not likely without massive investments. There is equal interest in direct and indirect consequences of regional changes in demands, both within the public and private sectors. The current dramatic shifts in the composition of the federal budget are quite unlikely to have equal regional consequences. Regions favored by budget changes may have local impacts requiring mitigation by federal agencies, just as those indirectly affected may require similar help. At the same time, regions adversely affected by decreases in (relative) outlays on other programs may need other types of assistance, measured both in direct and indirect terms. It is unlikely that the same regions facing declining programs in some/ areas are enjoying enhanced programs in other areas. A reasonable overall program assessment of changes in public sector budgets would allow measurement of impacts of these various changes in program directions. Unfortunately that is not possible at present, because we not only lack fundamental measurements of interregional economic structure at a point in time, but we moreover do not have a comprehensive understanding of the spatial qualities of the evolution of this structure through time.

This is not an issue confined to our domestic scene. Regional scientists seem to have overlooked the application of tools of analysis developed for regional economic systems to the development of interregional or multiregional economic systems at the international scale. 
models, notably the early work of Isard, Moses, Karaska, and Miller. ${ }^{7}$ These efforts were simulations of interregional flows, particularly of manufactured goods. In an economy dominated by services industries wherein we have largely unmeasured degrees of interregional trade, it is not easy to assess the contemporary significance of these findings. However, these studies all indicate that "feedback" effects on a particular region with respect to its demands in such interregional models are modest. This finding would seem to confined to beget the need for such considerations IF one's perspective is a single region. However, since the same modelling efforts document the generic spillover effects from given regions to other regions, the absence of "feedbacks" suggests that advanced economies are characterized by interdependence systems which are spatially "loose" or "extensive". 8 To the extent that any given region depends to a minor extent on any other region, the chain of indirect linkage effects will not produce strong spatial biases in multiplier effects. Of course, this generalization is likely to be overridden in particular contexts, where boundaries may produce stronger interregional interdependencies, or where Perrouxian growth poles may have particularly strong spatial manifestations. If modern economies exhibit these properties in their systems of production, consumption/final demand, and income generation among regions, it seems that we should have a reasonable understanding of these structures so as to discuss not only their structure at a point in time and evolution over time as scholars, but also to participate in the formulation of the programs within the public sector which impact this interconnected system so as to help achieve desired socio/political goals regarding the distribution of economic activity. However, it is not enough just to. describe changes in such systems through comparative static measurements. We must also be providing insights into the evolution of these systems that we realize are occurring, occurring due to the manifold operation of forces leading to a constant restructuring of human systems. 
One of the most common criticisms of the application of regional economic models of the interindustry variety has been the fixity of their coefficient structure in forecasting applications. ${ }^{9}$ It should be noted in this paper that this assumption is discarded. The relevant theory does not assume that economic structures at the regional or interregional scale are constant over time. Instead, all theoretical expositions and empirical evidence points to the gradual evolution of these systems; those that must use these modelling frameworks for projection purposes must wrestle with these assumed structural stabilities.

In this paper, the accounting frameworks utilized are seen as the backdrops on which the changing earvases of the economic and social system are painted. The key factors are the parameters which change over time, the forces which are at work causing those changes in the space-economy.

Prominent among the proximate causes are the following forces, which operate in combination to produce structural change in space as well as national territory : resource discoveries and depletions; changes in terms of trade; changes in consumer tastes; wars; movements of capital and labor (migrations); technological change in processes and products; shifts in public policies; pestilence, famines, climatic changes, natural disasters, etc.

This panoply of forces is clearly at work simultaneously; the scale of implementation of change is at the individual level of the productive and consumptive units in our society--households and establishments. Establishments are here taken to mean both public and private sector entities engaged in economic activities. At this microscale, a myriad of interregional linkage structures exist, whose theoretical specification has been the preoccupation of locational theorists. These locational models have generally been specified in static terms, although explorations of more temporally inclusive locational 
decision making and adaptation frameworks have occupied scholars in recent years. This author has recently documented aspects of these linkage systems; unfortunately space does not permit elaboration of their nature in this paper. Interest in description of economic change in a spatial, context has been a matter of central importance to the progress of Regional science since Isard's pioneering statements in the 1960's. Noting the "Anglo-Saxon bias" in economics towards time at the expense of space in 1956, Isard, Miernyk and other regional scientists and geographers labored to obtain the needed crosssectional measurements at both the micro and macro scale to allow us to begin to develop more realistic theories and models of the space economy.

It is fair to say that today Regional science encompasses spatial and temporal measurement systems. But in the process a reconciliation must be made regarding the rigid optimality conditions that have surrounded most intertemporal models in Regional Science. New theoretical and accounting (measurement) paradigms continue to develop. One framework that seems to be appealing emanates from systems science, the nonequilibrium systems framework as articulated by Prigonine, Allen, and recently embraced by Isard and Miernyk. ${ }^{10}$ This framework encompasses needed conceptual elements, providing opportunities for the manifold structural adjustments which we observe in a comparative static fashion taking place in the space-economy. However, we have yet to measure most of these factors in any large-scale modelling framework, so as to sort out the relative importance of the various forces identified above which are leading to the restructuring of economic systems at given periods of time in particular ensembles of economic and social activity.

It is not possible to develop a very exciting example of a nonequilibrium systems approach to the evolution of interregional economic structures in this 
paper; some previous efforts have been devoted to that topic. ${ }^{11}$ outcomes from such processes can be anticipated, in the form of redistributions of economic and social activity in space, resulting from processes identified (but not explored in detail) above.

We can assume that regional economic and social systems over time may grow, shrink, remain stable, or oscillate in various fashions. The development of these systems may lead to their division or bifurcation into multiple units (such as divisions of territories into states in early America), or they may move through time in a relative (or absolute) wave-like manner (such as the relatively cyclic economy of washington state dependent as it is on capital goods markets) which may be stable or occasionally catastrophic (such as the localized impact of the recent devaluation of the Mexican peso on border economies). More likely is the gradual evolution of complex economic systems; the development over time of measures of their performance which suggest a developmental sequence which trace a gentle path of redistribution.

While the type of evolution just described is easy to consider theoretically, measurement of its character has generally eluded regional scientists. Moreover, there has been strong interest in using measures of structures, status quo for political purposes, as these existing structures reflect an image of the world against which possible change can be cast. In general such assessments fail to admit the more general structural change which surrounds us, leading to inherently conservative visions of program changes or opportunities. The classic applications of interindustry models to regional development programs for the identification of "key sectors" which might then be the targets of development funds is a good example of the issue. ${ }^{12}$ Policy-makers have tended to seek sectors which already exist with "high" multiplier effects over the cycle of capital investment and to shy away from development of sectors associated 
with the restructuring of industry into new areas not currently (historically) embodied in regional economic models. How many industrial Dodos have been erected because of industrial development efforts rooted in the past?

The spontaneous revival of rural America in the last ten or fifteen years illustrates this issue well. For many in the sixties, rural decline required federal intervention to offset the evils of economic redistribution; programs like the ARDA and EDA were spawned to rescue these regions. Scholars such as Professor Miernyk have pointed out that the sum of monies spent on such programs were economic"peanuts", in comparison to other federal programs affecting regional development, but we did persist with efforts aimed at the belief that we could change the fate of these regional economies with the resources of the federal government. 13

It now begins to appear as though the revival of some rural regions of the country is rooted in the residential preferences of our populace, the natural inclination of industrial interests to seek relatively low-cost regions for labor and other factors of production, and because the space-economy of the country as a whole is becoming more integrated as a result of the decentralization of some types of productive capacity. ${ }^{14}$ In short, the system has restructured itself, changing the nature of interregional interaction patterns for intermediate and final goods, as well as for payments to the factors of production. We can anticipate this restructuring to continue, and while predictions have been made by institutions such as the BEA on probable future patterns, ${ }^{15}$ we should realize now that these visions of the future will be wrong, and that events will occur in terms of the broad forces of change outlined above which will lead to new paths of development in the near future which we cannot now anticipate. Maybe tomorrow people will decide to move en masse to Iowa for retirement, in the belief that the Florida option is old hat, too costly, 
fraught with concerns about the cost of food, and that subdivisions with a few acres per person tied to residential communities for the elderly caught up in gardening is the wisest retirement choice in an inflationary era.

If such movements did indeed occur, they would lead to redistributions of markets for various consumer goods, related infrastructures, and political power (eg. congressional representation and other public sector energy), which would in turn induce further redistribution. It seems likely that these cumulative effects have been at work in the growth of the sun Belt, but there is no reason to think that such trends will continue recursively in the indefinite future.

II

The preceding remarks suggest the need for extension of our modelling frameworks in economies such as the United States to a multiregional system, for if the types of redistributions occur as suggested above, single region models either will not capture them or will fail to anticipate the feedback changes resulting from such redistributions.

The balance of this paper will be devoted to the exposition of a model which is detailed in space and time, and which is estimated illustratively for the states of the United States.

Let us turn our attention to characteristics of this model. It is an incomplete system, in that it fails to develop adequately the demographic influences operating to restructure the economic system in space, but these changes will be embodied at a later date in a more elaborate version of the present framework.

Let us develop a one-sector model for each state of the United States. The national income and product accounts of the United States are commonly 
fromenonh presented at an aggregate national scale. However, within the of the flow diagram outlined in Figure 1, we could decompose this system of accounts into a multiregional flows framework. The following model emphasizes spatial detail at the expense of accompanying sectoral detail. Thus, at the national scale:

$$
\text { (1) } Y=C+I+G+E-M
$$

In a typical year, $E$ (exports) approximately equals imports (M), and for the purposes of this paper these flows will be ignored. ${ }^{16}$ Domestic components for final demand originating in any given region may be denoted as: 17

$$
\text { (2) } Y_{\cdot j}=C_{\cdot_{j}}+I_{\cdot_{j}}+G_{j}
$$

where $c_{j}=$ consumption outlays of consumers in region $j$ made across all regions in the national economy $\begin{aligned} I_{j}= & \text { investments made in region } j \text { of goods purchased across all regions } \\ & \text { in the national economy }\end{aligned}$

\section{$G_{j}=$ government outlays associated with region $j$ across all regions in the national economy}

thus $Y_{\cdot j}=$ total final demand associated with region $j$ purchased across all regions in the national economy.

Hence,

$$
\text { (3) } \quad . .=\sum_{i=1}^{N} \quad Y_{j}=Y
$$

or total gross national product is equal to the sum of the components of national product originating in the demands found in each of the regions in the national economic system. We can visualize this set of demands as a matrix, each column sum being equivalent to the value of $Y_{j_{j}}$. The row sum $\left(Y_{i}\right)$ are the magnitude of final demand accruing against any given region during a given time period.

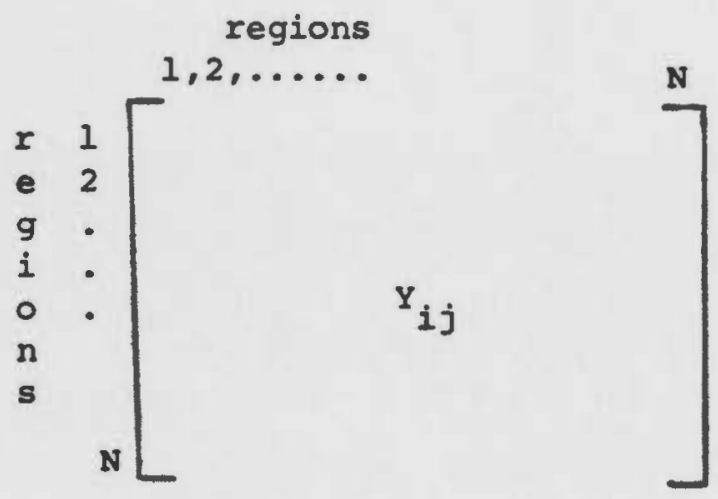




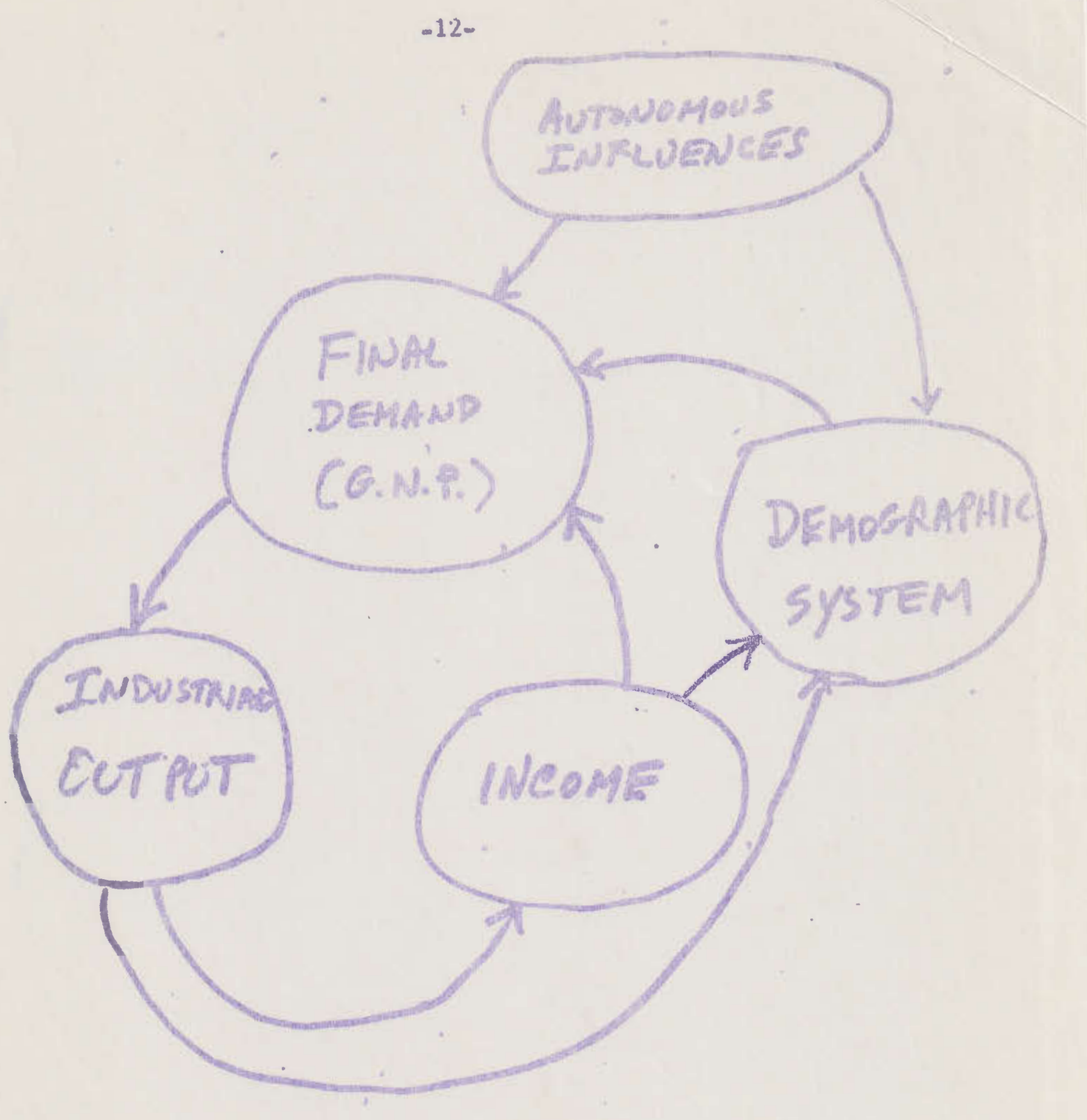

21.gura 1 
In a given time period, we know that gross national product is equal to income (with due regard to imbalances in this equivalence due to leakages). Income will be largely a function of industrial activity in each region, and we could denote the magnitude of income associated with a region's industrial activity as $v_{j}$. This income will be paid to its various recipients among the various regions within the national economic system. Most wage and salary income will be received in the regions where productive activities took place, although in cases where workers reside in a different region than where they work and earn their labor income, we can anticipate interregional movements of wage and salary income. Non-wage and salary income (capital returns, dividends, etc.) and payments to the public sector may involve considerable interregional movement. Accruals of income earned in various regions to any particular region $\left(\mathrm{V}_{i}\right)$ will be approximately equal to the level of final demand available in this $i$-th region for expenditure on the various categories of final demand. Needless to say, complex lead-lag formulations of this functional interdependence between the sources of income and its subsequent expenditure on final demands are possible, and prior research also suggests that persistent interregional capital flows characterize our economy. In this paper, a simple equivalence is suggested:

$$
\text { (4) } v_{i} \cong Y \cdot_{j} \text { when } i=j
$$

and the matrix $v$ defines the magnitude of interregional flows on the income account.

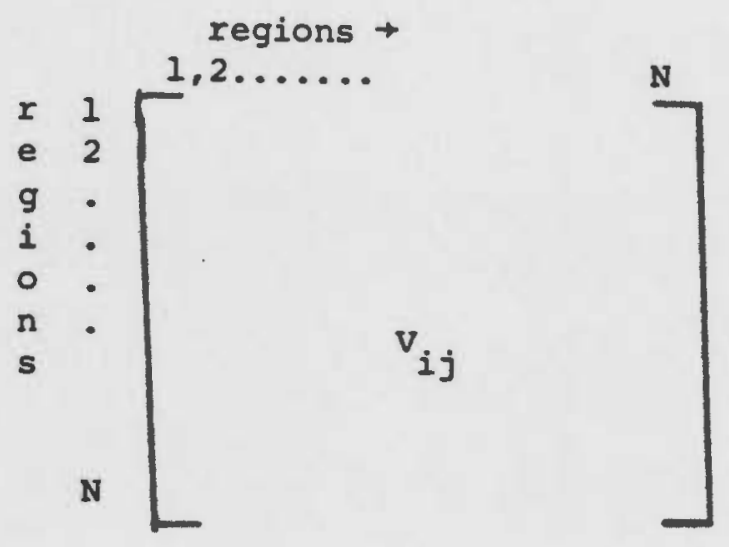


The linkage between the multiregional system of final demands and the multiregional system of income payments comes via the system of intermediate production and its ties to final demands. In accounting terms, total output (Z) is equal to intermediate output (T) plus final demands (Y). Similarly, total purchases equal total output, hence total purchases (z) equal intermediate output (T) plus income payments (V). In matrix form:

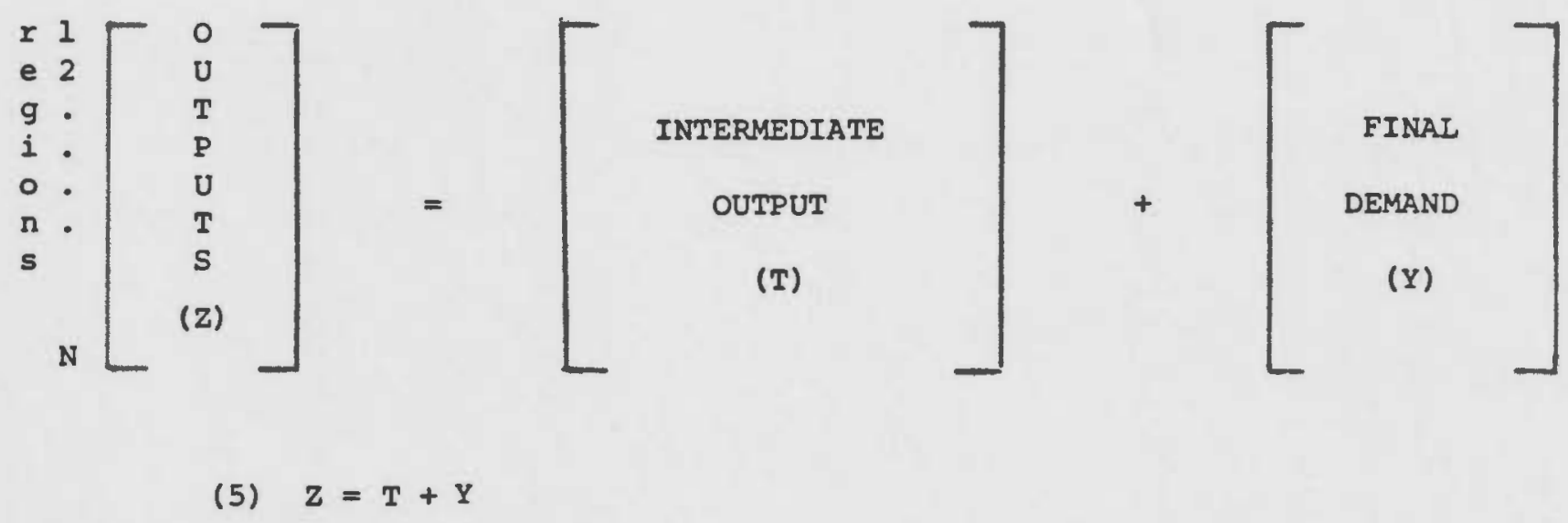

and

(6) $Z^{\prime}=T+V$

such that

$$
\text { (7) } z_{j}=\sum_{i} T_{i j}+\sum_{i} v_{i j}
$$

Following the discussion of the evolution of such systems outlined in section I of this paper, this simple model could be time-subscripted, and these accounting relationships elaborated over time. Changes in the structure of the systern, implicit in the magnitude of the flows matrices $T, Y$, and $V$ are to be anticipated in time..$^{1,8}$ At a point in time, the structural relationship between output and final demand may be defined as follows.

Following in the framework of interindustry models, let us define a coefficient, $s_{i j}$ as follows:

$$
\text { (8) } s_{i j}=\frac{T_{i j}}{z_{j}} \text { or }
$$




$$
\text { (9) } T_{i j}=s_{i j} z_{j} \text {. }
$$

Substituting into (5):

$$
\text { (10) } z_{i}=\sum_{j} s_{i j} z_{j}+\sum_{j} Y_{i j}
$$

Through simple rearrangement,

$$
\text { (11) } \mathrm{z}=(I-s)^{-1} \mathrm{Y} u
$$

where $u$ is a unit vector.

Income payments that result from this set of outputs among the regions can be defined as :

$$
\begin{aligned}
& \text { (12) } w_{i j}=\frac{v_{i j}}{z_{j}} \\
& \text { (13) } v_{i j}=w_{i j} z_{j}
\end{aligned}
$$

or

Hence, in matrix notation:

$$
\text { (14) } \mathrm{V}=\mathrm{w}\langle\mathrm{z}\rangle
$$

where $\langle\mathrm{Z}\rangle$ is the block diagonal form of $\mathrm{z}$.

The mathematical form of the linkages of this system to the demographic system shown in Figure 1 have been developed elsewhere, and will not be elaborated here. $^{19}$ However, it is a simple matter to extend the final demand matrix to include an autonomous component as shown in Figure 1. The remainder of this paper is devoted to an attempt at estimating an illustrative model of this type for the states of the United States; space does not permit detailed consideration of probable changes in the structure of the illustrative model over time.

\section{III}

Data Sources and Estimation Procedures

The model just outlined would require enormous financial resources for its estimation from primary data sources. Measurement of the intraregional components of such a model have occurred in a number of regions of the United States, in the form of survey-based input-output models. ${ }^{20}$ These models have 


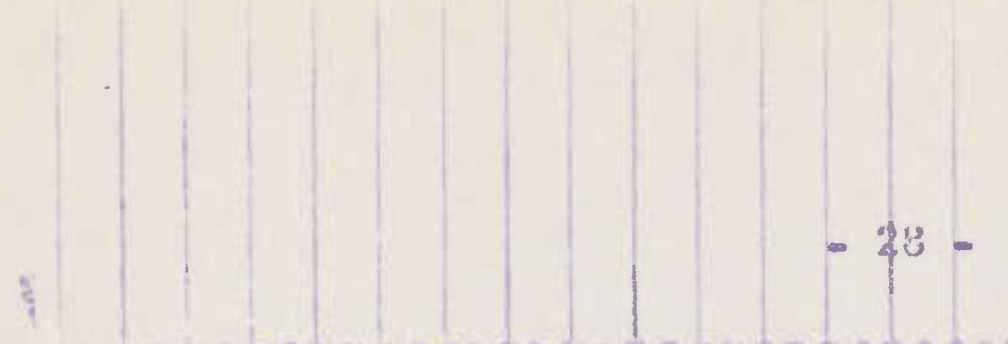

i.

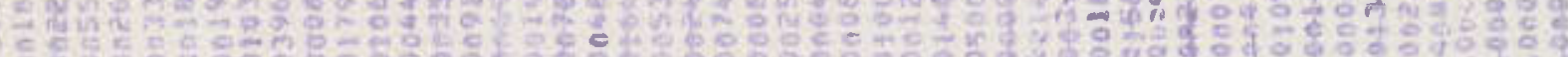

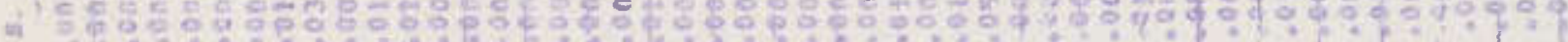

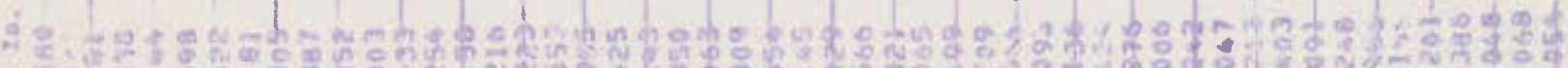

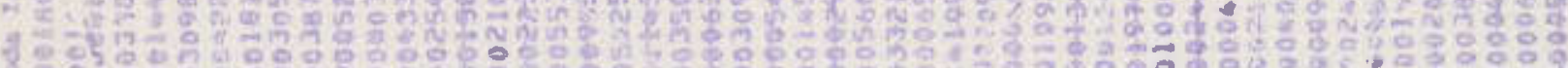

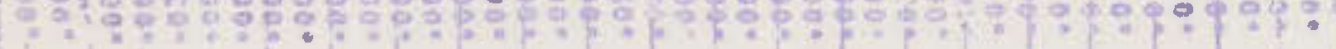

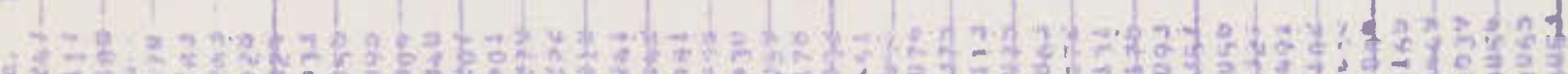

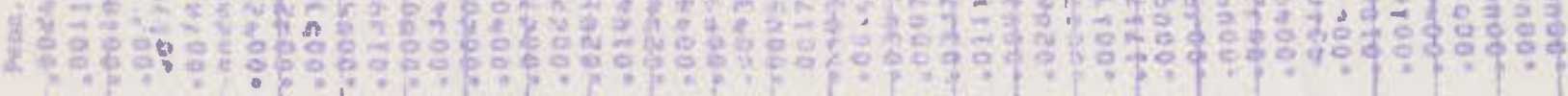

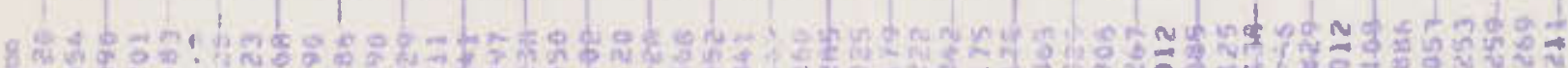

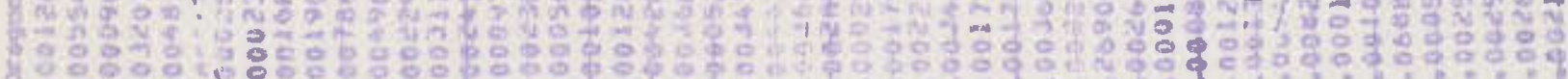
(1)

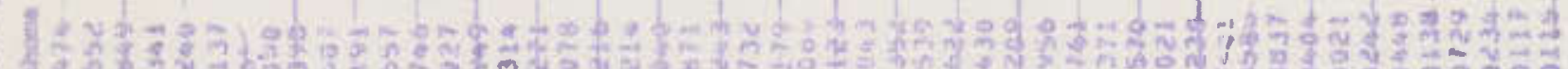

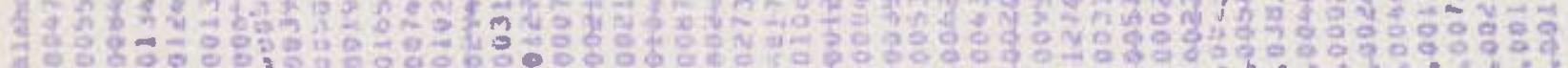

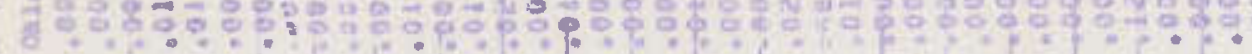

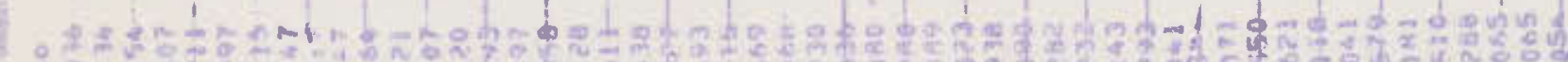

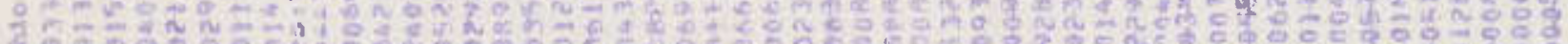

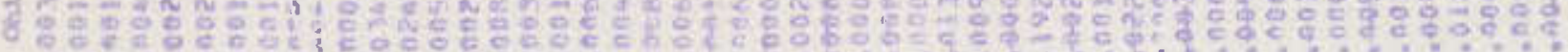
1.

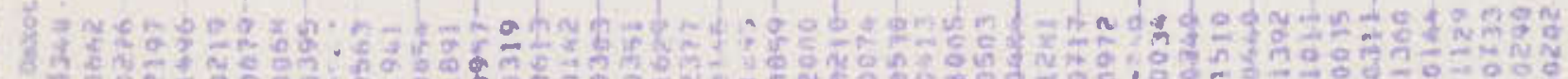

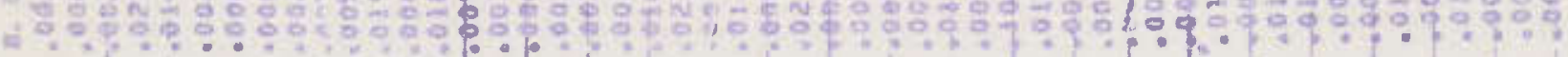

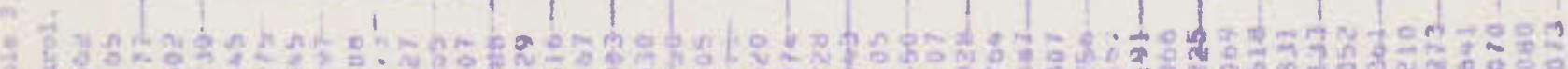

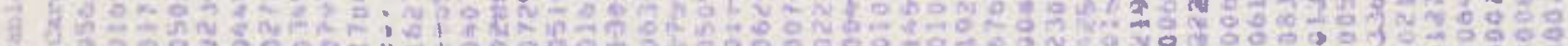

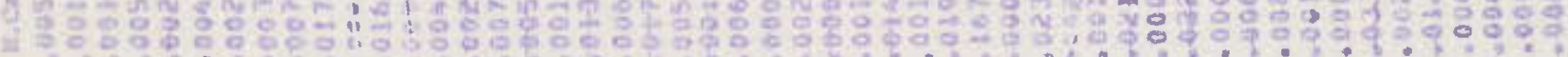

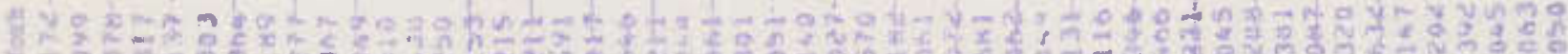

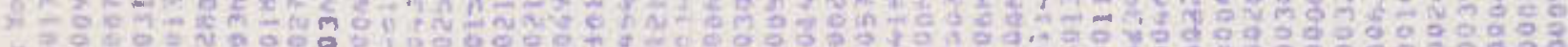

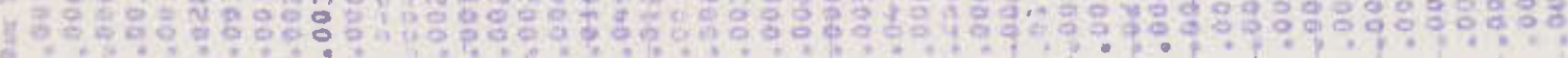

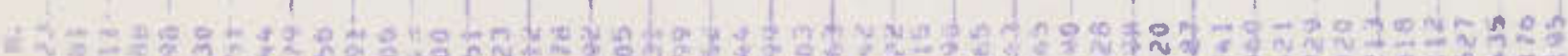

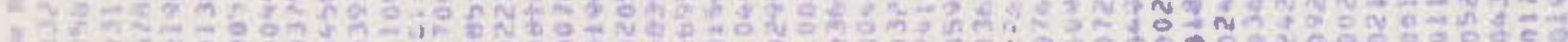

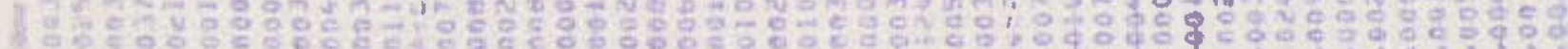

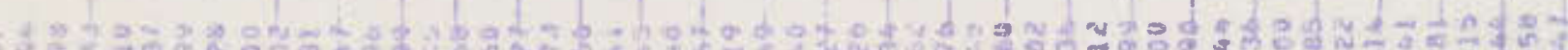
2.

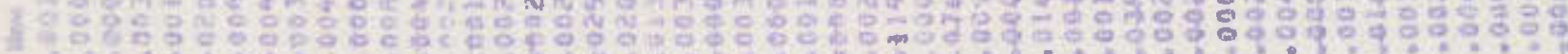

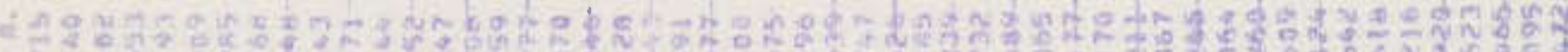

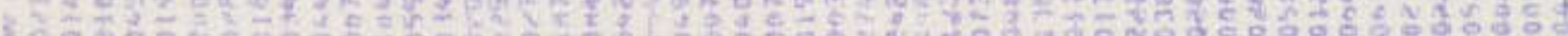

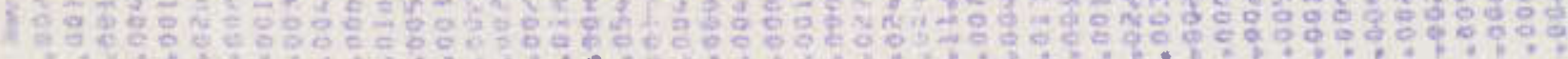

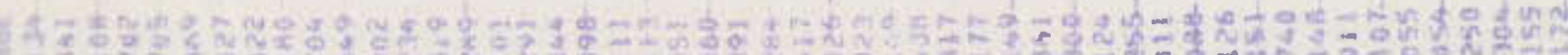
co을

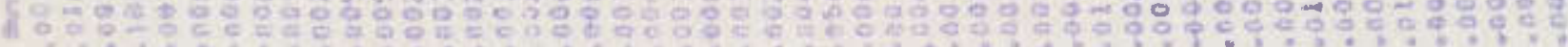

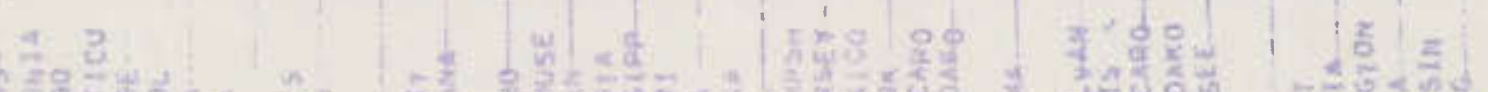

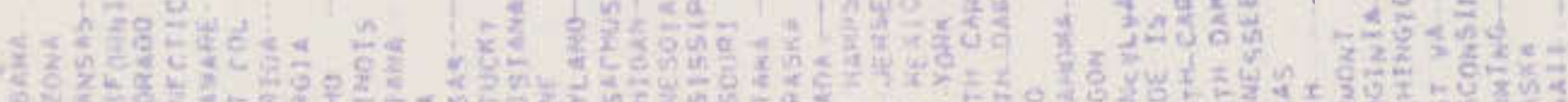

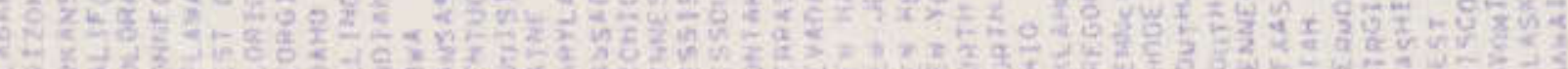
20
2

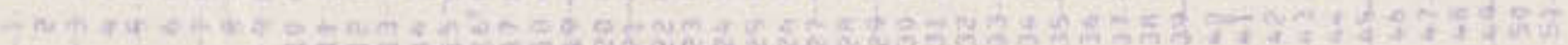


highlighted the openness of the typical regional economic system, a matter that has received ample discussion in the literature. ${ }^{21}$

In order to learn something of the interregional pattern of interaction, we have been engaged in survey work, asking firms to describe for us the structure of their markets and sources of supply in a detailed geographical manner. 22 This survey was conducted among a sample of Washington State firms, primarily manufacturers. While individual firm linkage patterns have great diversity, the aggregate of their sales and purchases turns out to exhibit a familiar gravity-model type distribution. Figures 2 and 3 illustrate the patterns of (domestic) sales and purchases for this sample.

The sample encompassed some 143 firms whose combined sales in 1978 were about $\$ 4.2$ billion, which was about $20 \%$ of the value of shipments of Washington State manufacturers in that year. The sampling procedure was not random across industries, but biased towards those sectors reasonably presumed to be engaged in interregional business for the procurement of their inputs, sales of their products, or both. ${ }^{23}$ A simple gravity model calibrated (in logarithmic form) with the populations of the states and their distances from Washington State as independent variables and the percentage of total sales or purchases as the dependent variable turned out to be highly significant from a statistical standpoint. 24 Experiments were conducted with various forms of this relationship, including the use of personal income, value added in manufacturing, etc., as measures of the independent "mass" variable for states linked to Washington State; the statistical performance of the model did not vary much among these formulations.

Given this regularity in interaction patterns, this rather speculative paper was developed, reasoning from the specific relationships observed for this sample of Washington firms to a possible image of the pattern of economic 


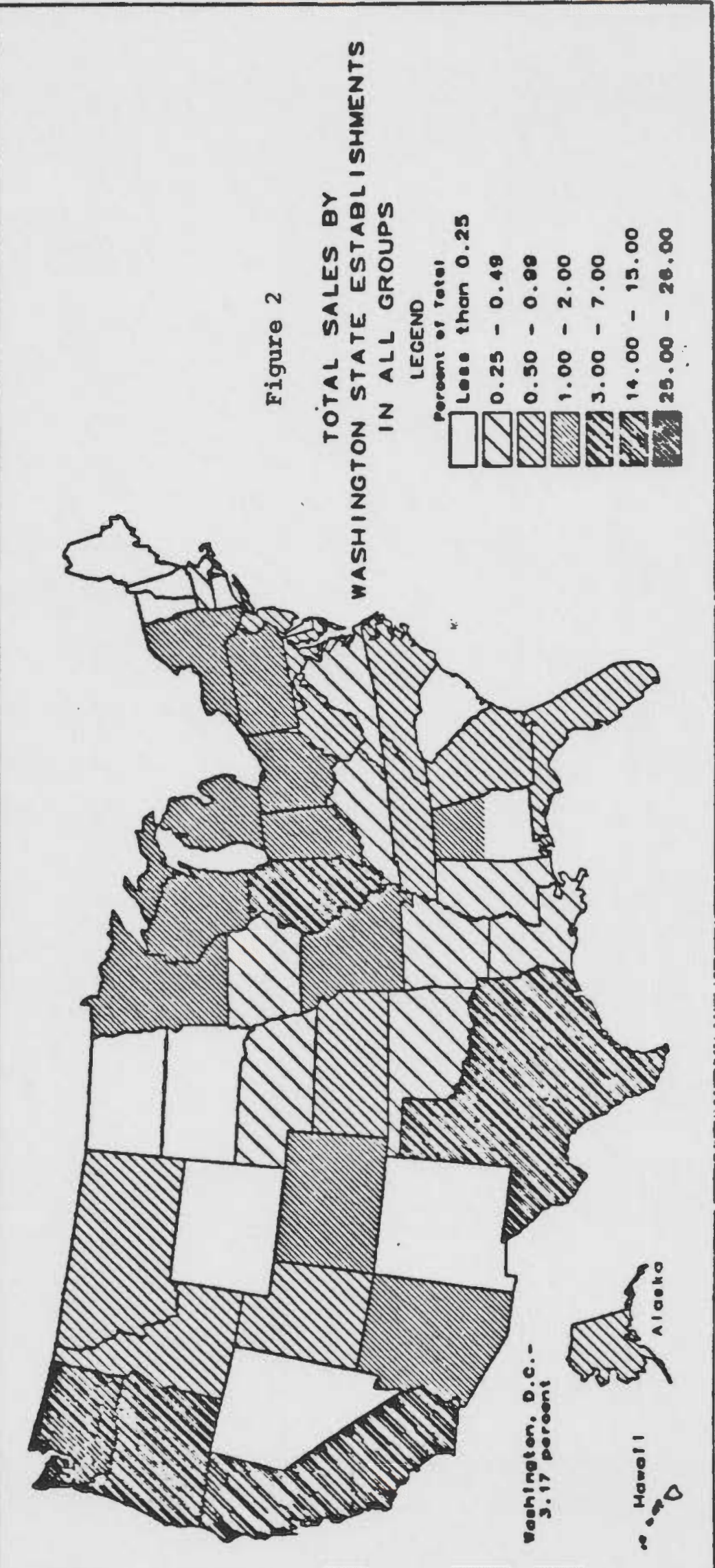

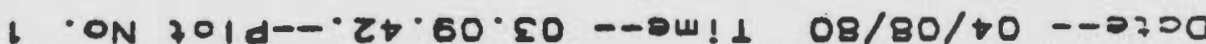


$-1^{8}-$

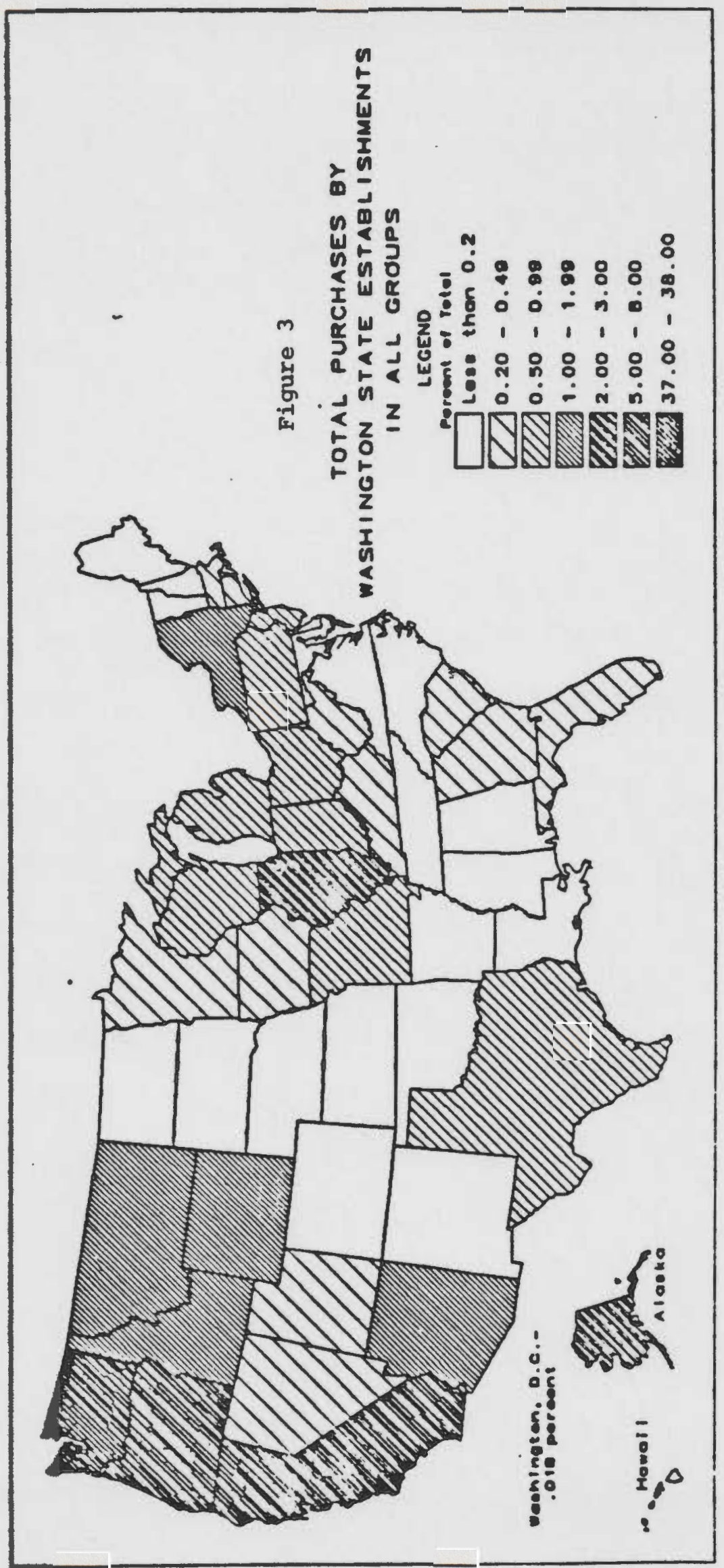

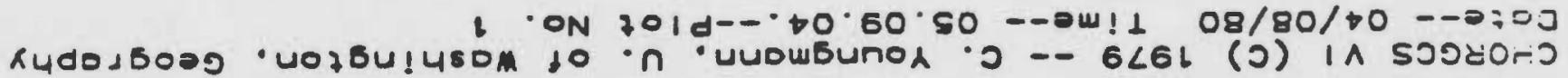


interdependence among the states of the United States as a whole. Clearly, this is reasoning from a specific case study to a general system, a dangerous scientific procedure, although Ullman's pioneering work on the spatial structure of comnodity flows and Sakai's analysis of interregional linkage structures in the Japanese economy exhibited similar characteristics. ${ }^{25}$ However, the survey results were sufficiently tantilizing to warrant the risk. The generalization procedure utilized is as follows.

The survey data on purchases from other states and final demand sales to other states by the sample of Washington establishments formed the basis of an equation system to estimate the matrices $T$ and $Y$. Control values were derived from several sources. Polenske's work on the multiregional input-output (MRIO) model provided key estimates of output (Z) by state for the year $1963{ }^{26}$ The Bureau of Economic Analysis estimates of state income accounts for the year 1980 and gross national product accounts for the year 1980 formed the basis for estimation of $\mathrm{V}$ and $\mathrm{Y} .{ }^{27}$

The most critical values for this modelling effort were the output series, z. No direct reports of these values are published. In this exploratory effort, the MRIO estimates for 1963 by state were adjusted, as a function of personal income by state in 1980 compared to personal income by state in 1963, and as a function of changes in per capita personal income by state between 1963 and 1980. The latter adjustment occurred as a result of explorations between the magnitudes of BEA 1963 personal income estimates and output estimates from the MRIO project. Given the convergence of per capita incomes among the states between 1963 and 1980, implicit adjustments to final demand accounts were also necessary. The following formulation was used:

(15) $\mathrm{z}_{i}=1980 \begin{aligned} & \text { personal income } \\ & \text { by region }\end{aligned} *\left(\begin{array}{c}1963 \text { output in } \\ \text { region } i \\ 1963 \text { personal } \\ \text { income, region i }\end{array}\right) * \begin{aligned} & \frac{1}{\text { ratio of per capita }} \\ & \text { personal income } \\ & \text { region i, } \frac{1980}{1963}\end{aligned}$ 
Simple ratios were formed between personal income levels in 1980 by state and final demands by state, building on this relationship for the nation as a whole. Similarly; a simple relationship between wage and salary plus proprietary income and national product was used to estimate income originating by region. These relations were as follows: 28

$$
\begin{aligned}
& \text { (16) } F_{j_{j}}=\frac{1980 \text { personal income by region }}{.815} \\
& \text { (17) } V_{e_{j}}=\frac{1980 \text { wages, salaries, proprietors income }}{.535}
\end{aligned}
$$

The formulations in equations and (16) and (17) are admittedly simple. It is recognized that in reality nonconsumption final demand varies significantly among regions, most particularly due to variations in the presence of the federal government. In addition, considerable variance is to be expected in state to state levels of savings rates, exports, and other factors influencing the magnitude of final demand. Unfortunately, resources did not permit a more realistic specification of this most significant structural issue. This matter will be referred to in later sections of this paper, as this is an important issue influencing the distributional questions addressed there.

Total intermediate purchases were then defined as:

$$
\begin{aligned}
& \text { (18) } \quad T_{j_{j}}=z_{j}-v_{\cdot_{j}} \\
& \text { (19) } v_{i}=F ._{j} \text { when } i=j
\end{aligned}
$$

These procedures provided estimates of the various control values needed to implement this model; implementation occurred as follows.

The values of $v_{i}$. anf $v_{j_{j}}$ and $w_{j}$ (wages, salaries and proprietors income in region $j)$ were the primary inputs in the estimation of the $v_{i j}$ income payments matrix. Nonwage income, the difference between $v_{{ }_{j}}$ and $w_{j}$, was initially spread equally among all regions. Then a biproportional matrix adjustment procedure was utilized to assure that income accruals actually equalled the estimates of $\mathrm{v}_{i} \cdot$; this procedure was implemented for ten iterations, 
and produced essential closure in the estimation process. ${ }^{29}$

The matrix of final demands, $Y$, was estimated using a modified form of the gravity-model equation which resulted from the survey work described above. Reference was made to the 1972 washington input-output study to compare the degree of non-Washington final demand among consumers, investors, and governments in that model in comparison to our survey. ${ }^{30}$ The survey data shown in Figures 2 and 3 were biased towards more interregional sales than estimated in the 1972 Washington input-output model Therefore, the gravity model equations were adjusted to produce an appropriate share of total sales in Washington State. This procedure assumed that the structure of observed non-local sales was a reasonable characterization of all non-Washington sales, a matter open to verification by additional survey work. The resulting gravitymodel equation was used with estimates of 1980 population and interstate distances among all states of the United States, yielding the matrix of flows $Y$. A scaling procedure was used to assure conformance of the sum of the estimated flows between each state with the estimated values of $Y_{{ }_{j}}$.

The sum of the flows in the rows of the $Y$ matrix, when subtracted from estimates of output ( $(\mathrm{z})$, by state, yielded estimates of intermediate output by state. The model was constrained to have $v_{i}$. equal to $F_{{ }_{j}}{ }$ so the aggregate value of intermediate sales was equal to the aggregate estimate of intermediate purchases defined in equation (18), i.e., T..

The intermediate flows matrix, $T$, was also obtained through the use of a modified form of a gravity-model equation, based on the purchases observations from the survey data. As with final demands, adjustments were made in the magnitude of the Washington State purchases share to more nearly correspond with relationships in the 1972 washington input-output model. The resulting initial distribution of intermediate purchases was then constrained by the estimates of $T_{i}$ and $T_{j}$ to produce by biproportional matrix adjustment procedures a balanced flows matrix. 
The numerical model which results from the application of the methodology just described to the accounting framework laid out in this paper must be seen as tentative. Thus, it seems appropriate to ask after viewing the general nature of the results whether they seem reasonable, given other knowledge about the structure of the national economy. The principal focus in this paper will be on the structural qualities of the interregional trade matrix, $T$. The flows matrices F, $T$, and $V$ are reproduced as appendices to this paper. It should be recalled that these matrices are controlled by the 1980 series of national income and product accounts produced by BEA.

Table 1 reports estimates of control values. 31 column 1 shows estimates of wages, salaries, and proprietors income accruing in each state in 1980, and column 2 is an index of personal income per capita in 1980 vs. 1963, using personal income change in the nation as a whole as a benchmark. Column 3 presents estimated output levels in 1980, while column contains estimates of 1980 final demands by state. Column 5 indicates estimates of income originating by state in 1980, while column 6 is the difference between estimated state output and income, equalling estimates of intermediate purchases by state. Column 7 expresses column 6 as a fraction of total purchases by state. This set of estimates has at the national scale income almost equivalent to demands, and output approximately equal to an appropriate proportion of income or final demand (roughly twice the magnitude of intermediate transactions). 32

Some relationships shown in Table 1 suggest that these control values exhibit reasonable magnitudes. In general, states are estimated to have very similar levels of income accruals and final demands. Deviations from these relations are expected in states with a substantial proportion of personal income derived from non-wage and salary sources. Florida emerges as the archetype 
Table 1, Control Values

(i) 1990, stilions) f5: 23

Der nowe

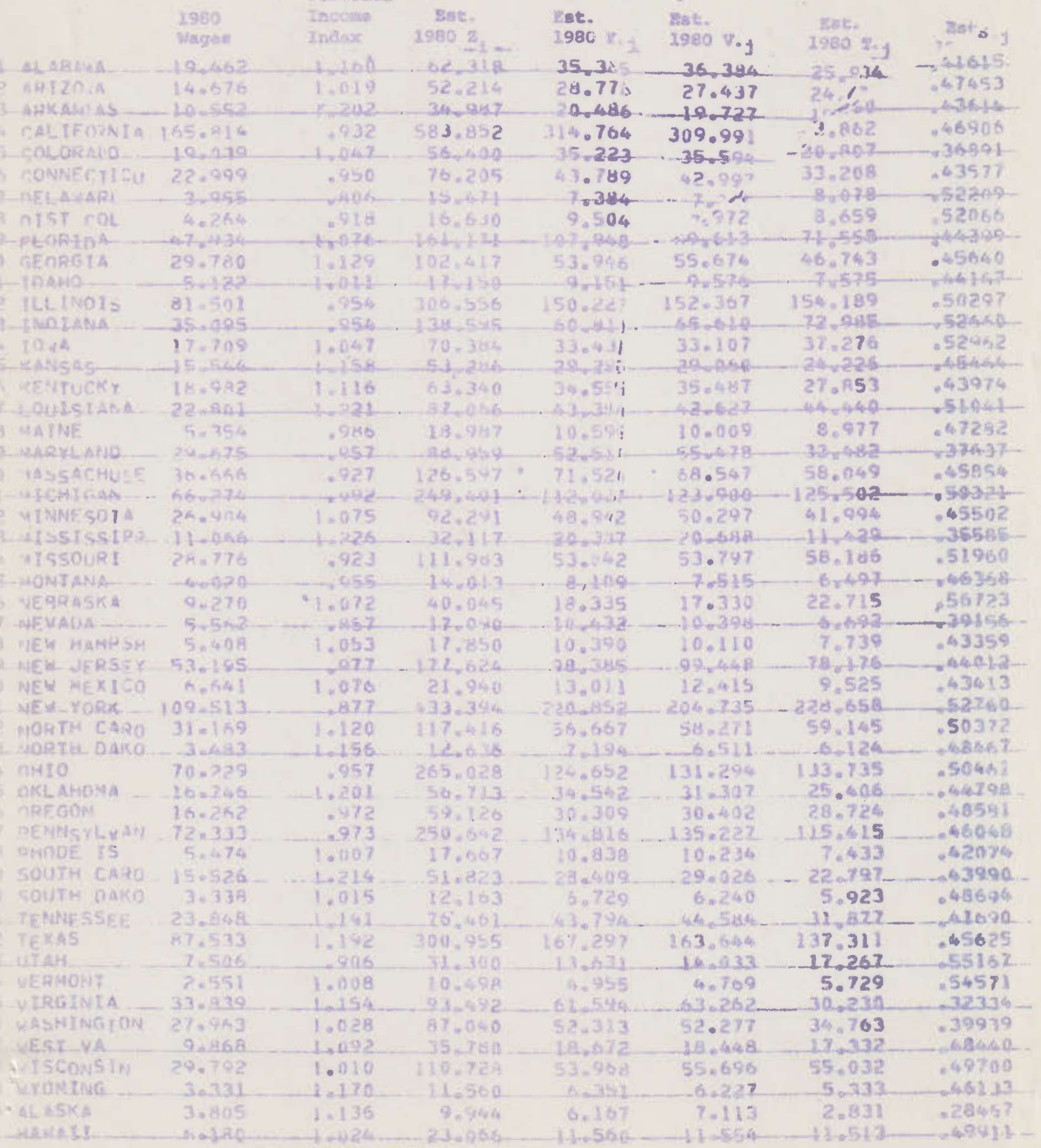




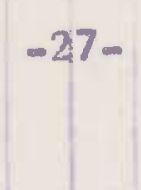

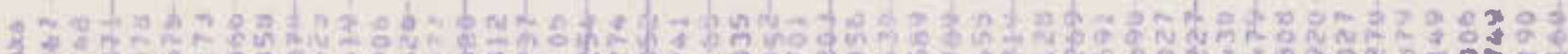
2

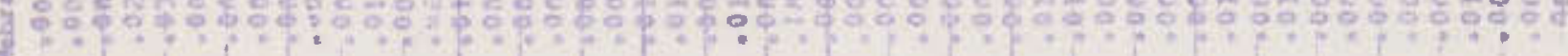

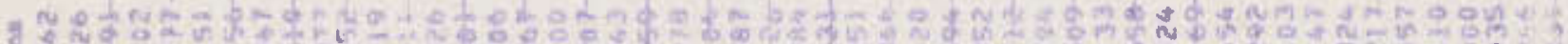

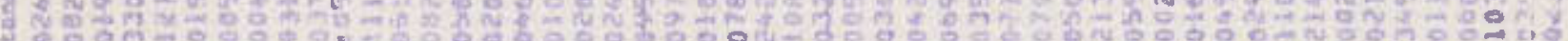

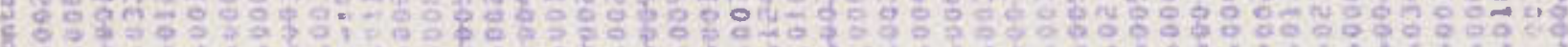

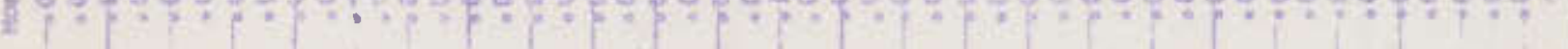

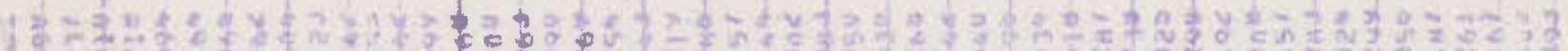
5.

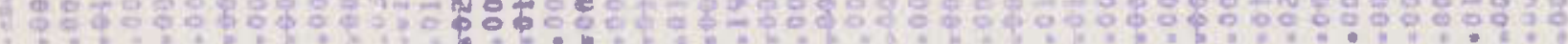

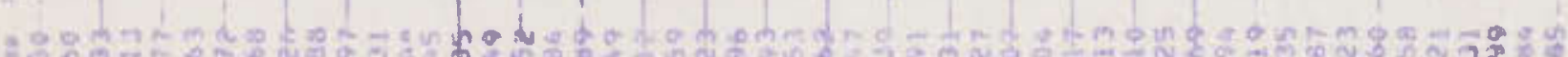
2.

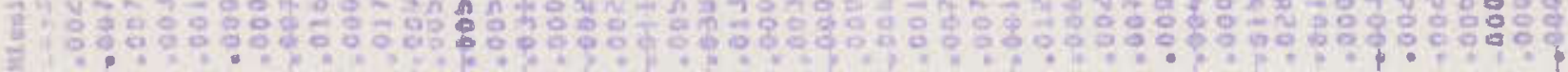

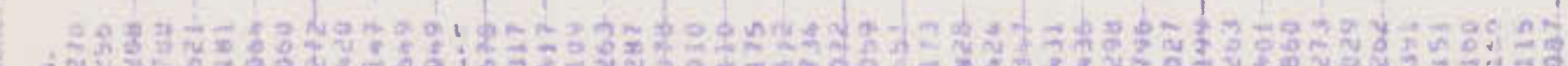

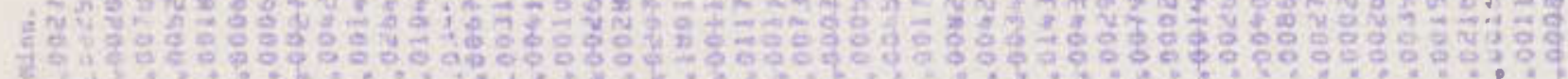

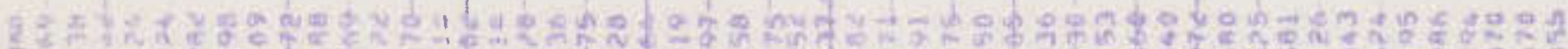

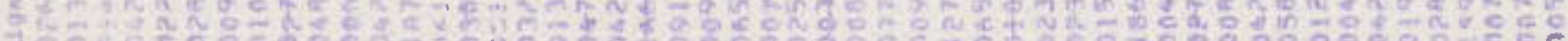

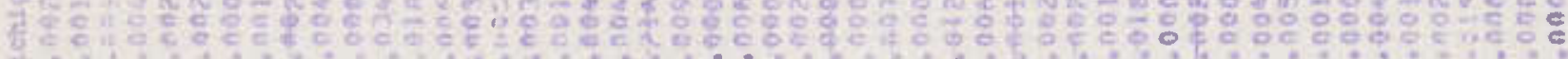

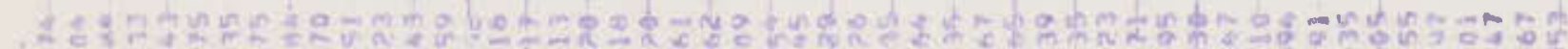

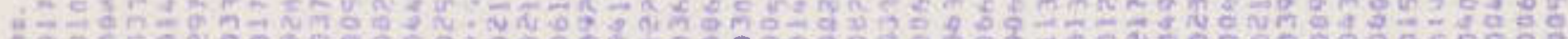

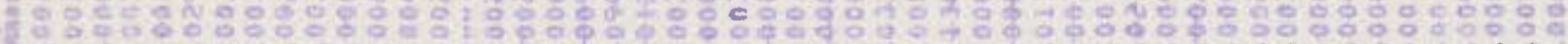

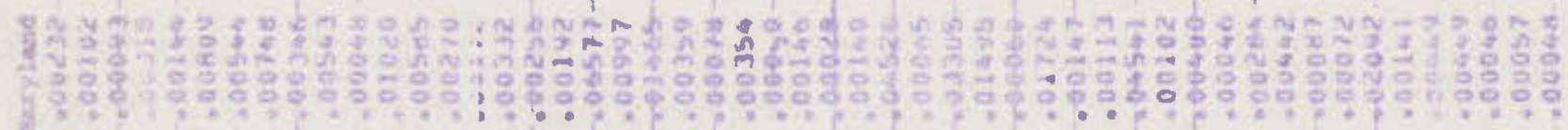

hof

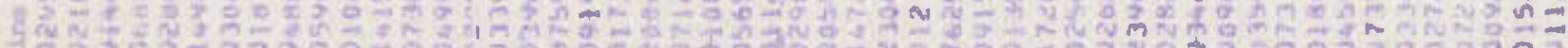

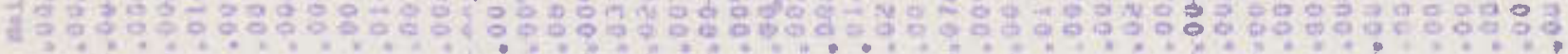

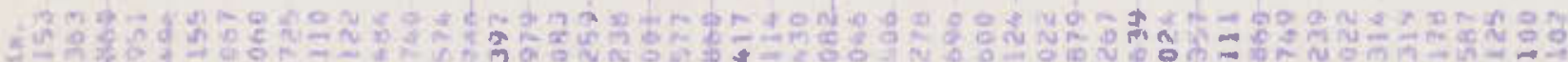

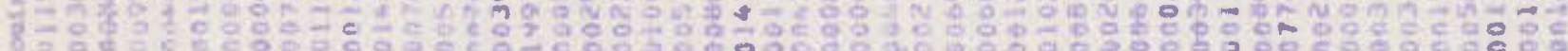
. : :

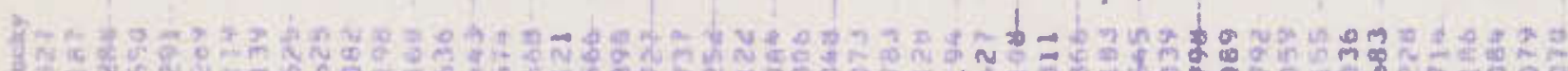

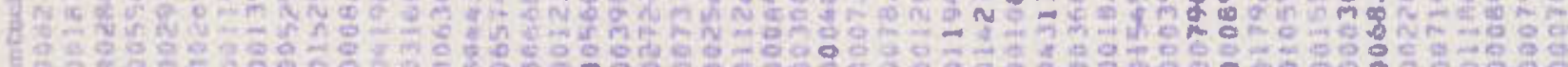

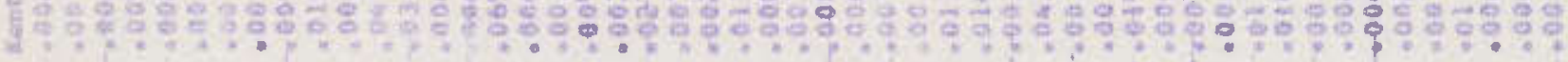

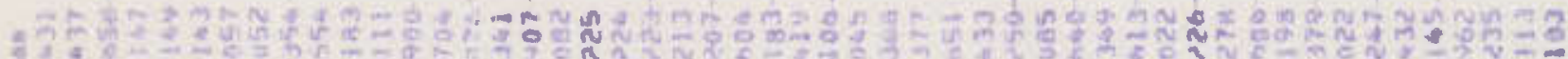

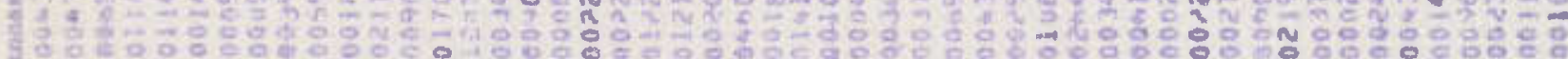

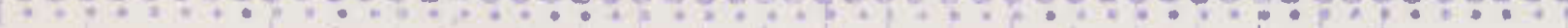

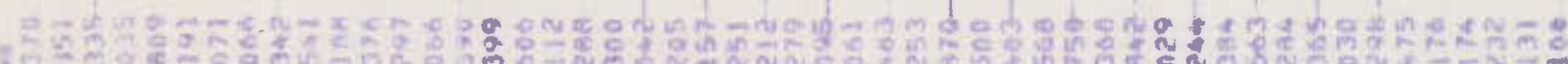

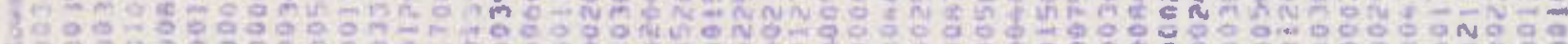

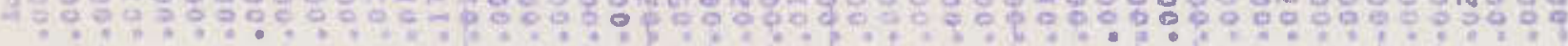

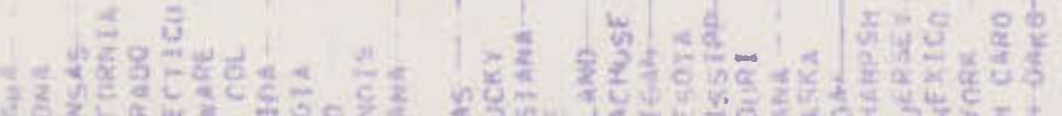

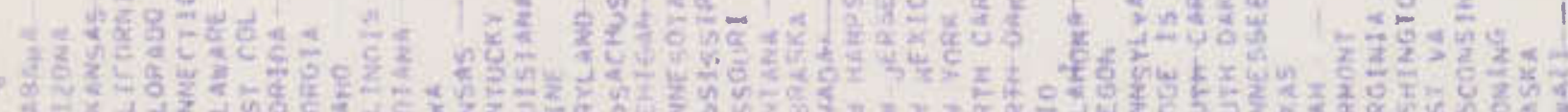

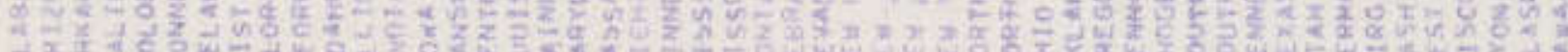

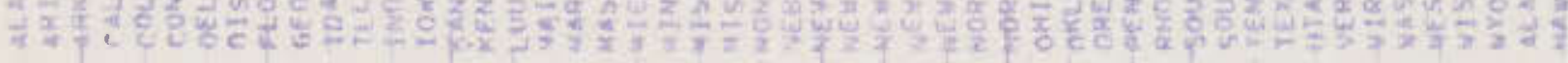

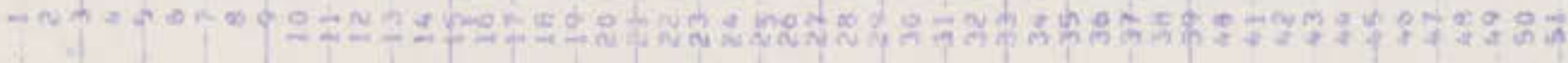


Table 2

(6) bilisons, 29E0)

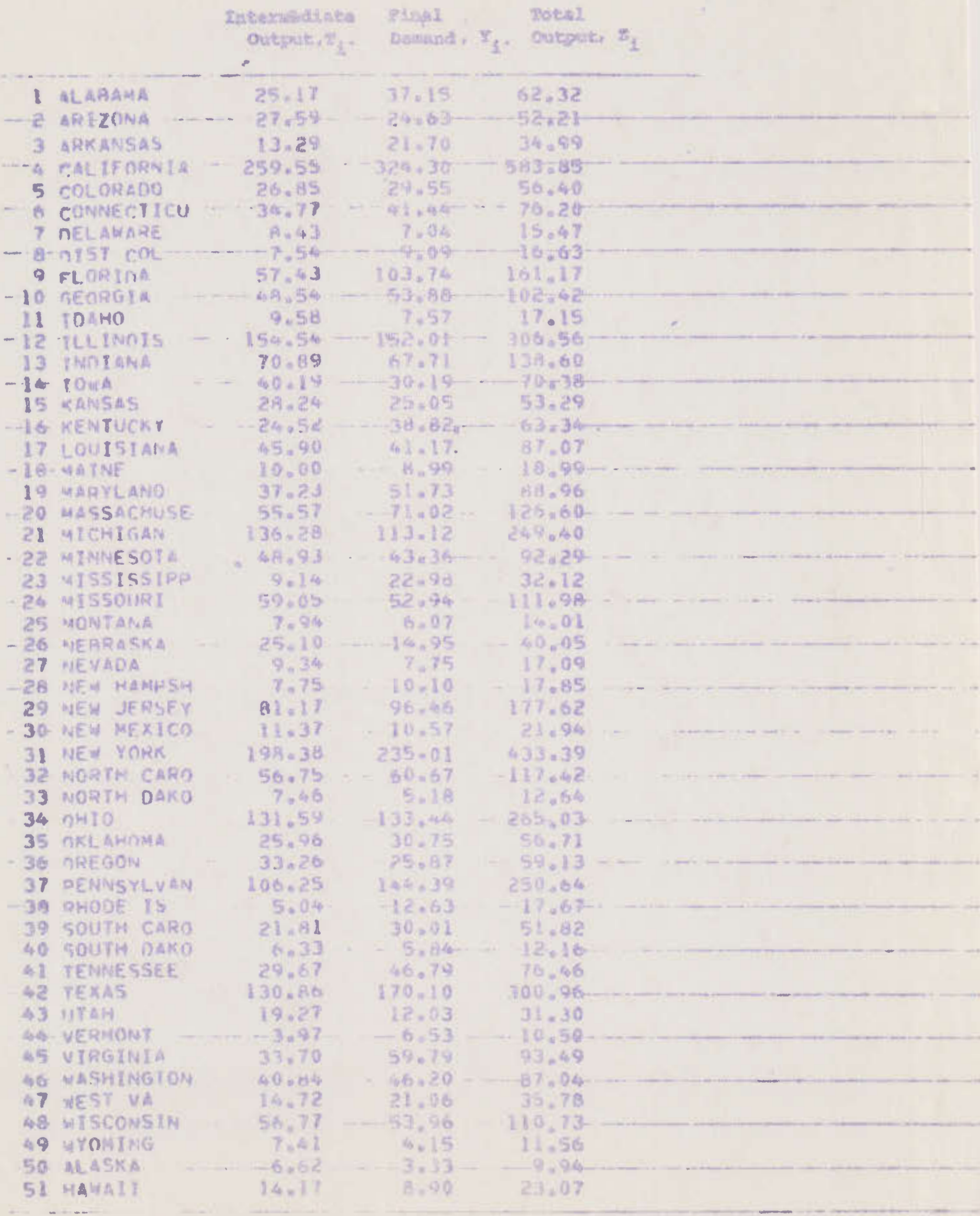


in this comparison, while some of the industrial states such as Ohio or Indiana that are undoubtedly providing the flows of capital to regions such as Florida side

turn up on the opposite/of the ledger. Generally speaking, the tendency is for the $S j^{\prime}$ 's to be larger in the states with big economies, and small in states with smaller economies and/or a lack of local resource/industrial output being processed.

Table 2 presents estimates of flows of intermediate outputs and final demands accruing against each state economy. While the overall structure of this table reasonably corresponds to the structure of the national economy, corroborative evidence is lacking to determine the reasonableness of the State distributions. The shares of intermediate and final product closely correspond to output characteristics of the Washington economy, but cross-checks need to be made with other regions where survey-based input-output models exist to ascertain the general accuracy of these estimates.

Table 3 presents estimates of the 5 matrix for the year 1980, while Table 4 sumarizes the coefficient structure of Table 3 in an integer classification scheme. In general, Table 4 shows that intraregional direct requirements are larger than direct requirements from any other single region, while nonlocal requirements exceed the magnitude of local requirements, although these linkages are spread widely among regions of the national economic system. Table 5 is the direct and indirect requirements matrix based on Table 3 , while Table 6 presents the same classification of linkage strength as is shown in Table 4. Comparison of Table 6 with Table 4 immediately suggests a significant increase in complexity of interregional structural effects within the interindustry inlirent system as interregional interdependencies are estimated. These differences are highlighted in Table 7, which presents a classification of the strength of indirect interregional linkages included in Table 6. Table 7 shows a much larger number of entries than Table 4, with 701 and 461 nonzero entries, respectively. This suggests that indirect interregional effects are relatively 


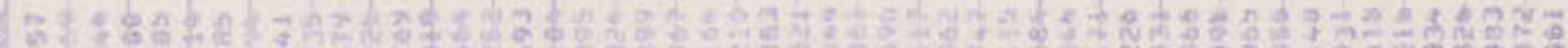

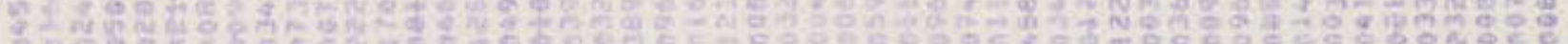

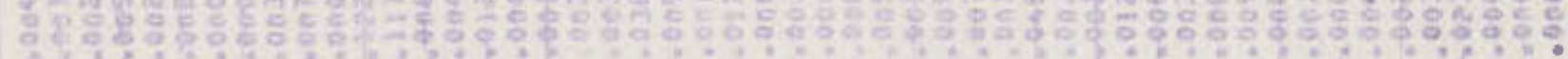

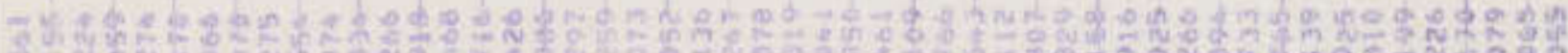
$\mathrm{e}=\mathrm{N}$;

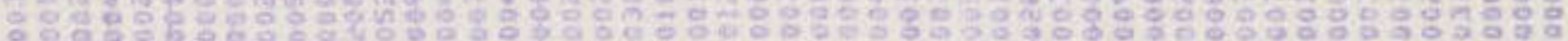

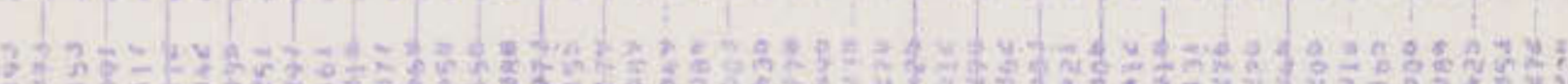

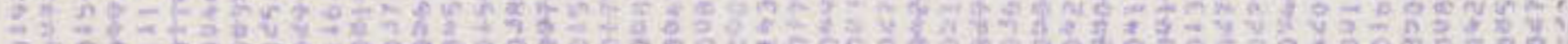

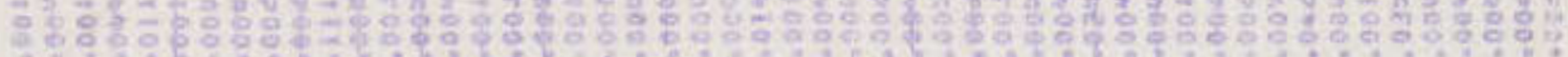

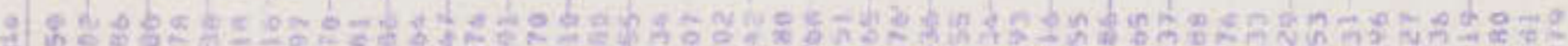

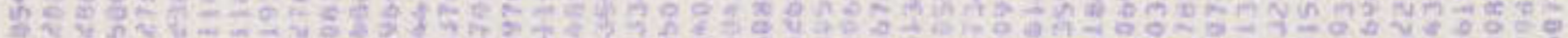

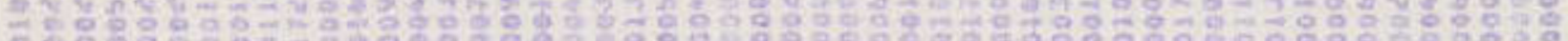

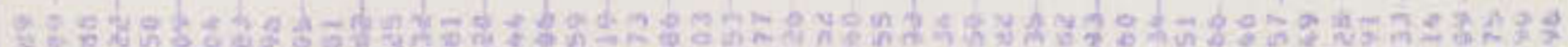

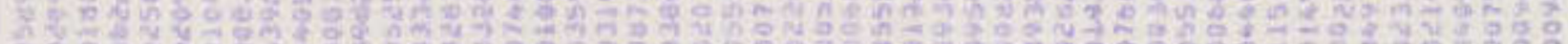

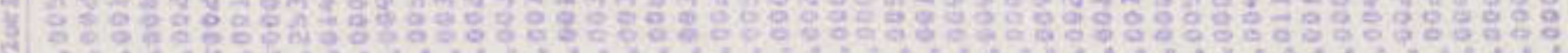
¿

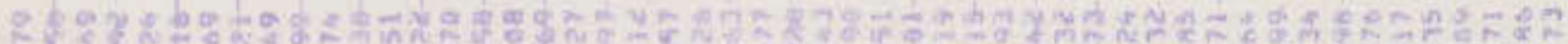

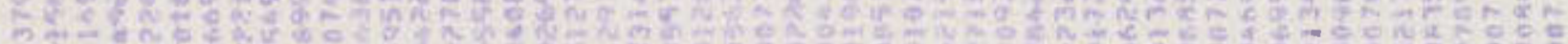

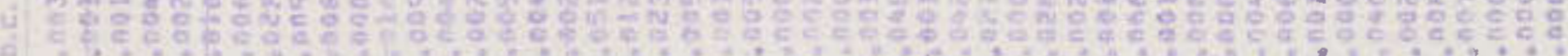

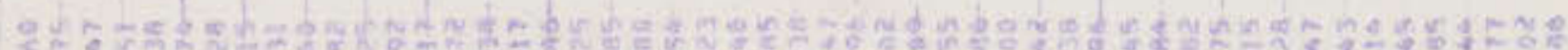

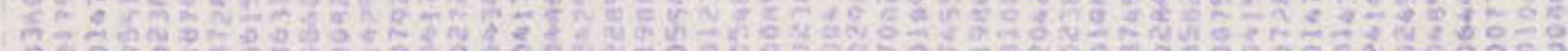

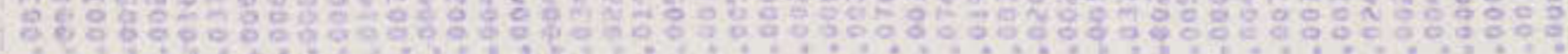
8

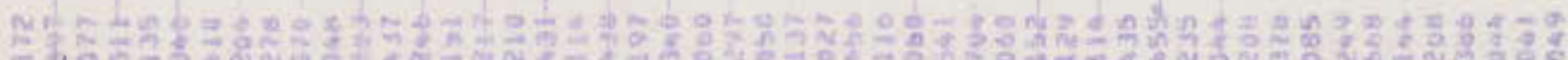

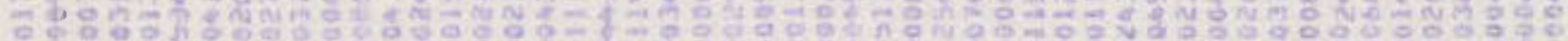

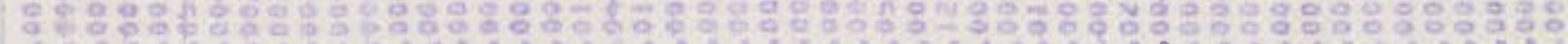

8. un N5 N

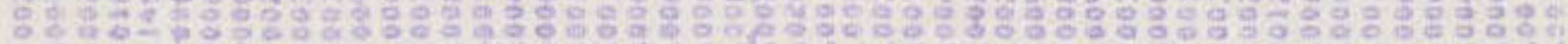

A

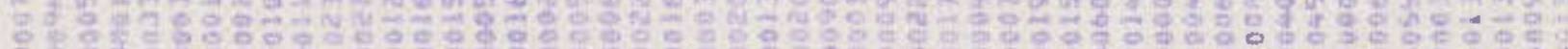

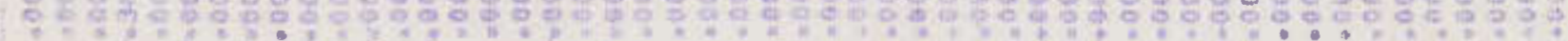

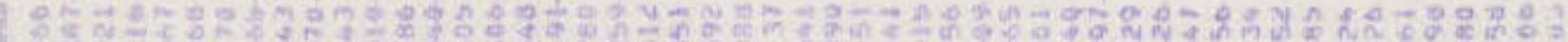

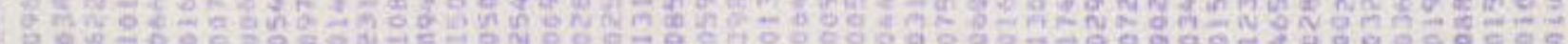

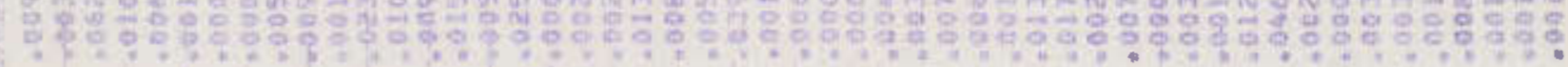

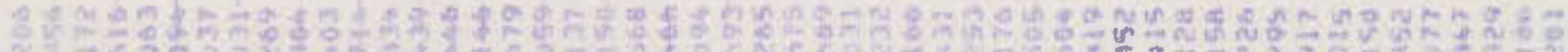

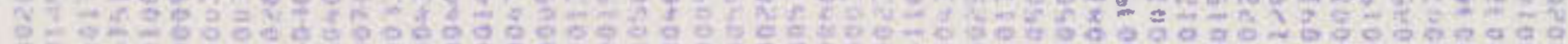
(9)

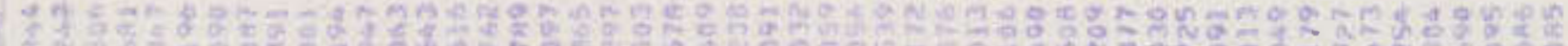
난 강

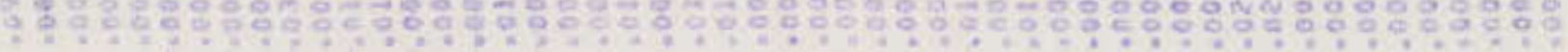

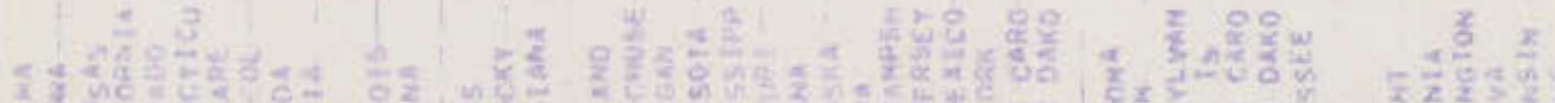
열 2 is

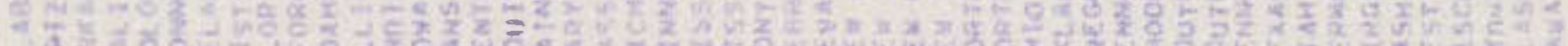

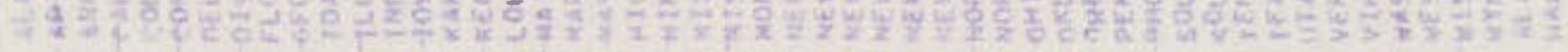

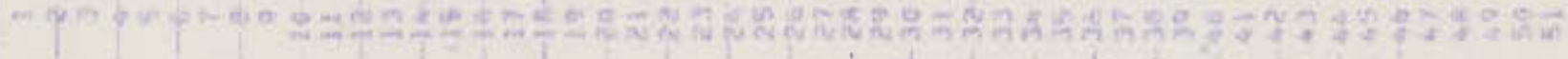




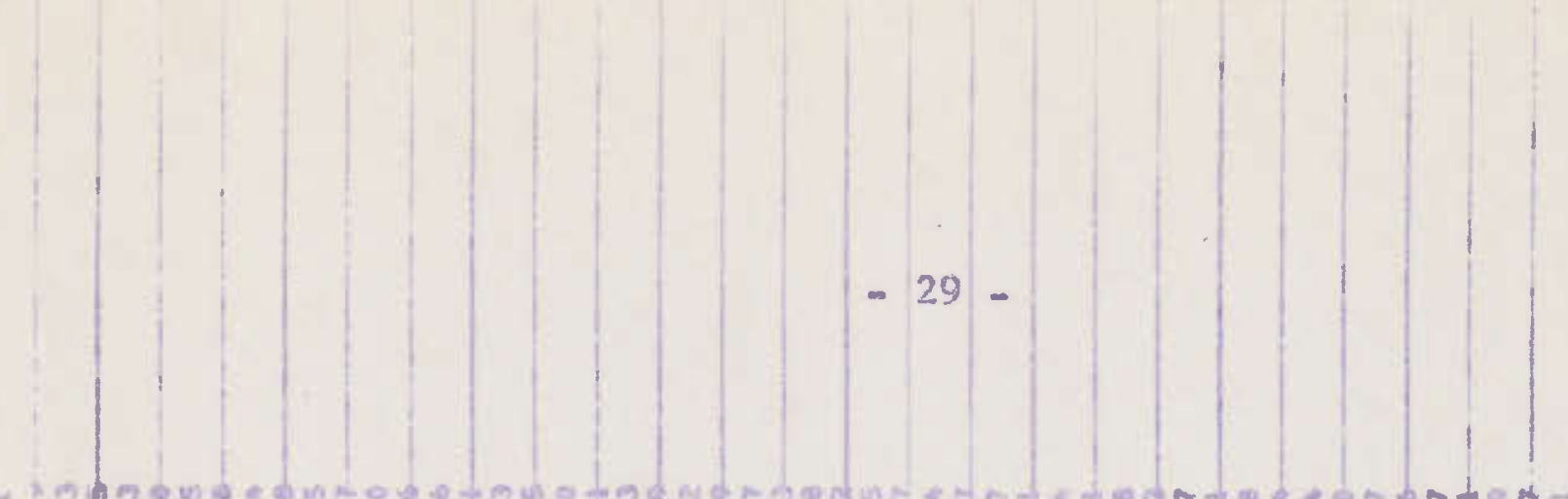

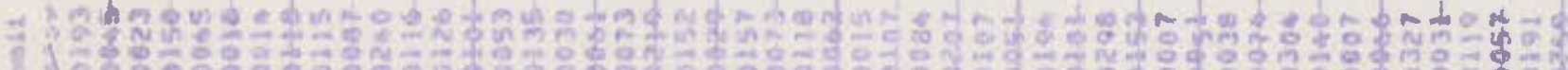
(

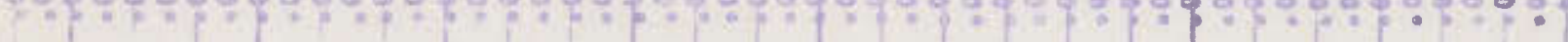

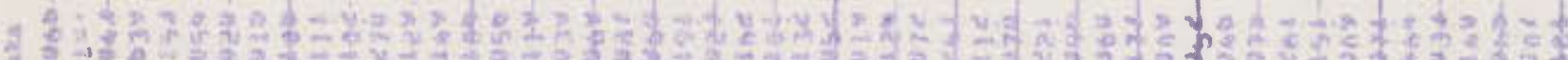

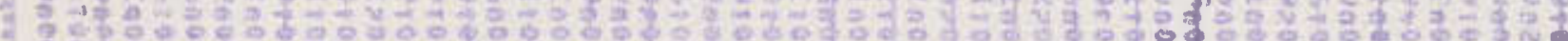

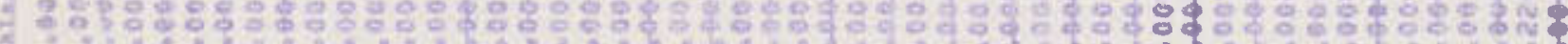

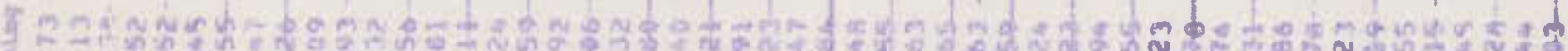

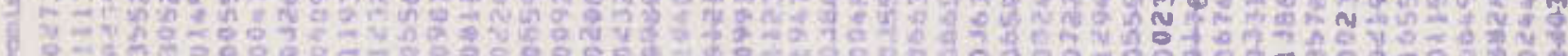

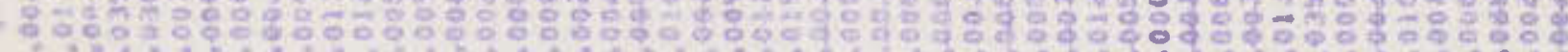

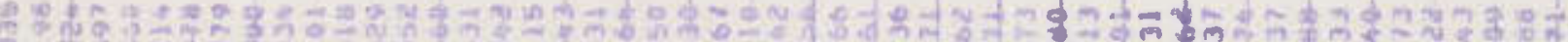

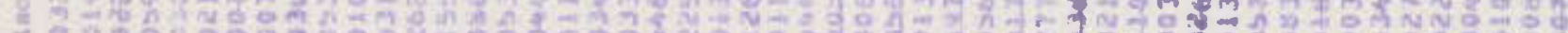

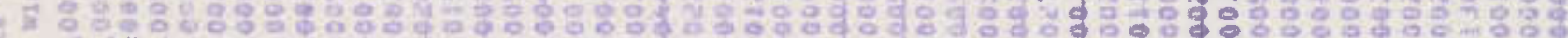

1 1 (

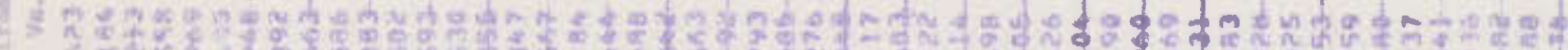

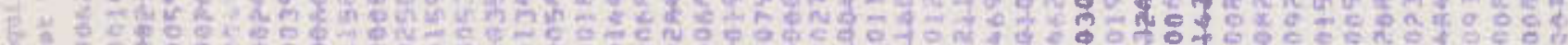

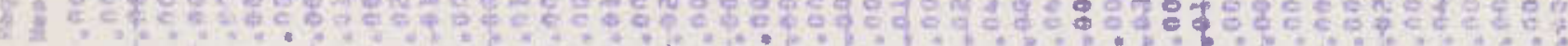

E

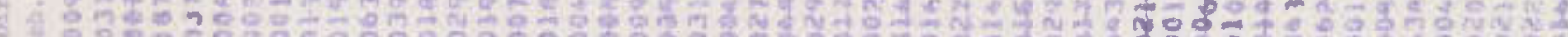

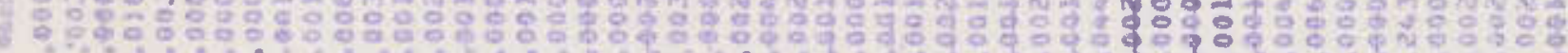

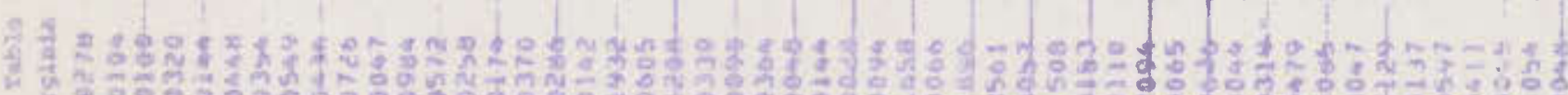

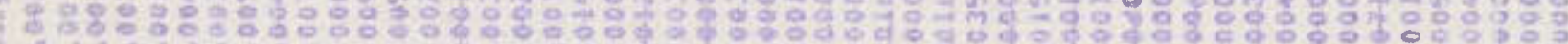

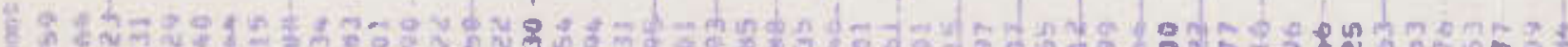

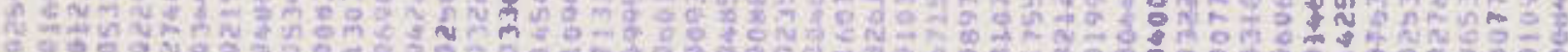

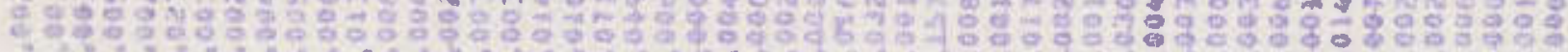

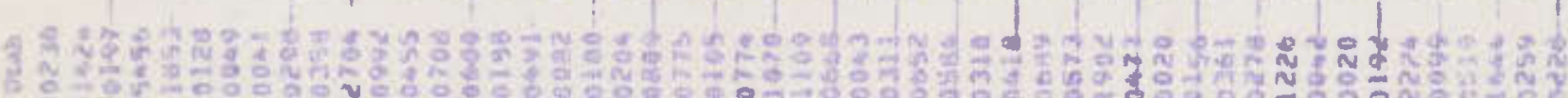

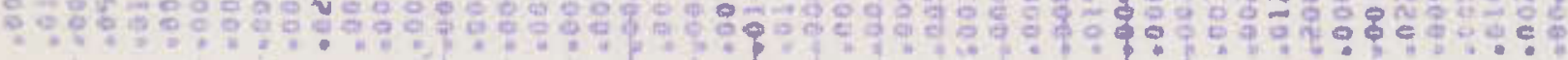

I

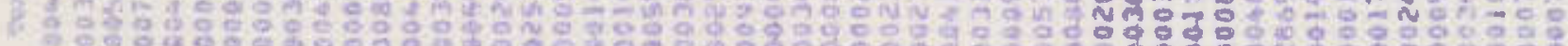

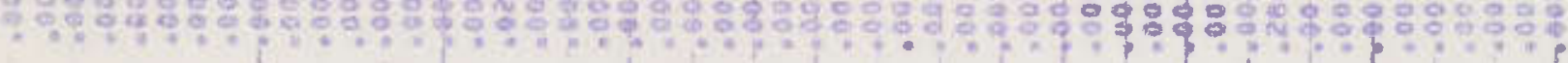

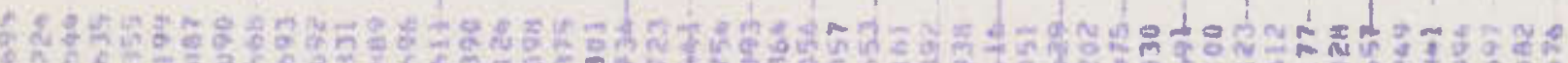

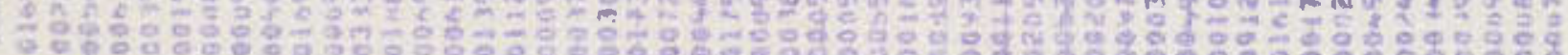

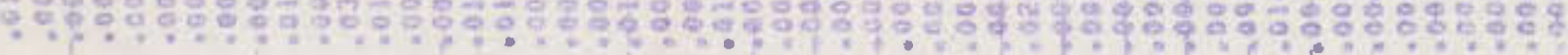

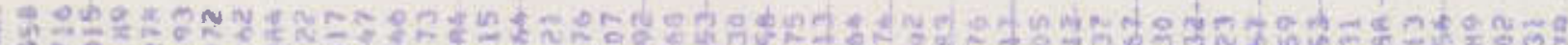

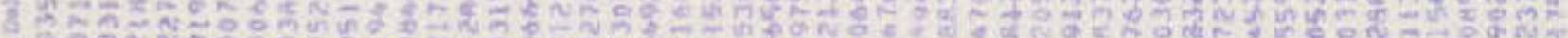
4:

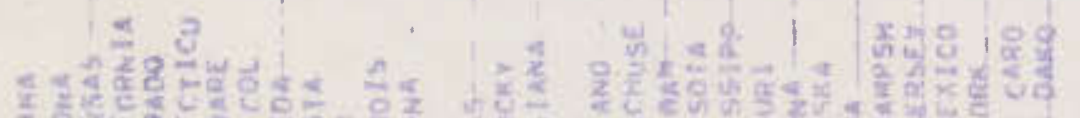

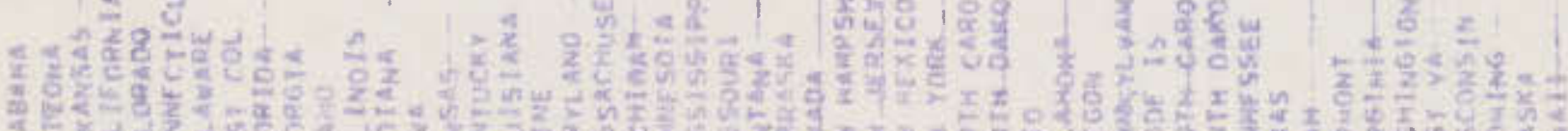

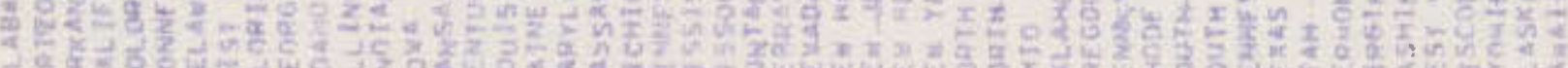

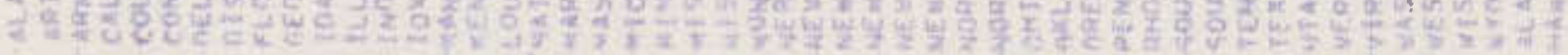

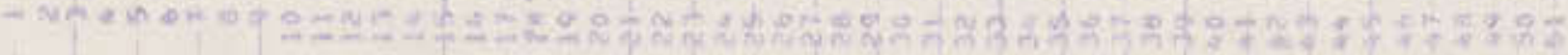




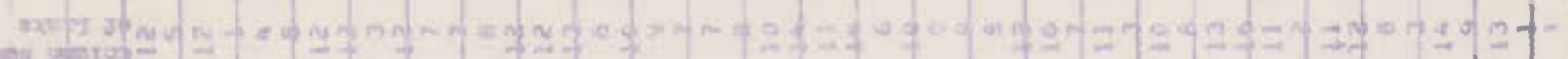

ingut? 3

$\min$ nat $^{2}$

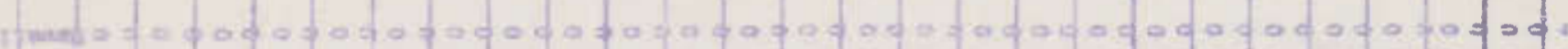

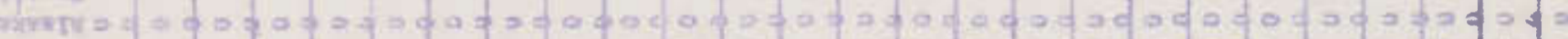

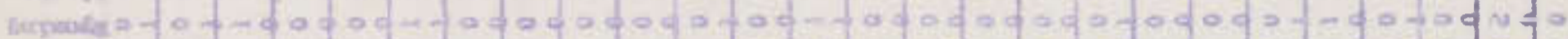

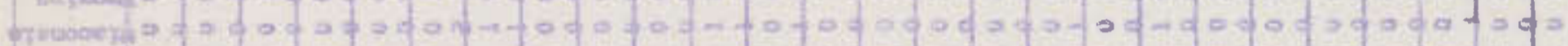

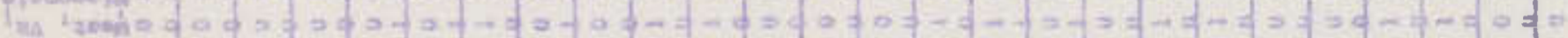

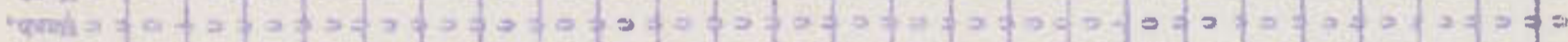

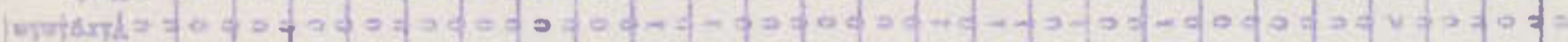

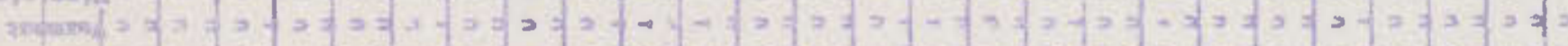

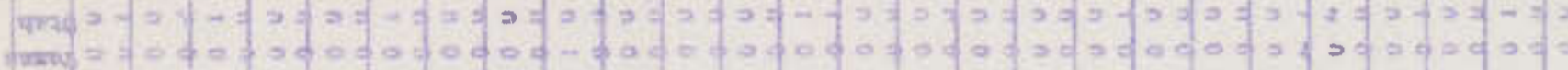

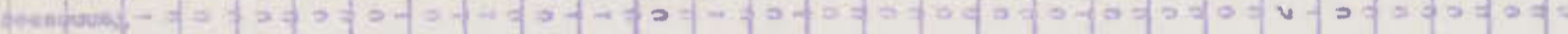

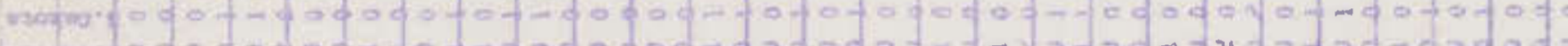

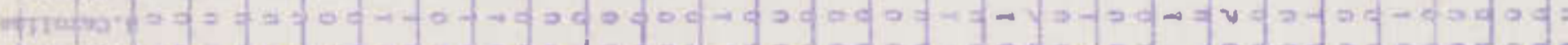

20

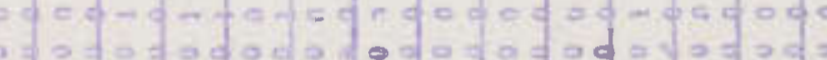

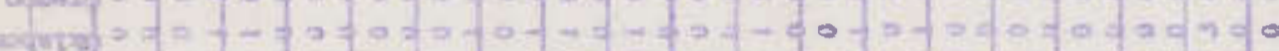

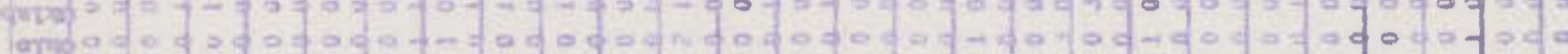

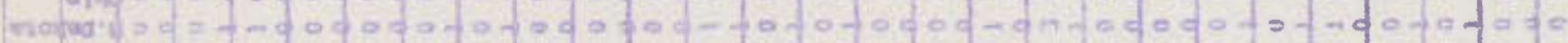

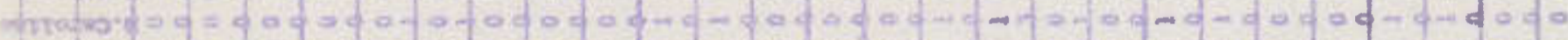

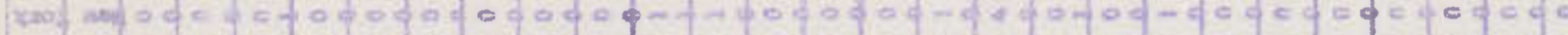

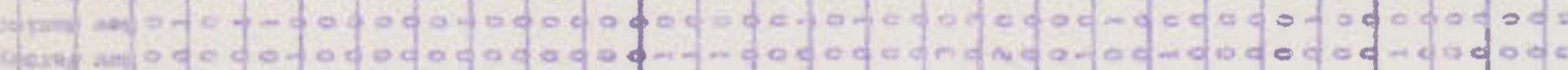

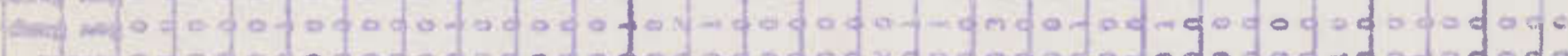

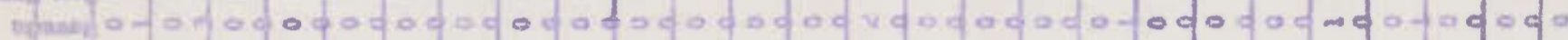

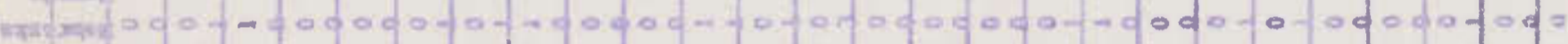

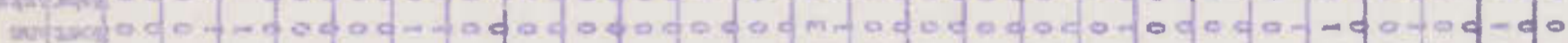

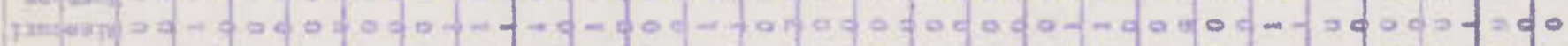

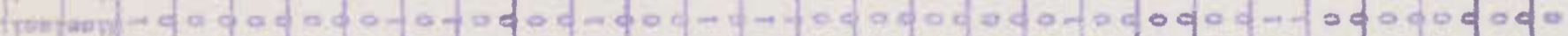

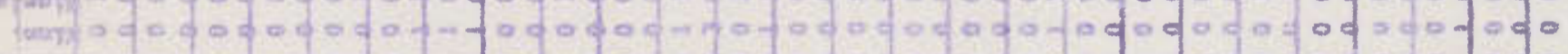

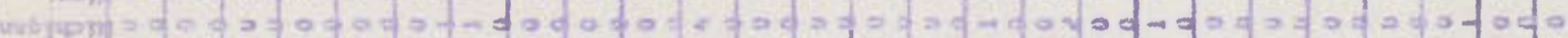

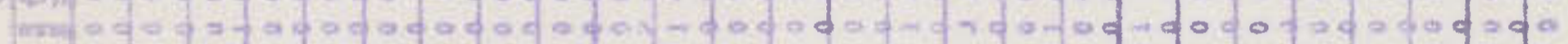

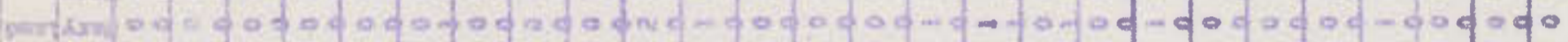

Nermack Furn motLegrisura

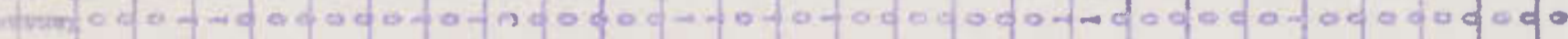

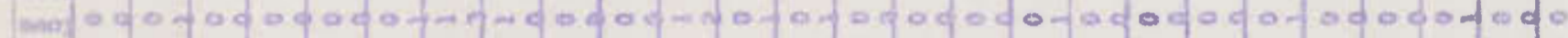

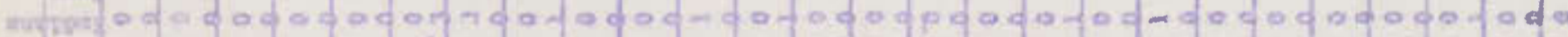

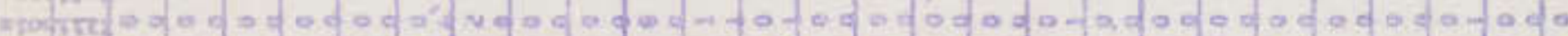

durvo

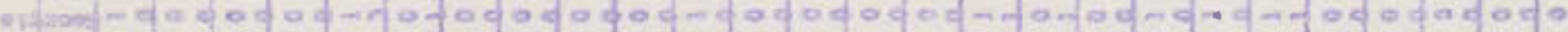

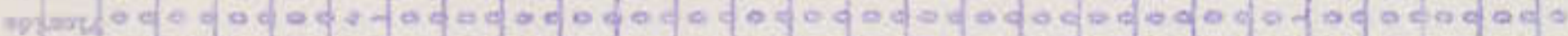

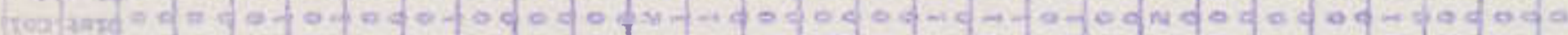

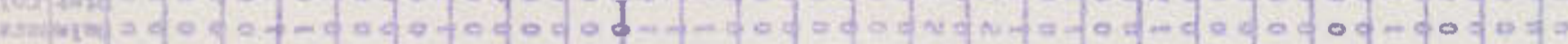

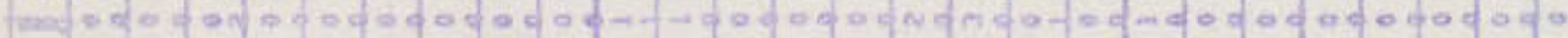

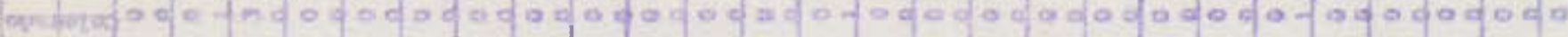

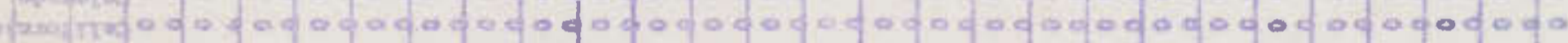

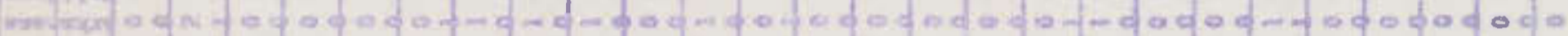

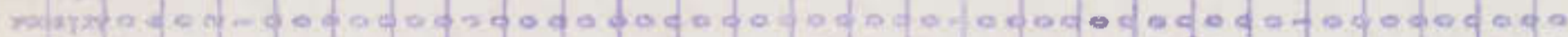

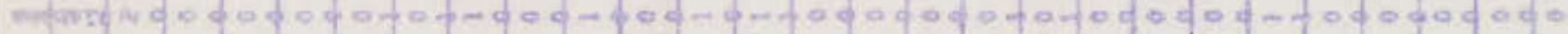

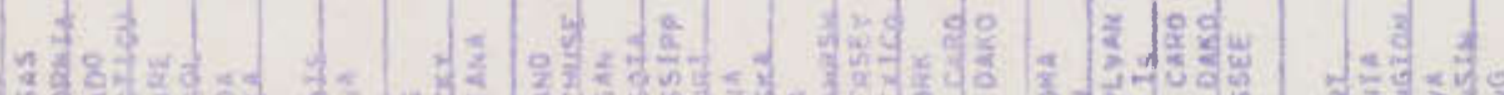

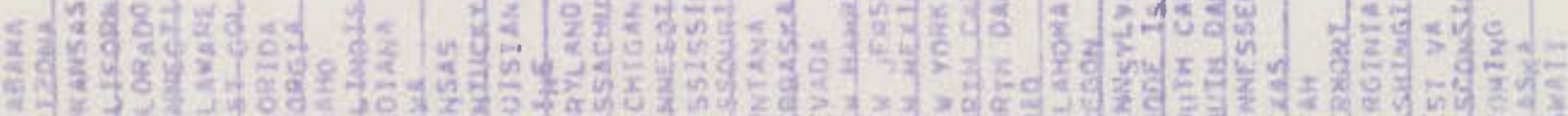

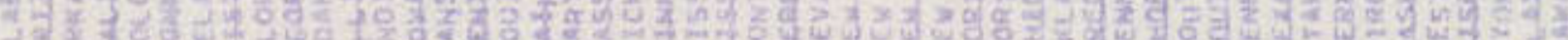

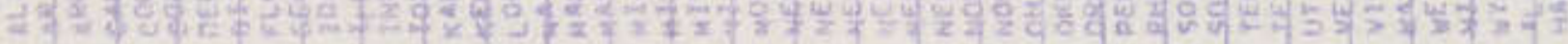

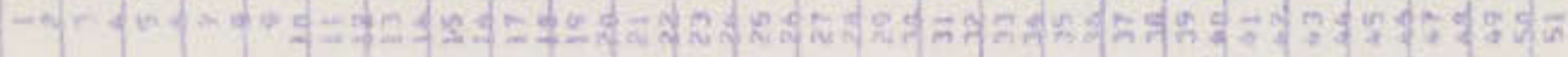


$-31-$

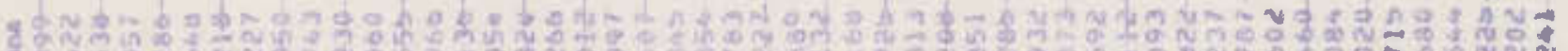

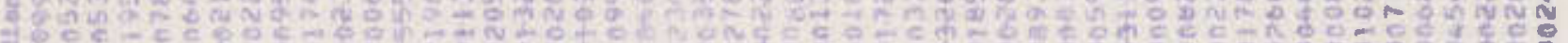

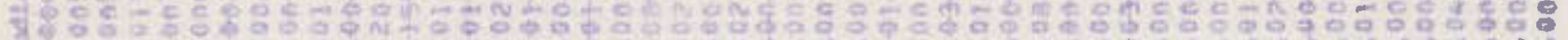

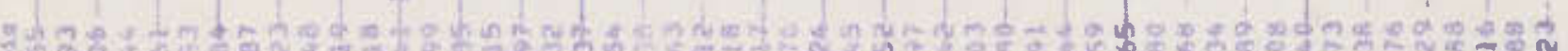

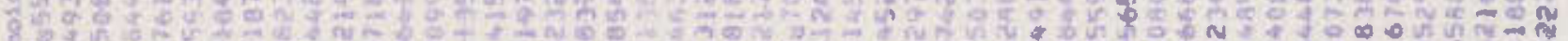

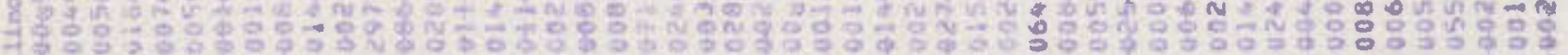

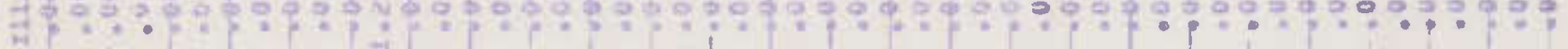

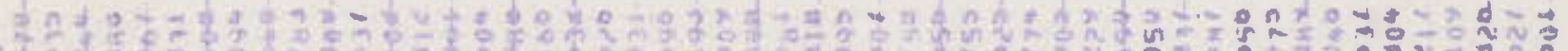

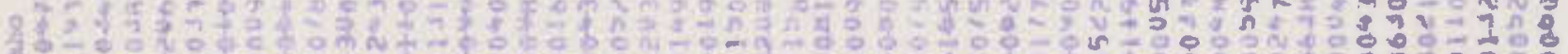

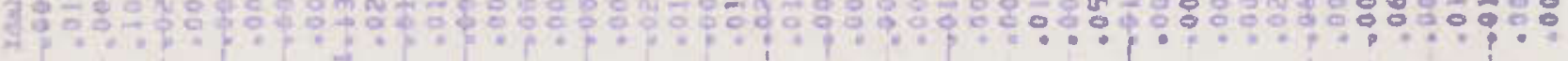

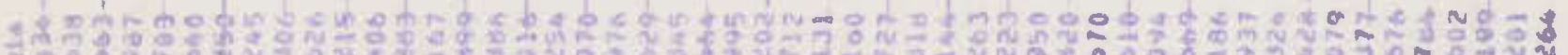
然

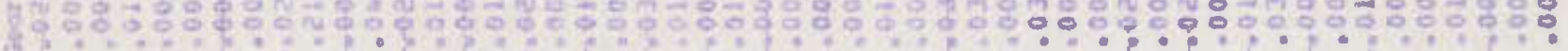

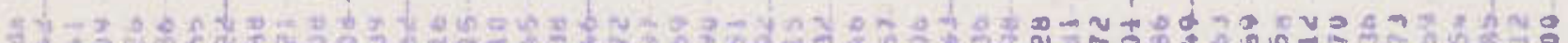

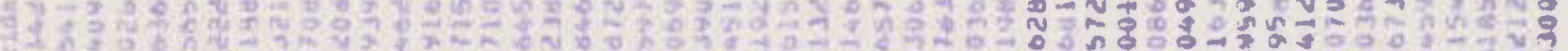

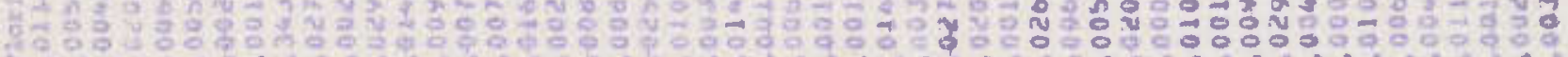

B̈난

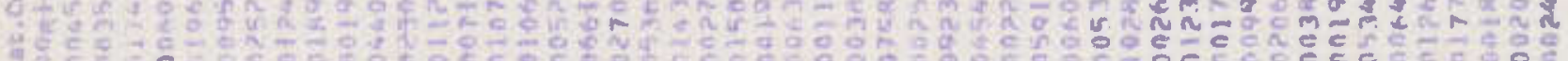

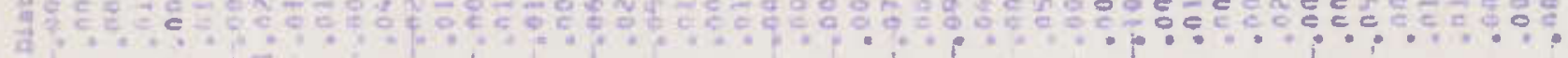

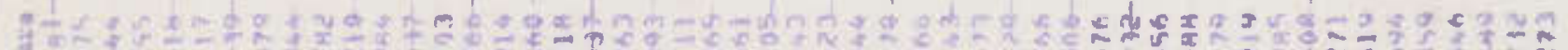

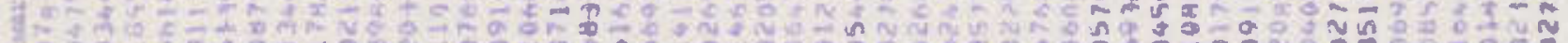

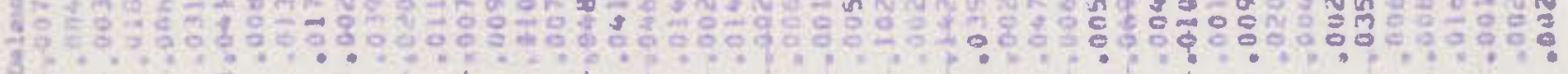

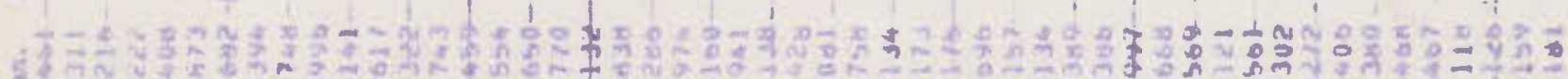

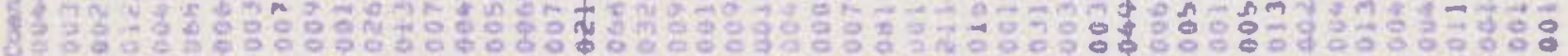

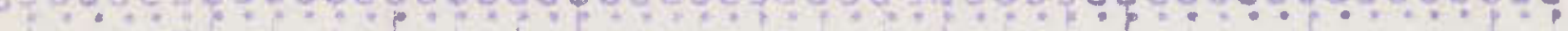

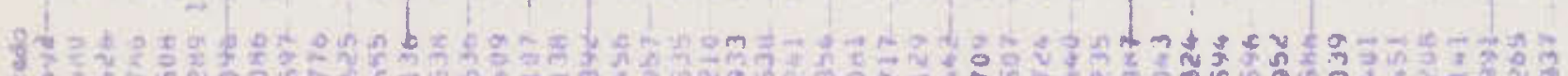

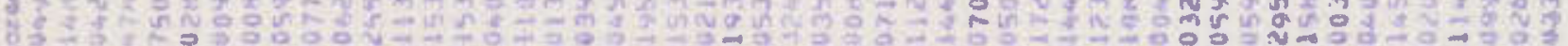

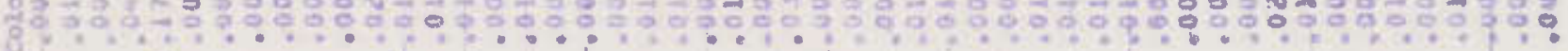

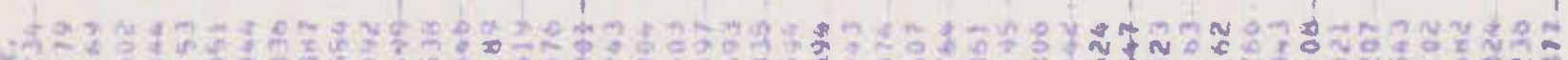

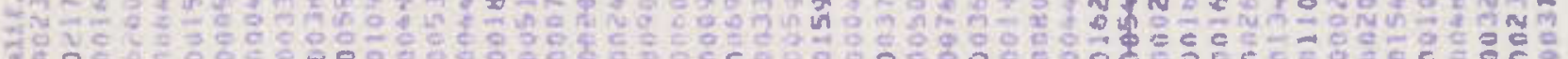

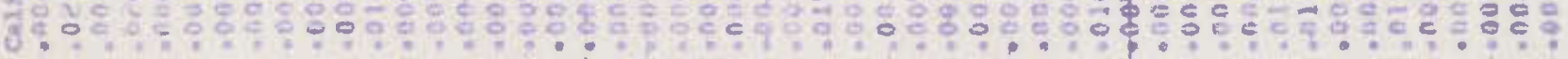

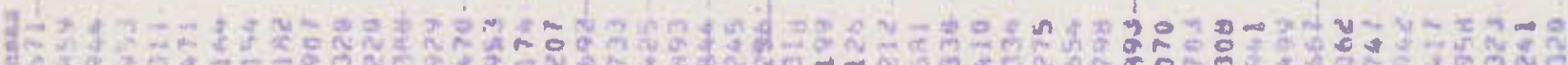

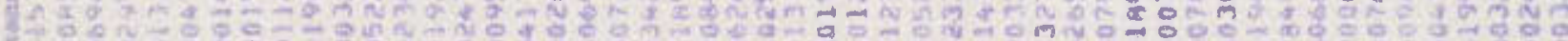

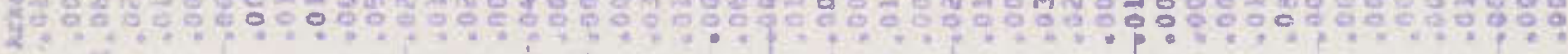

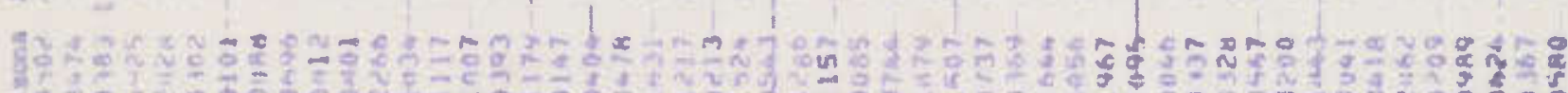

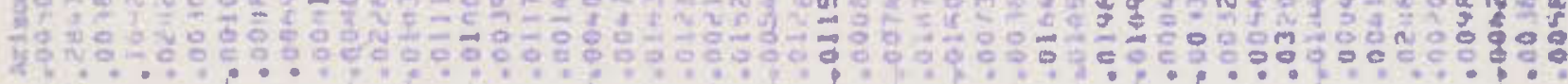

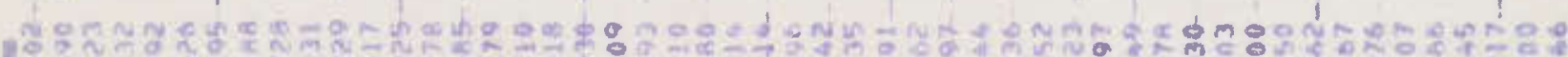

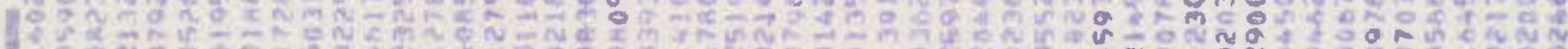

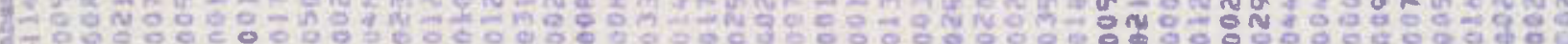

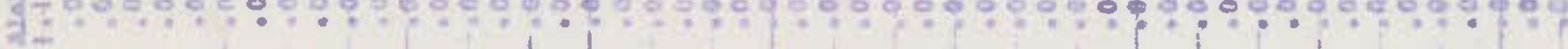

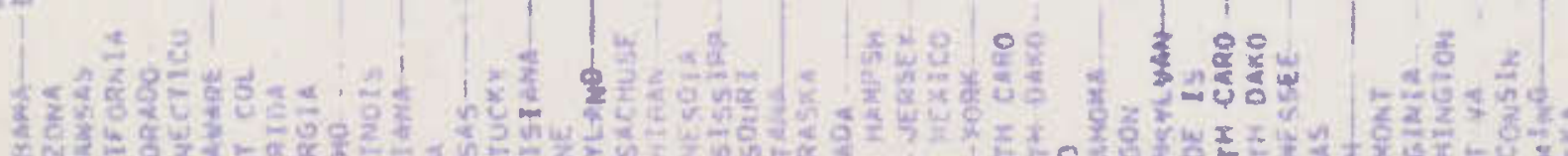
r. x. 줄

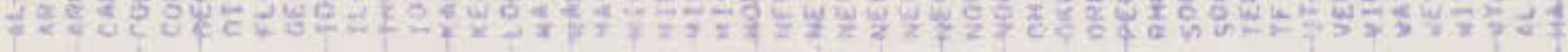

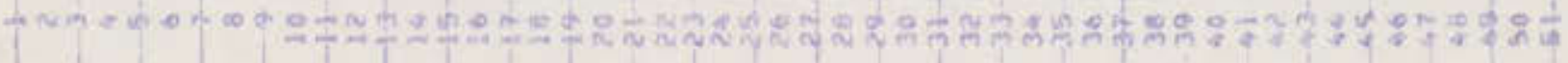




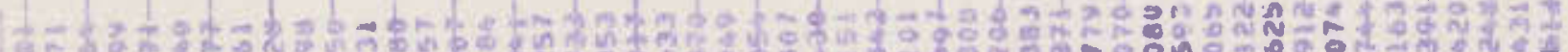

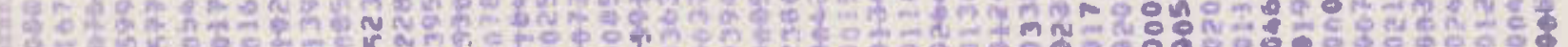

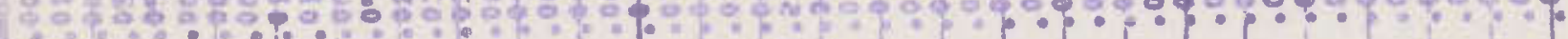

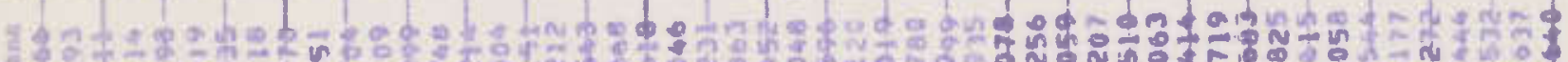

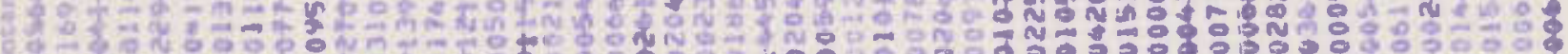

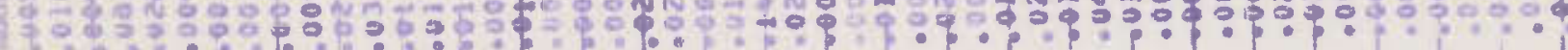

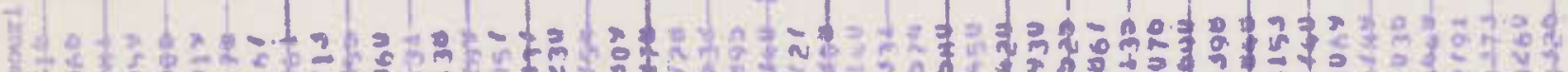

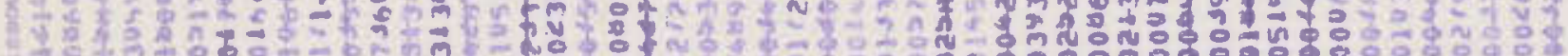

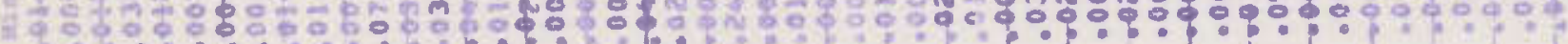

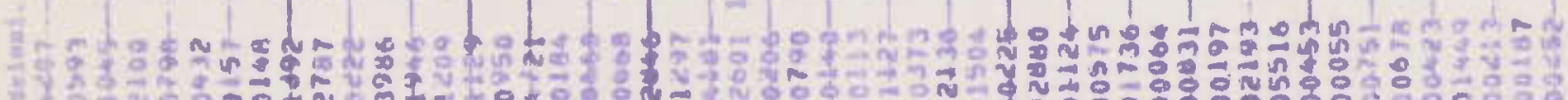

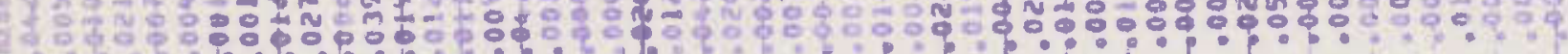

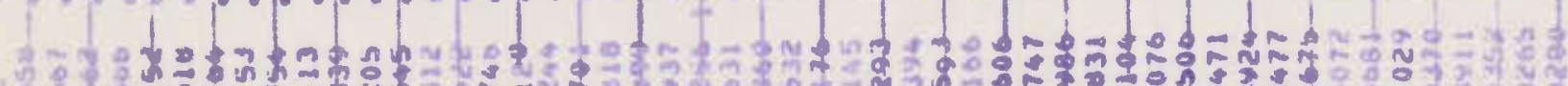

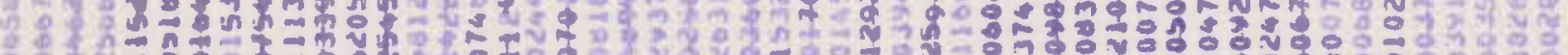

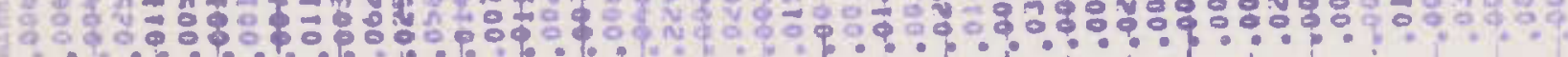

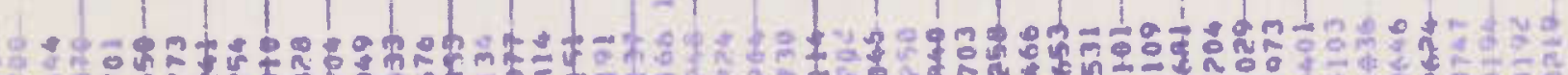

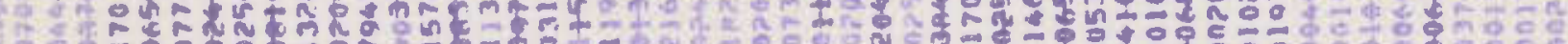

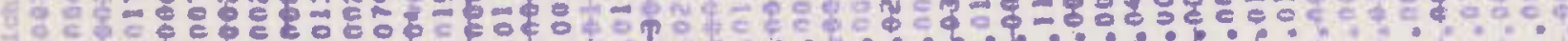

dof-

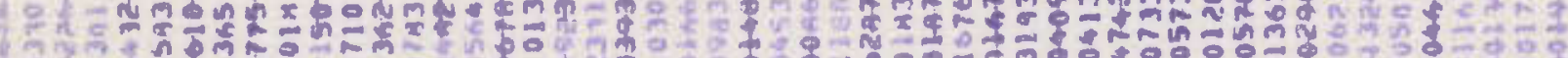
遂官 S7y

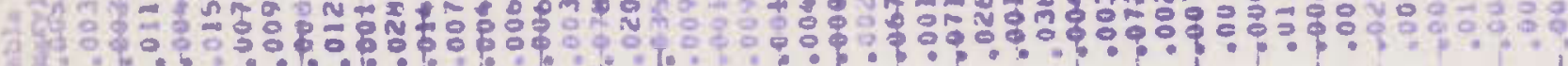
E

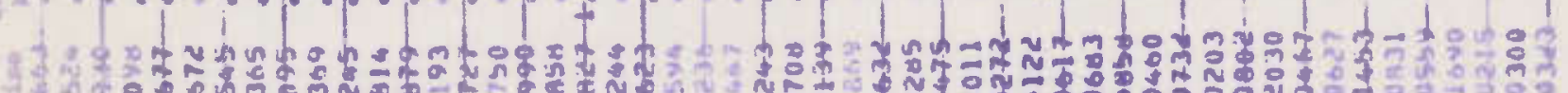

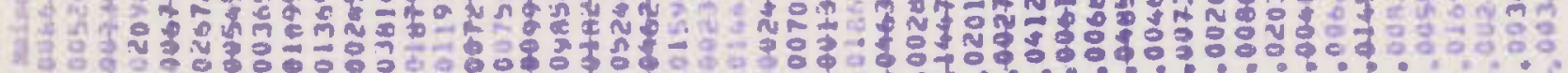

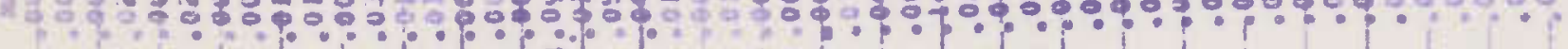

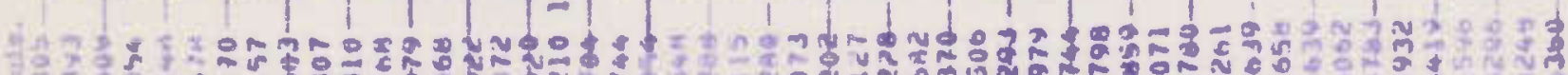

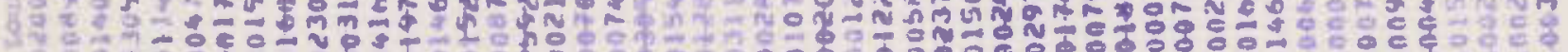

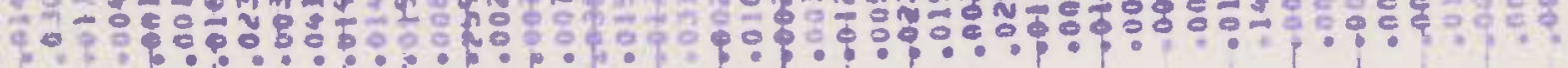

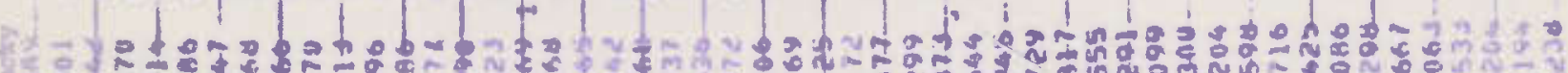
(5)

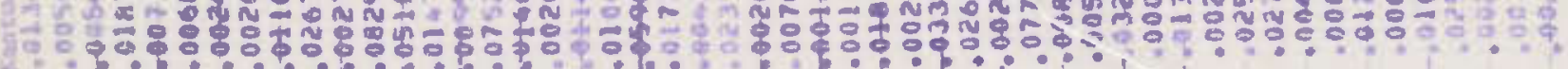

F

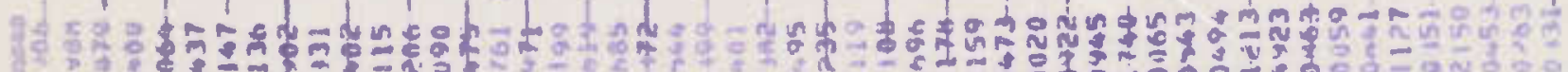

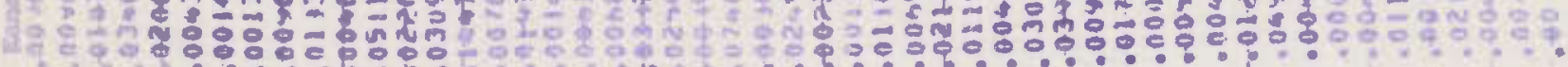
(1)

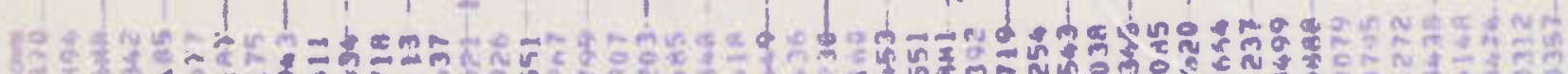

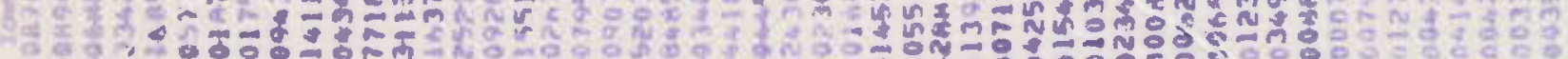

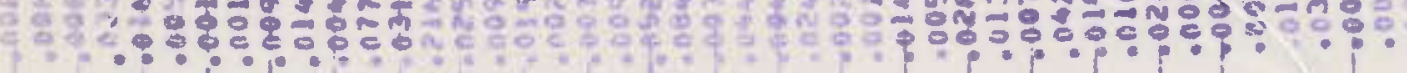

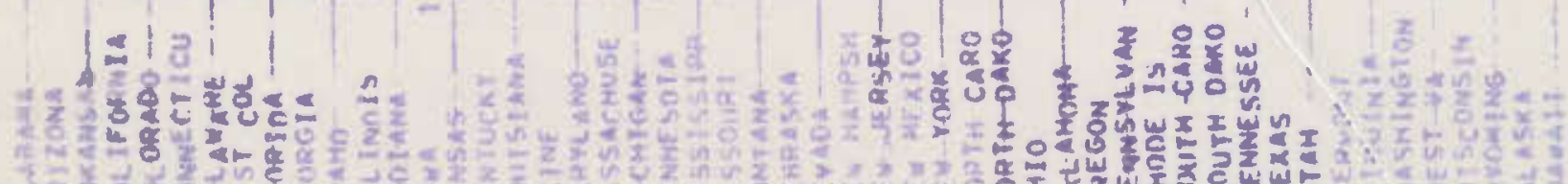

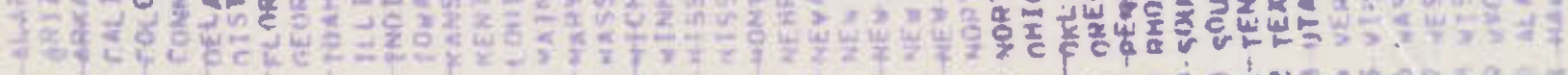

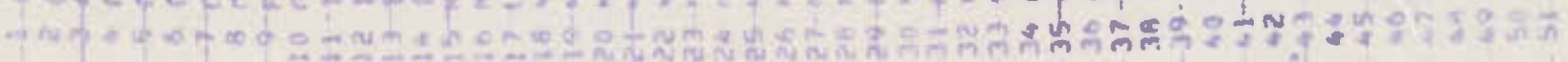




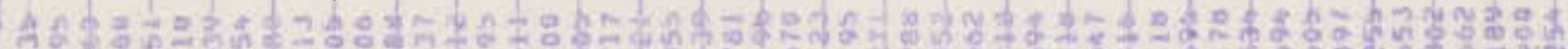

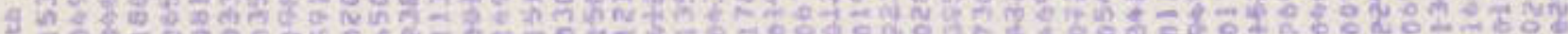

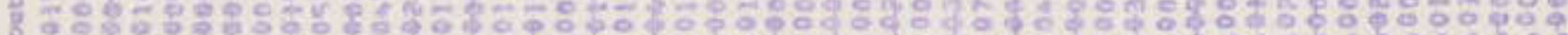

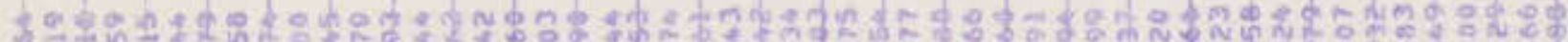

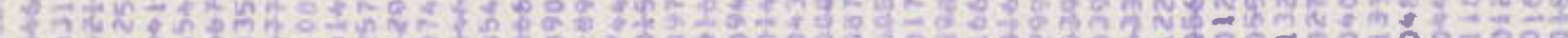

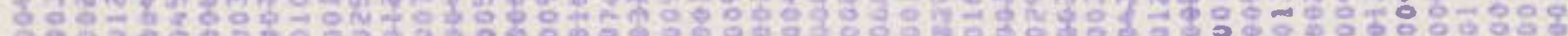

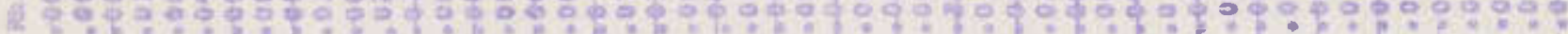

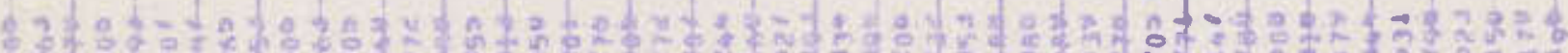

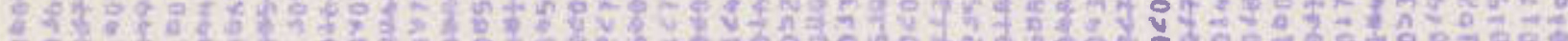

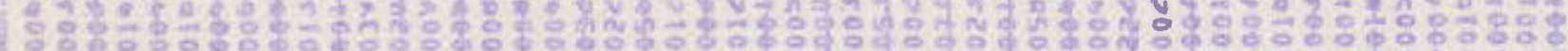
-

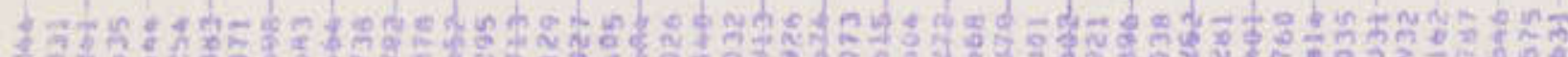
Aे

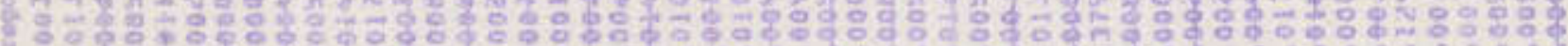

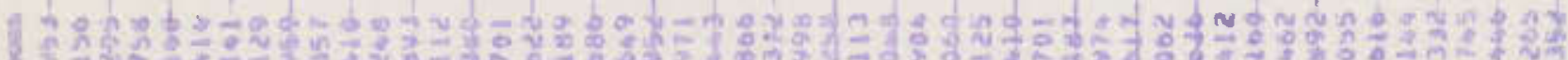

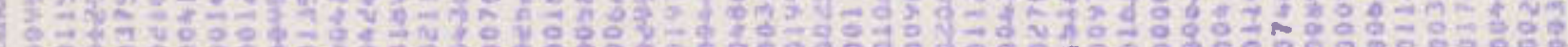

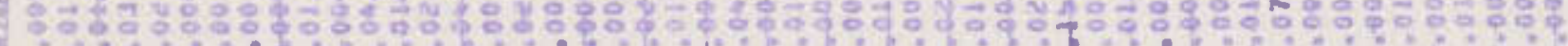

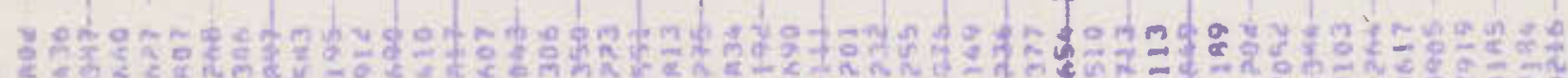

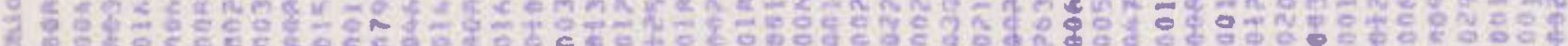

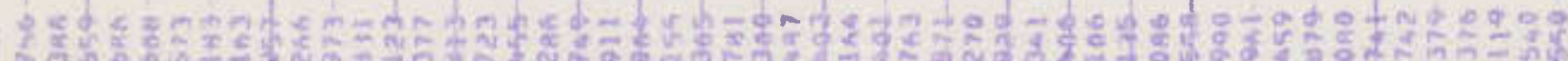

6 g

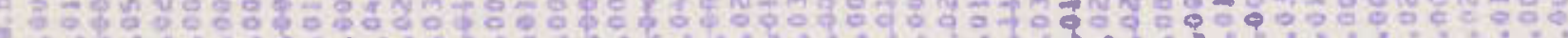

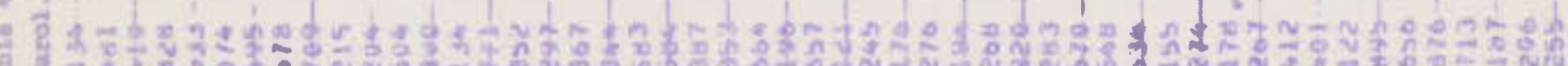

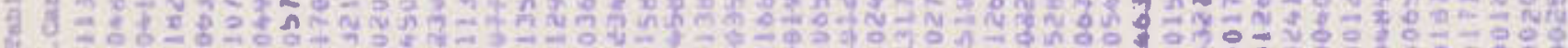

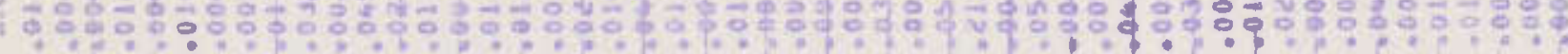

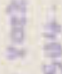

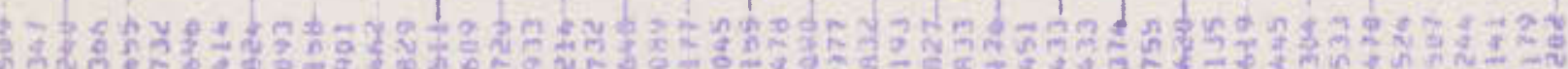
की

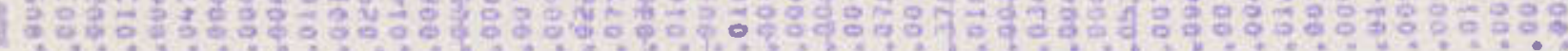

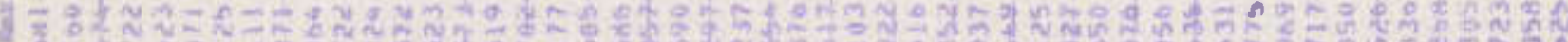

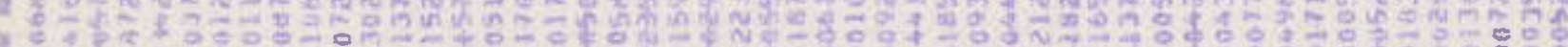

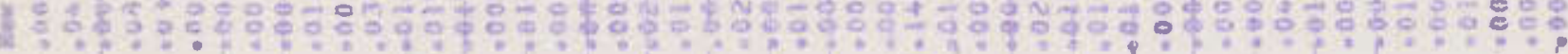

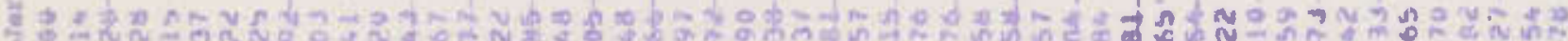

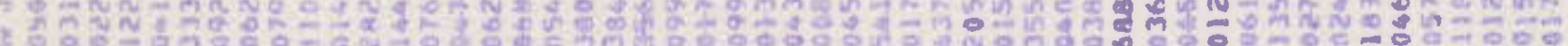

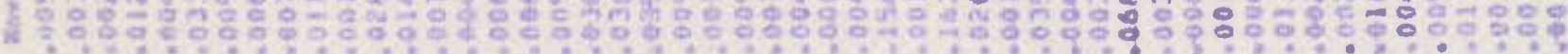

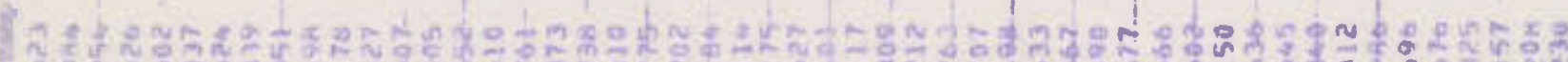

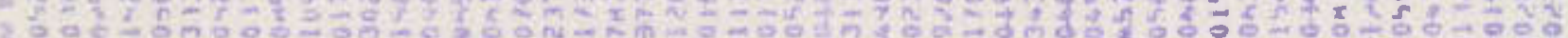

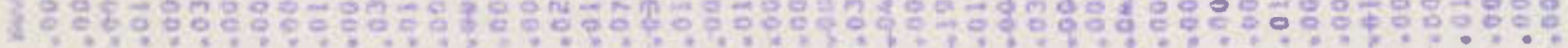

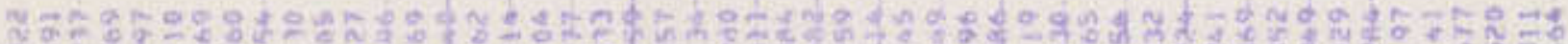

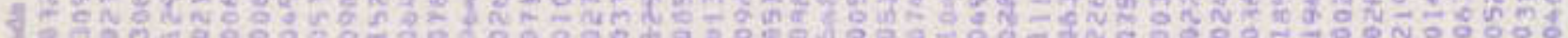

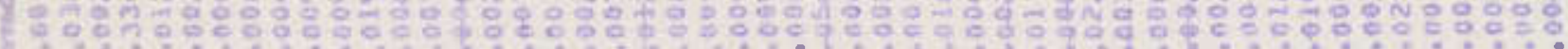

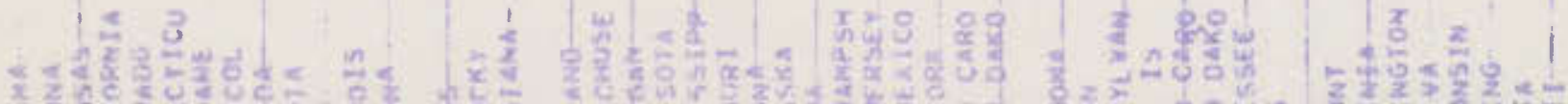

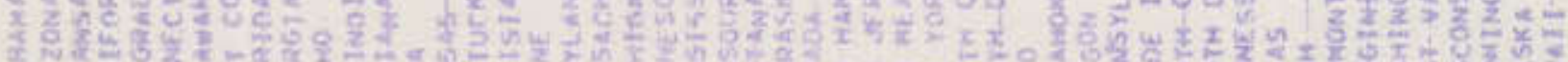

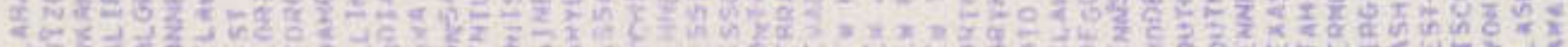

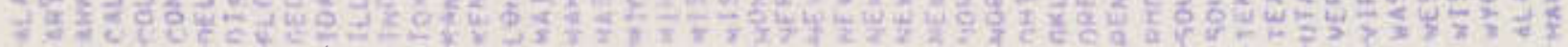

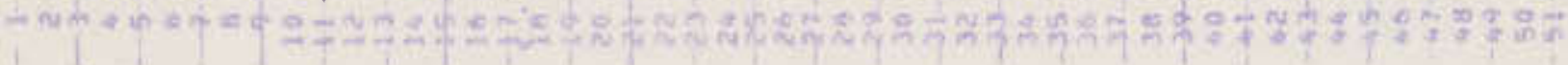




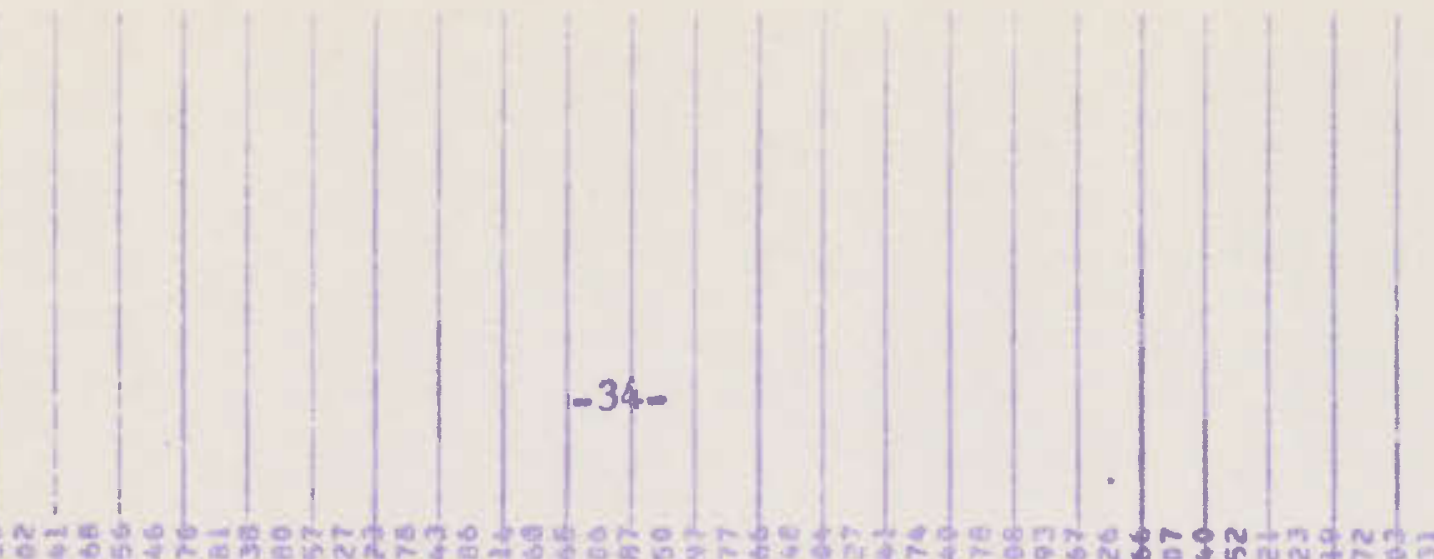

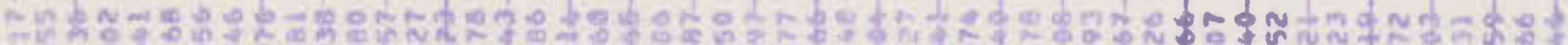

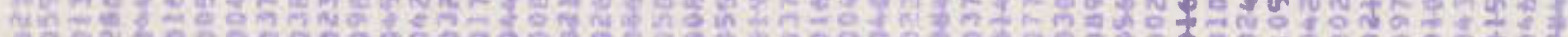

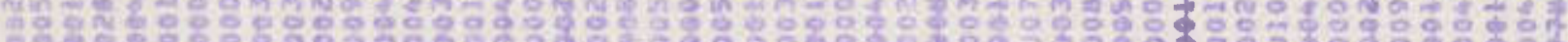

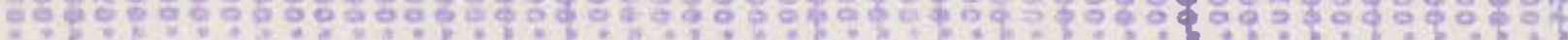

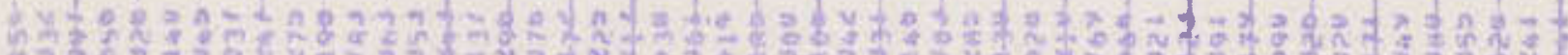

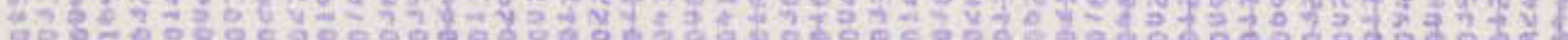

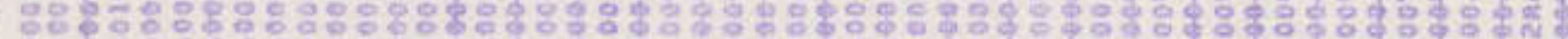

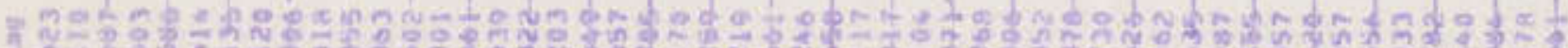

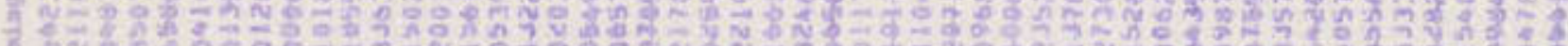

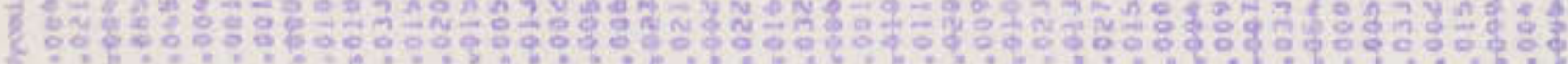

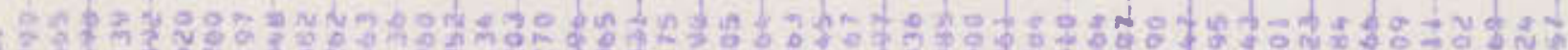

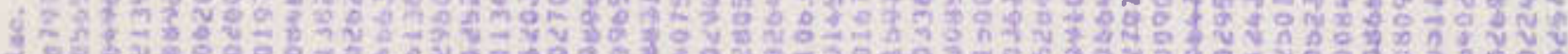

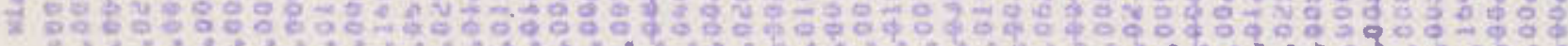

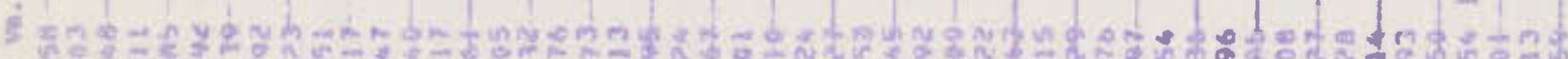

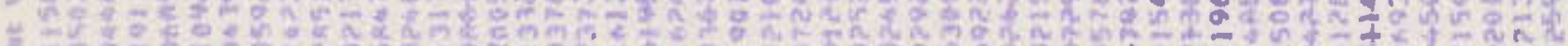

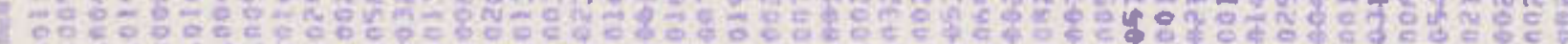

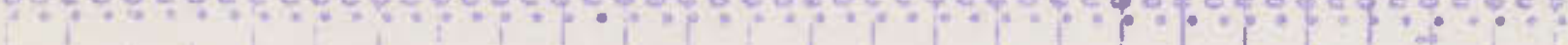

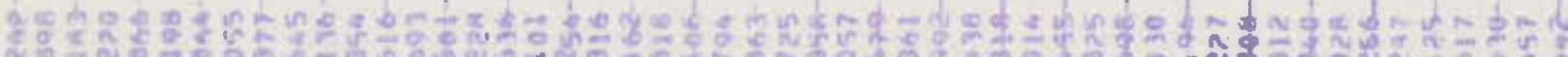

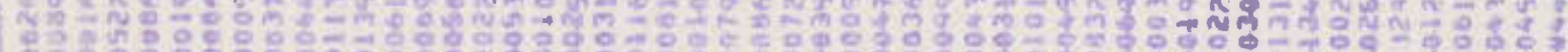

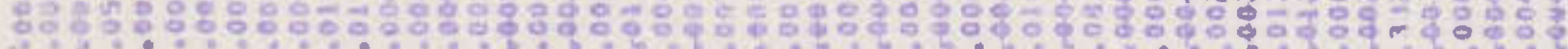

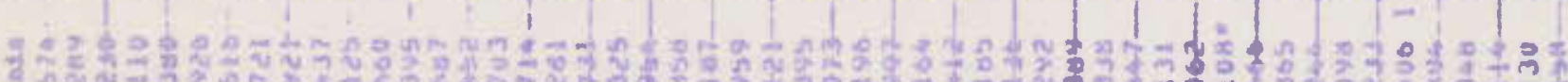

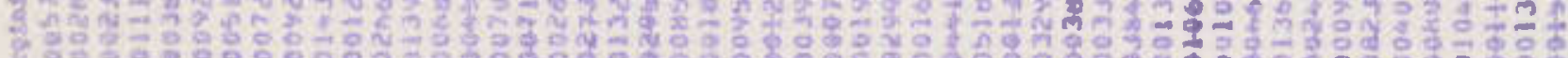

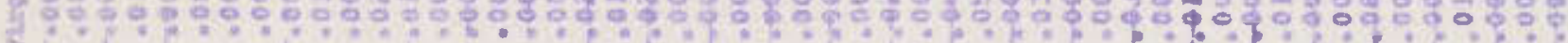

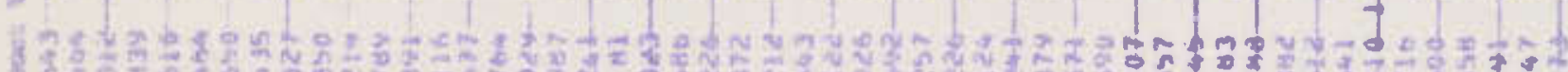

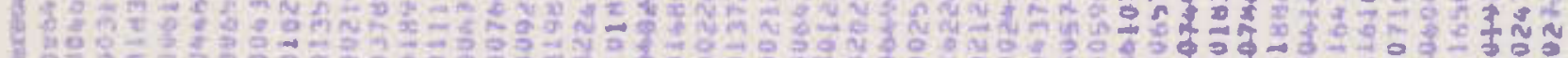

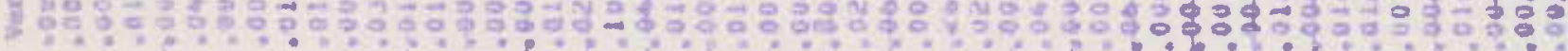

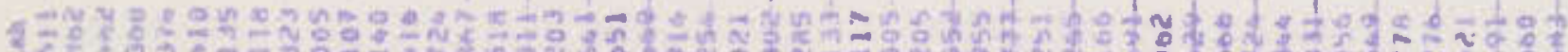

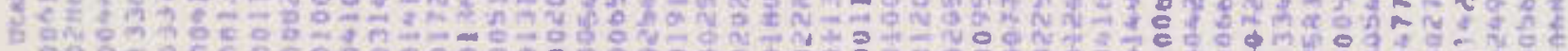

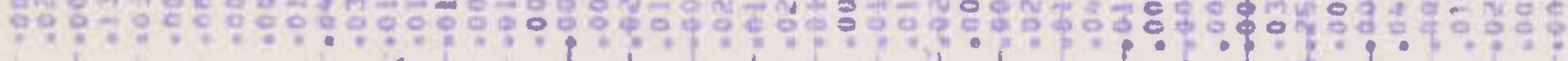

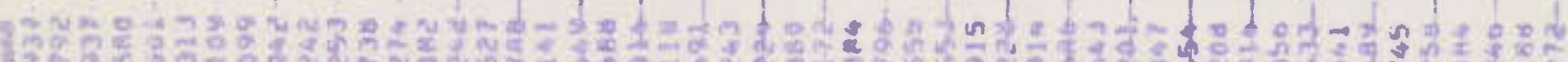

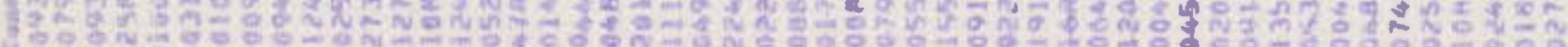

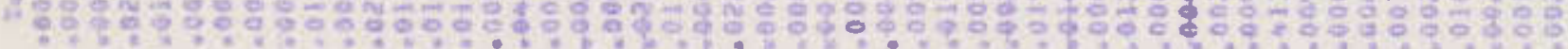

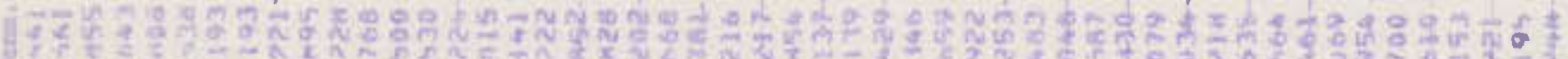

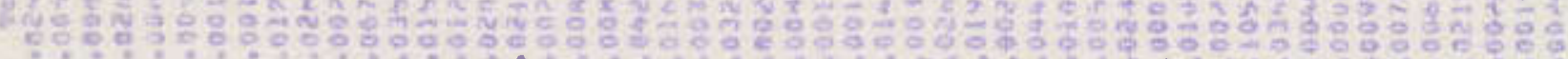
3

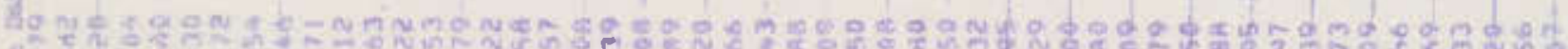

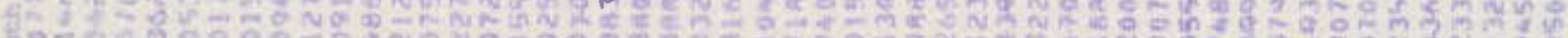

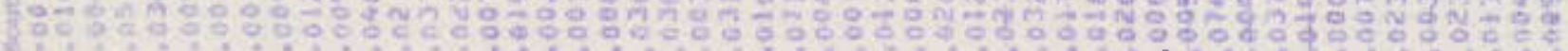

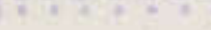

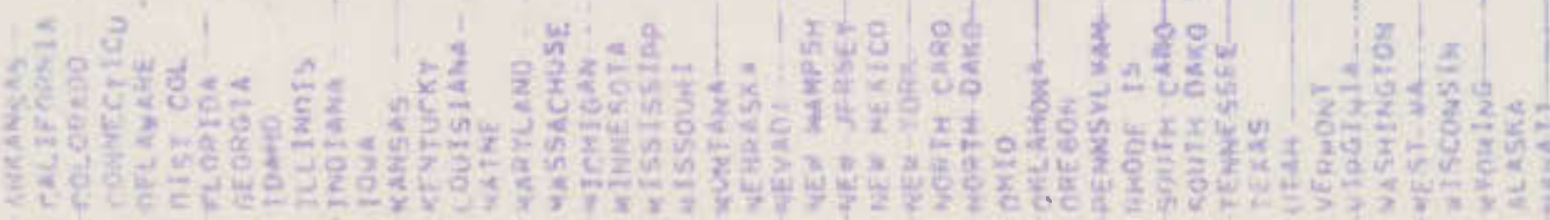



$\Rightarrow$ esty

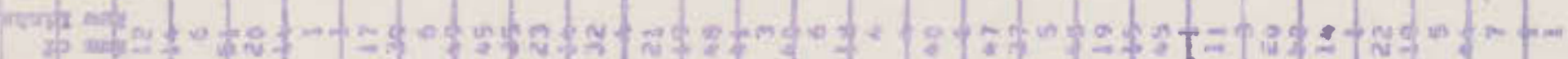

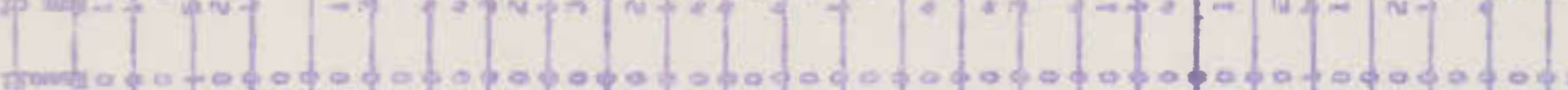

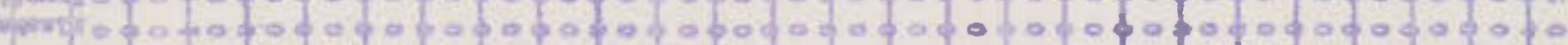

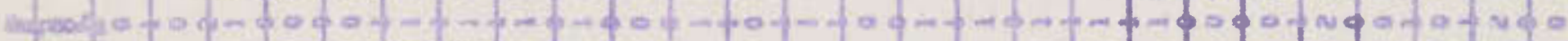

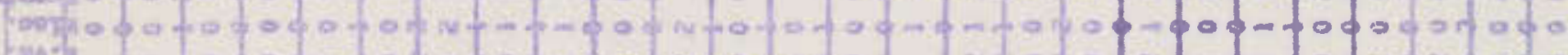

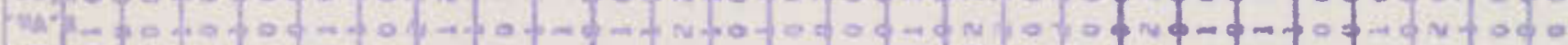

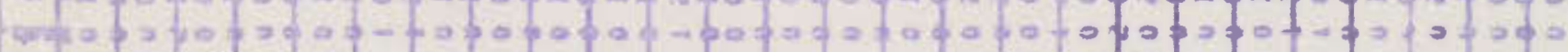

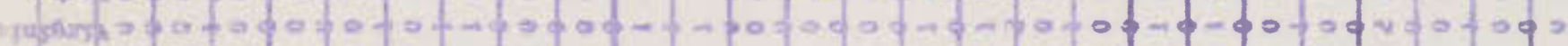

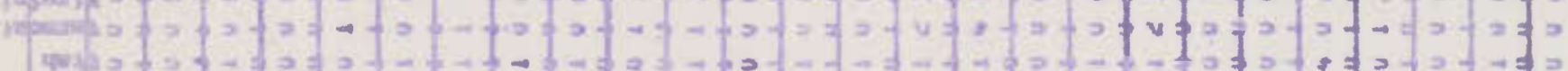

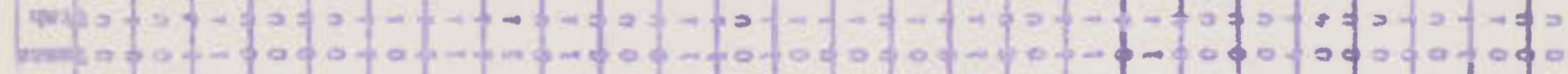

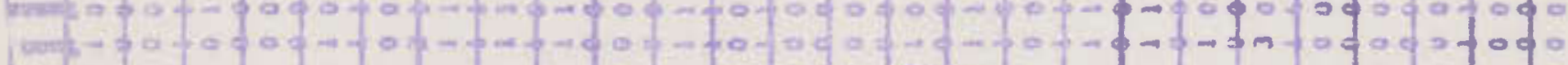

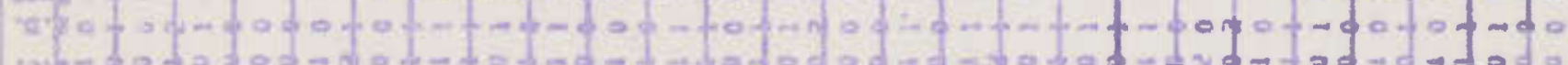

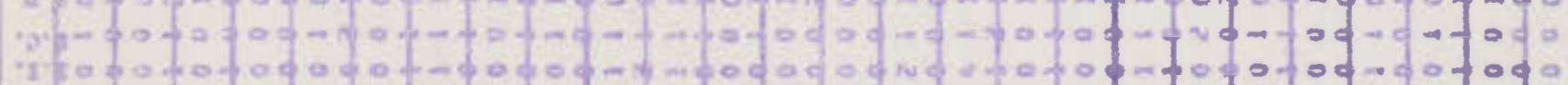

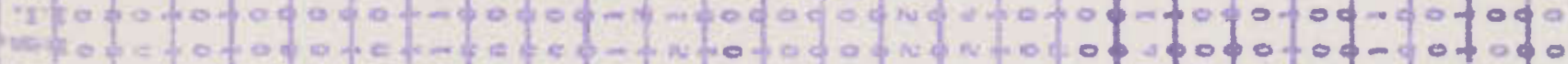

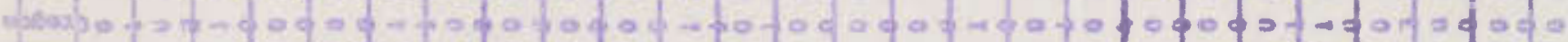

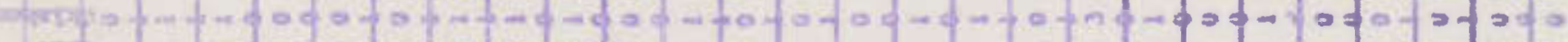
rrpen

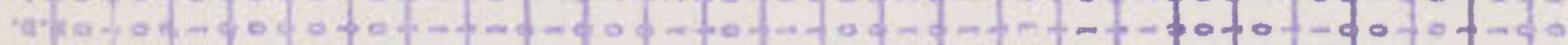

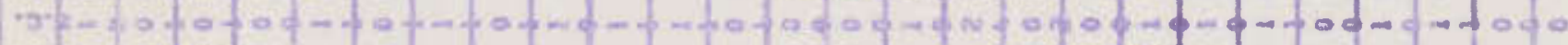

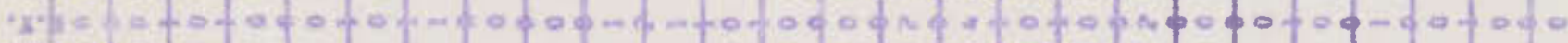

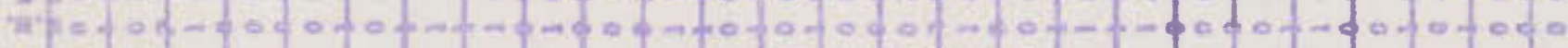

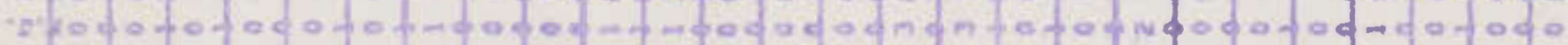

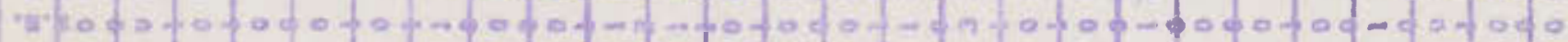

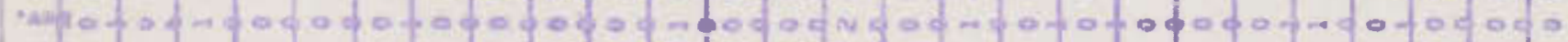

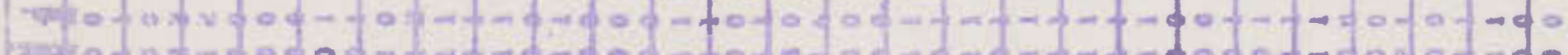
Fing

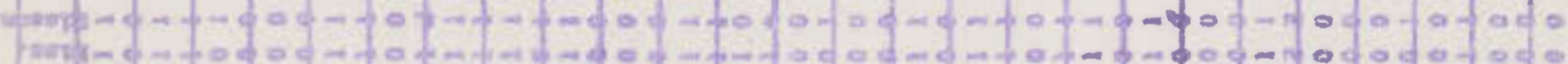
more of

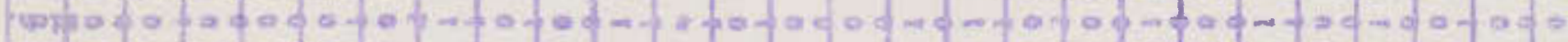

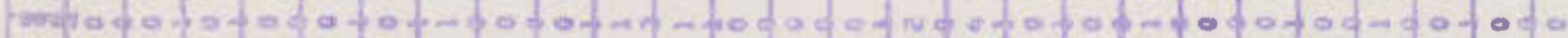

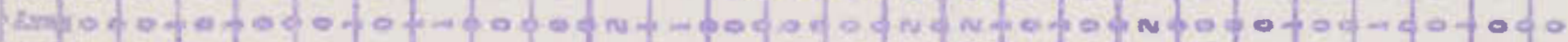

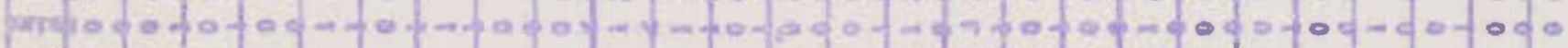

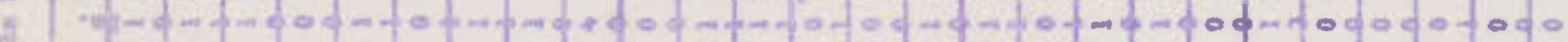

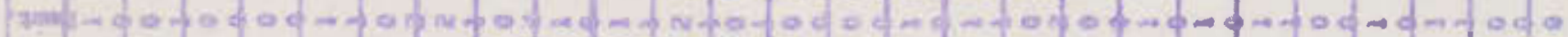
2)

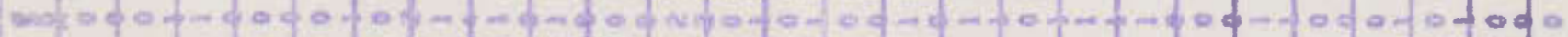

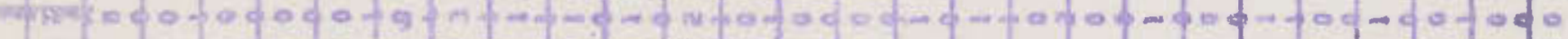

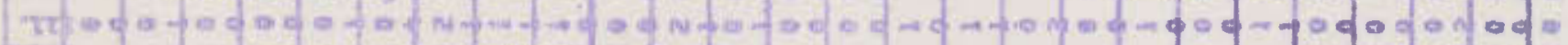

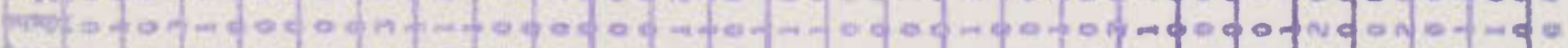

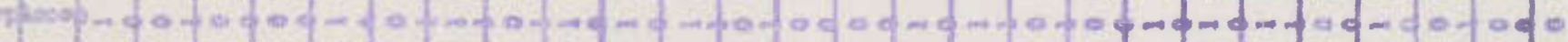

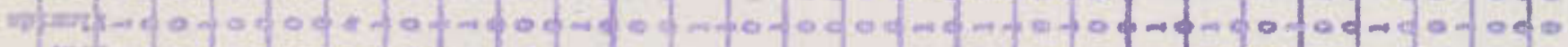

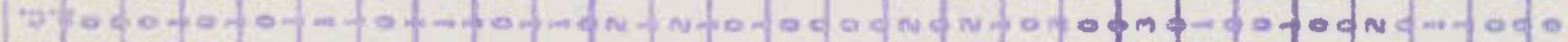

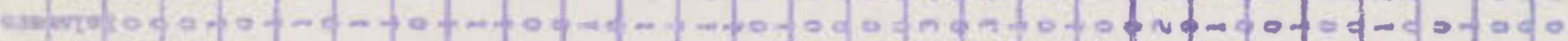

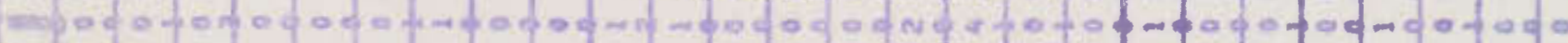

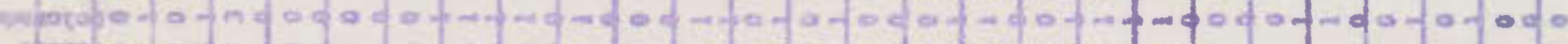

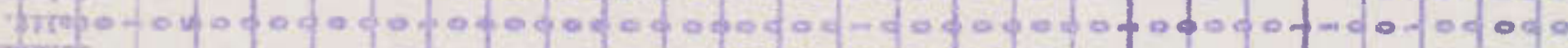

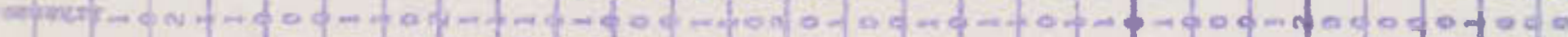
mompla

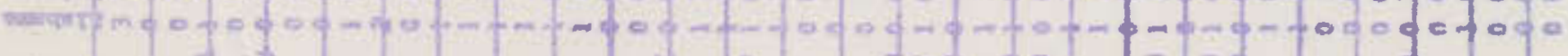

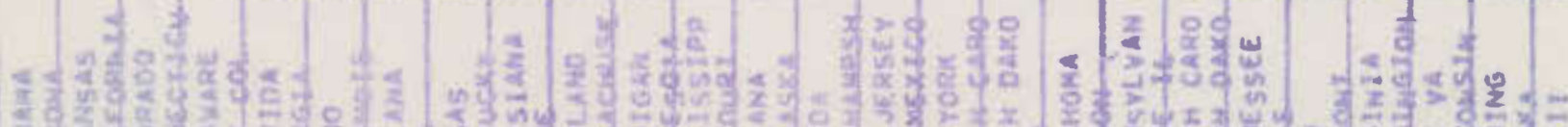

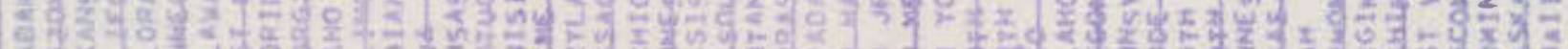

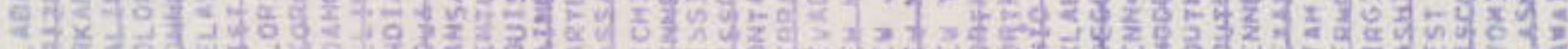

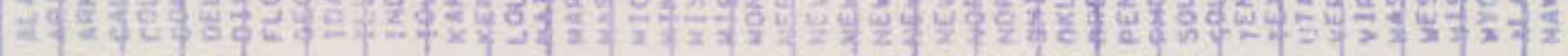

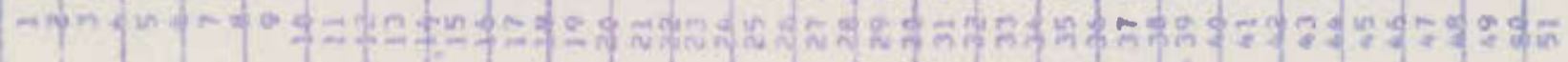

के

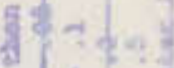

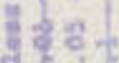

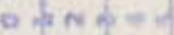

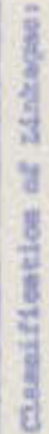




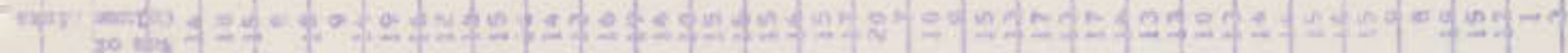

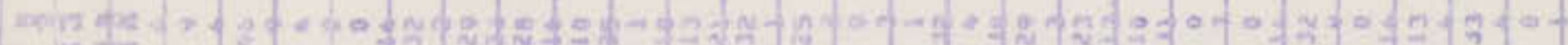
(150 $\sin ^{2}$

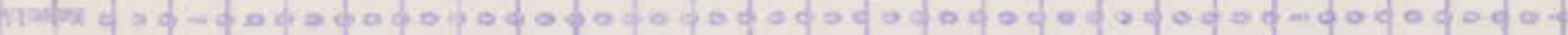

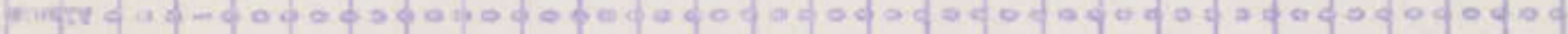

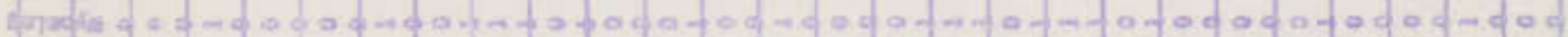

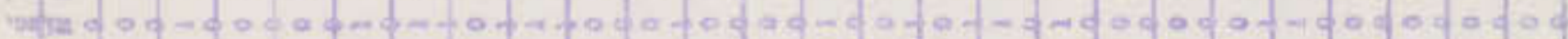

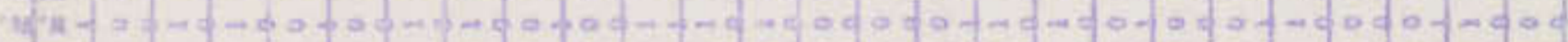

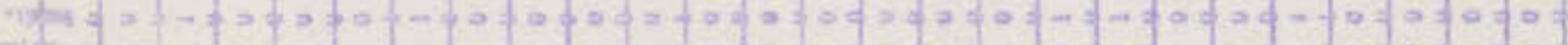

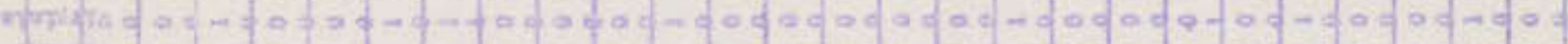

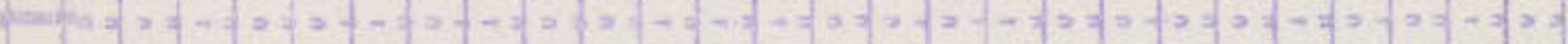

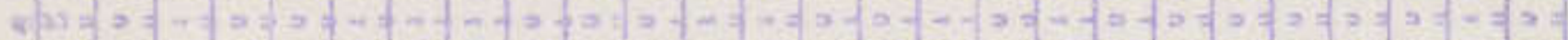
wives a

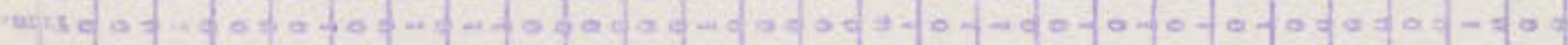

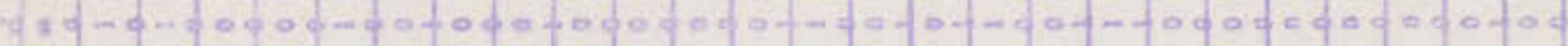

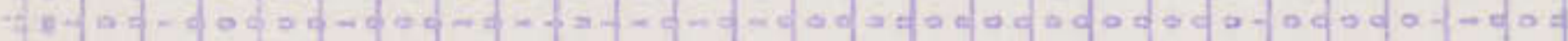

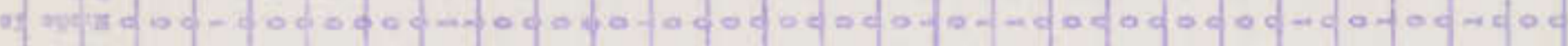

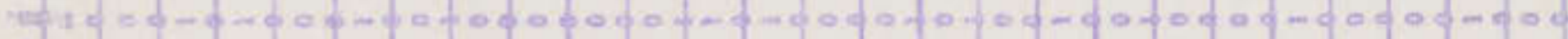

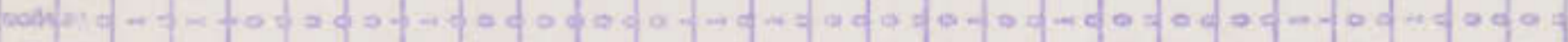

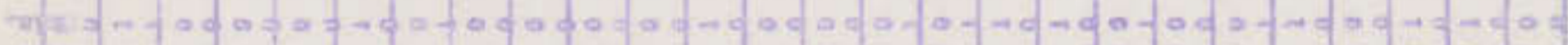
qved a d)

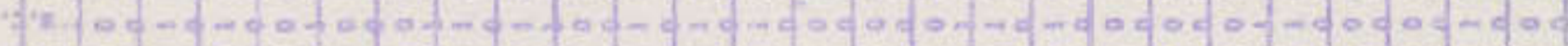

PII

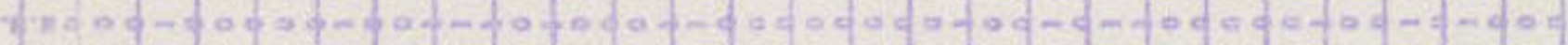

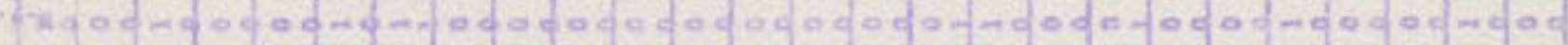

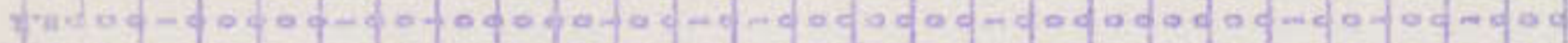

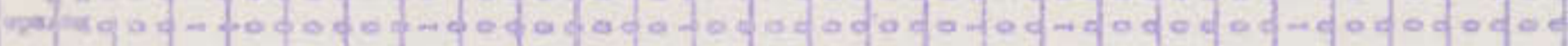

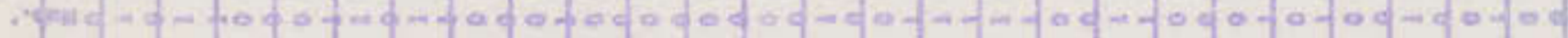

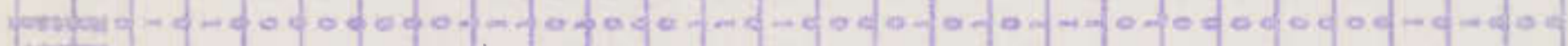
tomplata

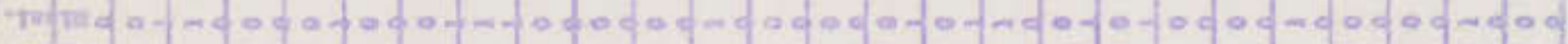

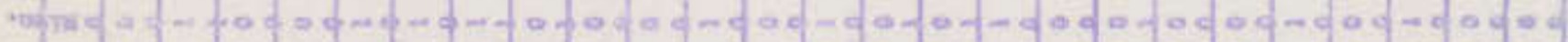

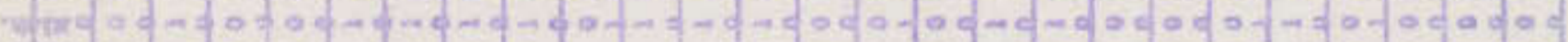

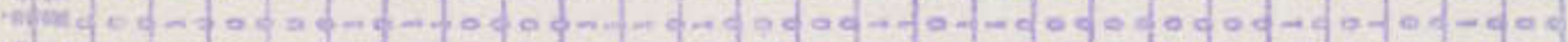

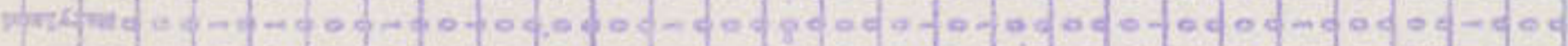

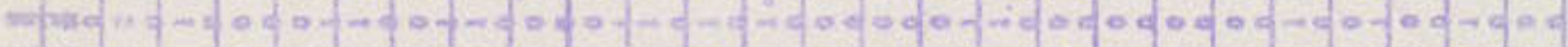

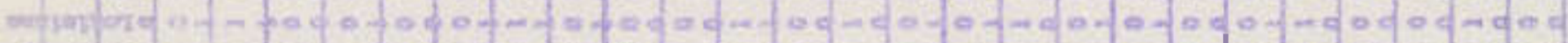

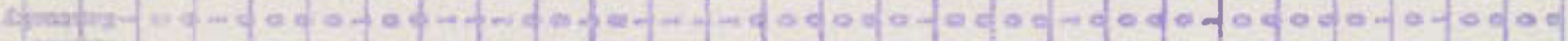

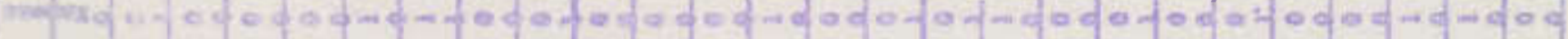

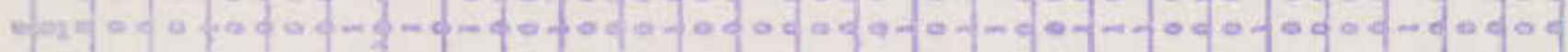
farked a

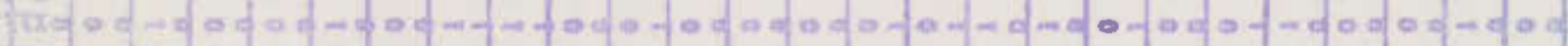

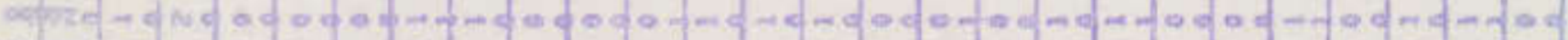

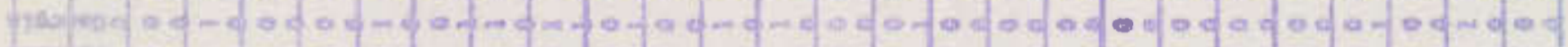

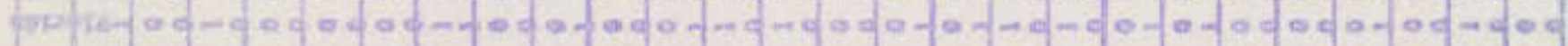

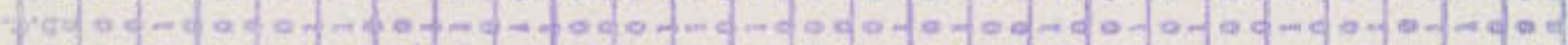

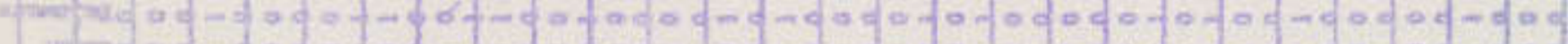

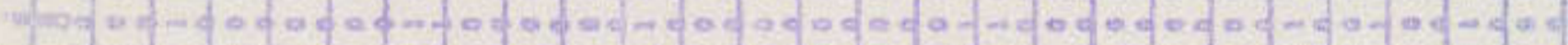

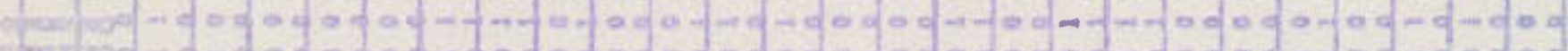

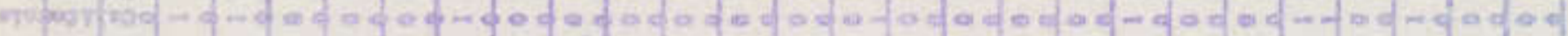

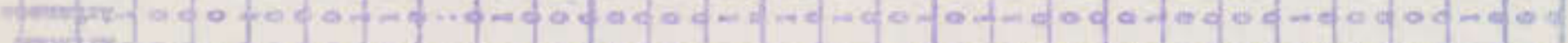

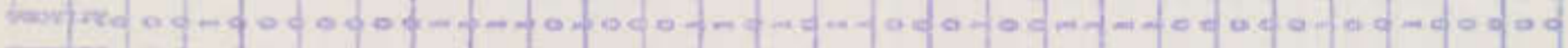

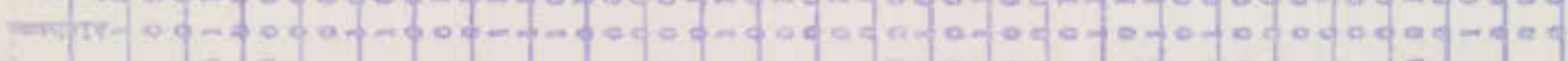

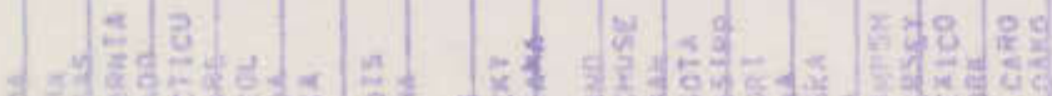

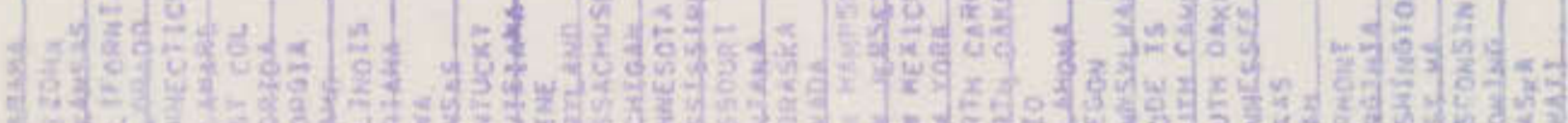

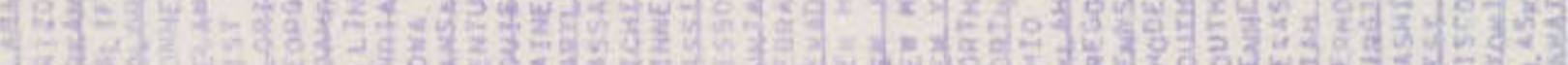

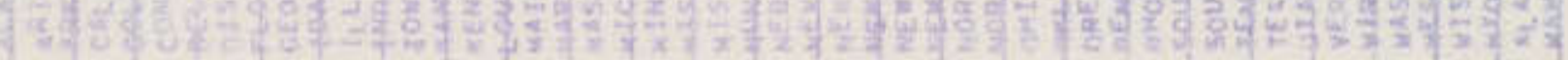

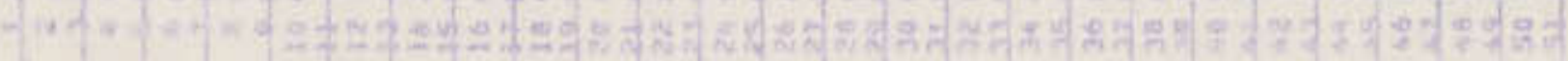


significant, although it is of interest to note that the magnitude estimated in any particular region appears to be modest. Explorations of data of this type within a framework which ranks the states according to linkage criteria remains to be undertaken. 33

Table 8 presents a variety of information related to the interregional inverse matrix shown in Table 5. Column 1 indicates the magnitude of intraregional direct and indirect requirements, computed as the Leontief inverse of the intraregional coefficient shown on the principal diagonal of Table 3 . The intraregional multipliers in Table 5 are shown in column 2, while column 3 is the difference between the two multipliers, or the measure of feedback onto each region given its connectivity to the interstate economic system. In every case the feedback measure is small compared to the entries in columns 1 and 2 (ignoring the unitary entry which is associated directly with final demand). This finding corroborates the work of Miller and Miller and Blair; while most states are relatively strongly tied externally in the aggregate, their ties to any other specific state are generally relatively small, leading to modest indirect opportunities for feedback. For example, the direct backward linkage between Iowa and Indiana is .01297 , and the Indiana requirement from Iowa is .009 , so the first-round feedback to Iowa is only $.01297 \times .009$ or .00012 . The estimated Iowa intraregional direct requirement is .17066 , and direct and indirect requirement intraregionally is .20578 (plus 1. to final demand). Taking into account national feedback to the Iowa economy, this multiplier only increases to .21637 , or .01059 .

While intraregional feedback effects are shown to be modest in this model, non-local multiplier relations are much stronger. For example, Table 3 shows that the intraregional direct requirements in Iowa were estimated to be .17 while Table 1 provided an estimate of total Iowa backward direct linkages per dollar of output of .529 . Table 8 suggests that in the aggregate this multiplier impact at the national scale rises to 1.034 (e.g., 2.034 - 1. to final demand). Hence, direct non-Iowa backward linkages are estimated to be 


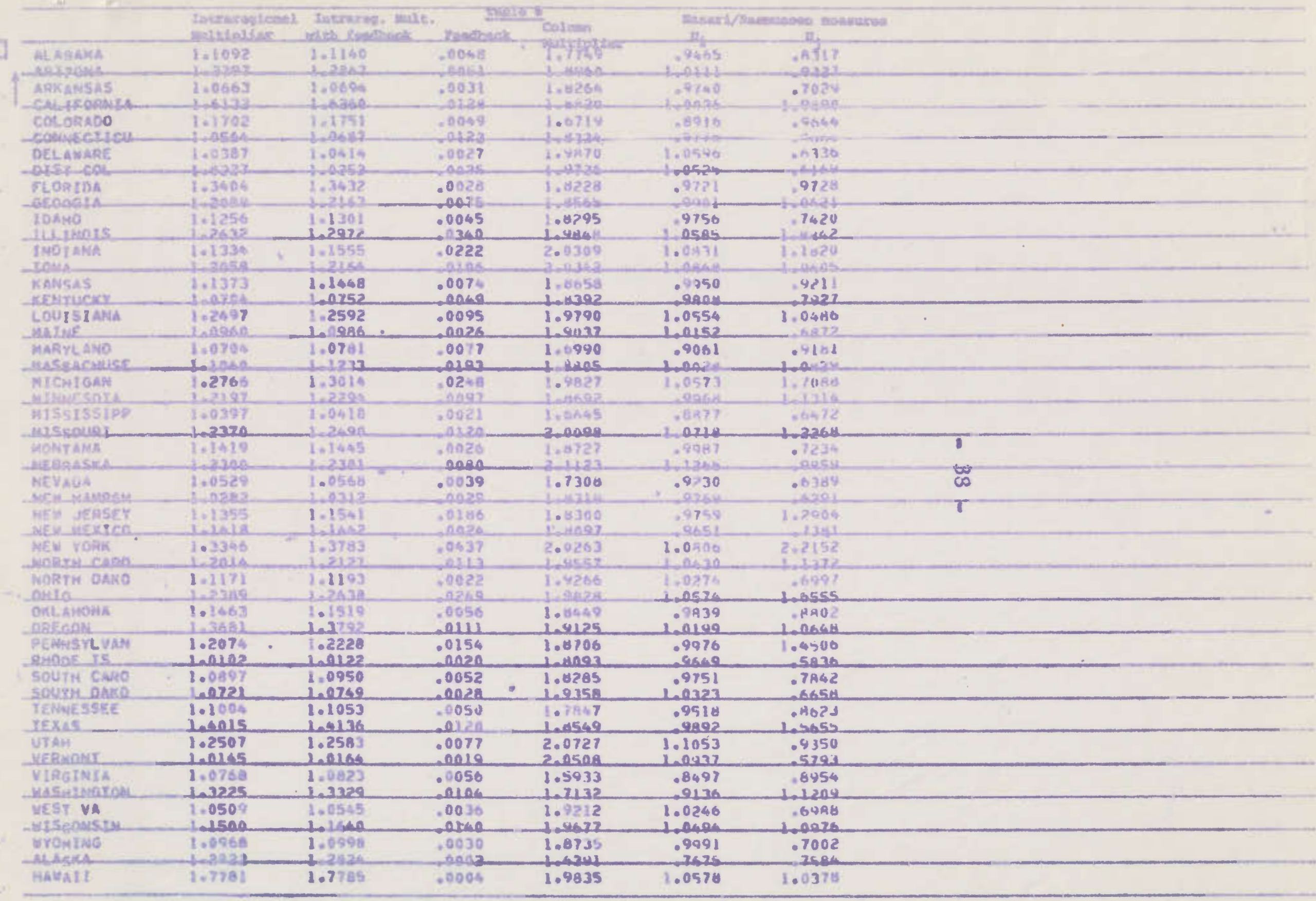


$.359(.529-.17)$, or more than twice the magnitude of intraregional direct requirements, and indirect non-Iowa backward linkages are estimated to be .459 , or significantly more than direct non-Iowa backward linkages. These results for Iowa are illustrative of multiplier relationships in this model for most states in the national economic system. This model suggests that while feedback relations are not generally significant at the scale of an individual region which is small in comparison to the national economic system to which it is linked, that the aggregate system does exhibit interdyper relationships. In the Iowa case presented here, while intraregional indirect feedback effects were only about $5 \%$ of direct effects, interregional indirect effects were more than 125 of the interregional direct effects, a striking scalar difference.

Table 8 also portrays column or output multipliers across all regions in the national economic system, and the magnitudes of these multipliers are displayed on Figure 4. The pattern of multipliers is contoured selectively in Figure 4, and it is interesting to note that relatively high contiguous values are found in the traditionally regarded "industrial belt", while more peripheral regions exhibit generally lower values. Point values for these multipliers should probably be disregarded, and their general structural properties taken as indicative. The fact that industrial output multipliers are found to be high in the industrial belt region means within the framework of this model that their direct and indirect requirement/are relatively high (and Table 8 does suggest somewhat higher feedback values for these states), but also that the proportion of their industrial requirements originating as semi-finished goods are relatively high in comparison to other states, which in turn have a higher degree of output accounted for by primary factor payments. Thus, a state such as Waşhington is relatively dependent on forest products and agricultural processing, sectors with relatively high primary sector dependence and relatively modest interindustry requirements. 
Flgare 4 Ontput thuleipliexa

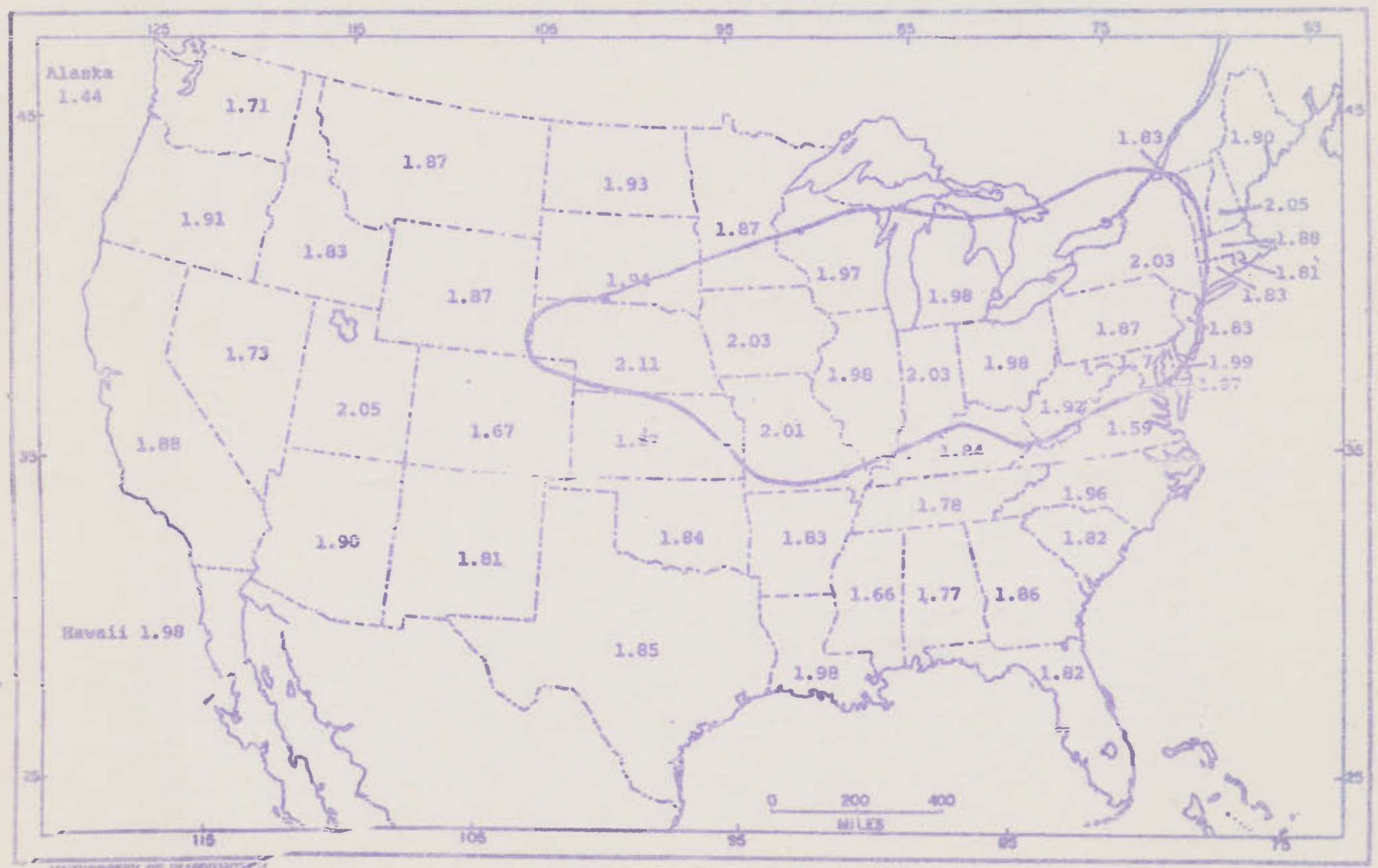

\&

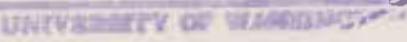


Patterns of output by state per dollar of final demand are described in Table 5. Figure 5 shows as an illustration the pattern of interregional interdependence associated with Texas final demand. Nearby states have relatively high multipliers, a result of the gravity model used to estimate this model; yet the corridor of interaction to the nearby midwestern and lake states industrial regions seems intuitive. It would be interesting to see if data on interaction from sources such as business airline travel, telephone connections or other information flows provided corresponding evidence for the pattern implied here.

Another view of the linkage structures emerging from this modelling attempt is provided by a mapping of the Rasmussen measures of linkage strength. ${ }^{35}$ These measures are shown in Table 8 and on Figure 6, using Rasmussen's two-way classification scheme as a basis for division of the mapping. In general, this mapping suggests propulsive state economics in the "industrial belt", and on the Pacific Coast littoral, while some of the more agrarian states are shown to have weaker interindustry linkages with the national industrial system. However, demand regions which have a strong final / orientation (e.g., Texas, Pennsylvania, Minnesota, Washington), highlight the need to view measures of propulsiveness in a framework which goes beyond the traditional focus on interindustry relationships.

It is difficult to assess the accuracy of this initial model, as there are really no benchmark data against which these results can be compared. No doubt the actual patterns of interdependence between the states will be a function of their industrial specialties, and knowledge of these channelling or structuring influences can only be obtained from survey work. Transportation census data for certain types of commodities could help refine the spatial structure presented here, as this model is based on a simple constrained gravity model equation applied across all states in the nation for estimation of final demands and interindustry sales relationships. 


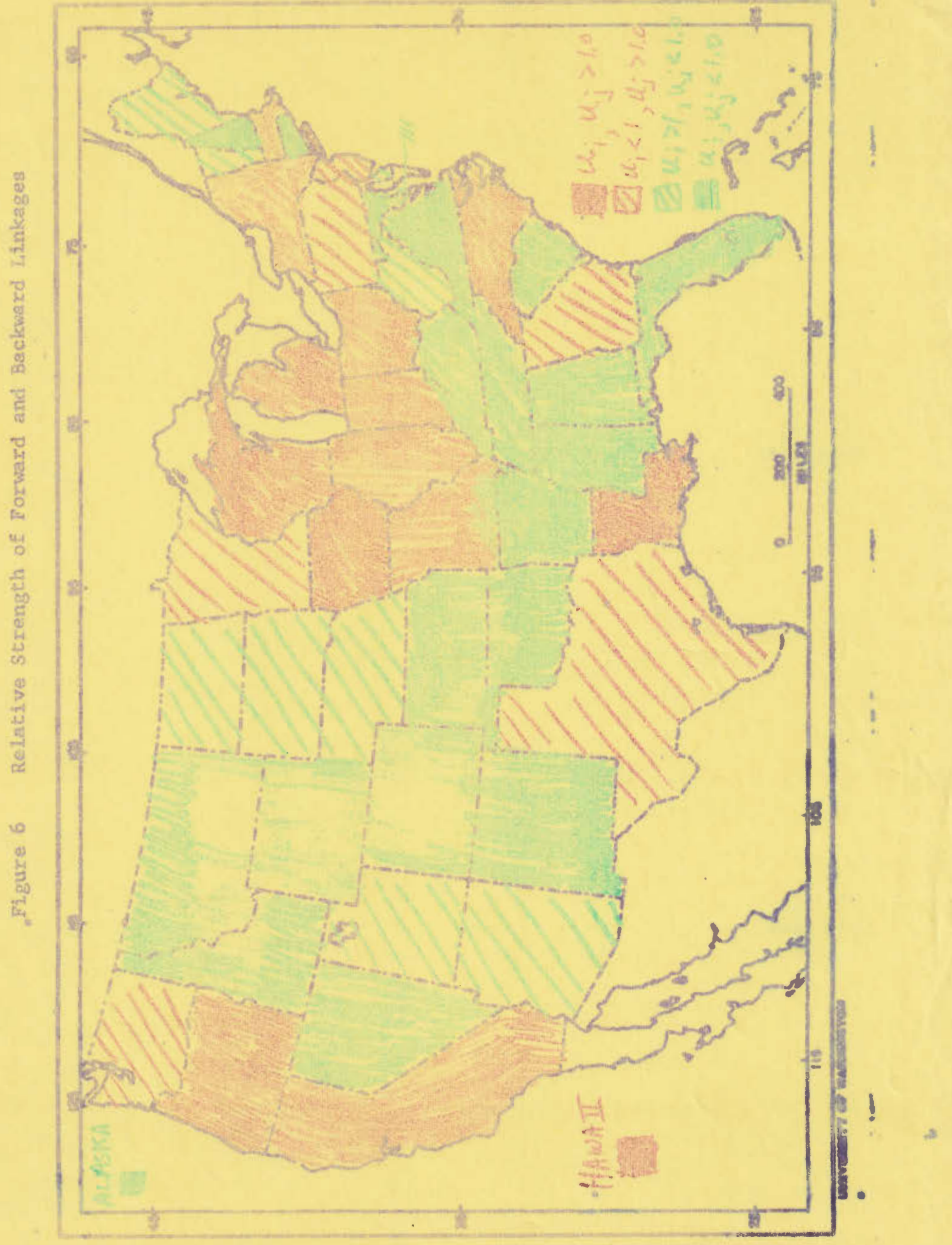


The numerical example in this paper has been elaborated for one time period. However, as pointed out in section II, this system should also be viewed intertemporally; in which case the evolution of the system would become evident by comparison of estimates of the structure of the accounts over time. Some bases for redistribution were already discussed in section $I$, but at present we lack data on historical qualities of change in the spatial macrostructure. Ideally, survey data of the type utilized to estimate the model which has been presented in this paper should be gathered at different points in time, allowing us to visualize changes in macrospatial interaction patterns over time.

In the survey work which we undertook to describe spatial linkages of Washington establishments, respondents were asked to describe how their geographical patterns of purchases and sales had changed over the past five years, and to estimate the direction of change in their marketing and purchasing patterns five years from now. Figure 7 shows a map of the anticipated pattern of future sales. Comparison of this distribution with Figure 2 shows a much more dispersed pattern of expected interaction in Figure 7 than portrayed in Figure 2. If this expected trend actually prevails, then the distribution of sales percentages shown in Figure 2 would indicate a less strong attenuating effect of distance. This would tend to imply that the economic system may be becoming more open over time, with a greater degree of interregional interdependence. Given the direction of change expected by the producers covered in our survey, some experiments were conducted evaluating possible scenarios of general regional structural change with the model which has been outlined above. As a backdrop for these experiments, it is instructive to note the magnitude of the redistribution of economic activity/has taken place among the states in the U.S. economy in recent years. A simple illustration of this degree of change is given in Figure 8 , which shows the percentage of U.S. personal 
income accruing to each state in 1960 and 1980. States with percentages on the diagonal in both time periods accounted for the same share of personal income in both time periods, while those to the right of the principal diagonal accounted for a greater share of national personal income in 1980 than in 1960, and those to the left of the principal diagonal were less significant contributors to national personal income in 1980 than they were in 1960 . In general, it is clear that there are few cases where changes in shares were extremely dramatic, even over the relatively long time period of two decades. These relatively modest changes in relative contributions to national personal income should be reflected in simulations of possible regional structural change.

Consideration was given to a number of ways of simulating changes in the accounting relationships shown in equations (11), (14), and (4), and related identities. Autonomous changes in final demand, structural changes in the $S$ and $w$ matrices, and a matrix (F) relating income received in a region with its regional disposition, as well as regionally variable growth rates in income were considered as bases for restructuring of this multiregional system. These experiments were in part tied to the results of the survey work described above, which indicated that a relative expansion of distant markets was a common situation for most firms which were interviewed. This finding suggests that intraregional interdependencies in an interindustry and final demand accounting framework should be expected proportionately

to be declining/over time. The general growth of non-wage payments relative to wage payments as a component of value added leads to a similar expectation for the spatial distribution of these payments, in part because the non-wage components of the income stream can be anticipated to be much more spatially fluid than wage and salary payments.

Taking the initial values of the matrix shown in Table 3 , and values of the $\bigwedge$ parameters $W$ and $F$ matrices implicit in appendix tables of the $Y$ and $V$ matrices as structural/ 
and the accounting relationships shown in equations (4), (11), and (14) specified as a temporally-continuous system, experiments were undertaken evaluating the effects of autonomous changes in final demand and changes in the $S, W$, and $F$ matrices over time. The relationship between income earned (V) in a given time period and final demand in the next time period was expressed as a simple first-order difference equation:

$$
Y_{t+1}=F V_{t}
$$

In the absence of changes in the parametric matrices $S, W$, and $F, a$ change in the aggregate values of $\mathrm{Y}$ for any given time period will lead to given and lasting changes in the overall level of output $\mathrm{z}$, and a change in $\mathrm{V}$ equal to the change in $Y$. This change may initially impact certain regions, regions possibly the recipients of initial autonomous impacts due to exogenous changes in demand for their products. However, the share of output among regions after several time periods will not be altered within the equation system in use here, without more pervasive structural adjustments. If final demand is increased continuously over time, but in a regionally selective manner, the system of regional output will also tend to display proportional expansionary properties, in the absence of parametric changes in the $S, W$, and $F$ matrices which govern the allocations of output, income and demand among regions. This conservative property for such circular systems in well documented in the literature on the allometric characteristics of the growth of urban systems; it remains to be seen if this analogy can be demonstrated more directly. ${ }^{36}$

In reality, we know that producers are continuously adjusting their sources of inputs and redistributing their productive capacity, consumers are continuously changing their consumption functions with varying spatial ramifications, and that similar adjustments are taking place in the stream of requirements of investors and governments. Similarly, we know that payments of income are 
shifting in their geographical disposition. Figure 8 indicated the net direction of these adjustments in the United States in the last two decades. To illustrate these redistributive processes, structural adjustments were made to the basic model reported earlier in this paper. Results of one experiment embodying changes of this type will now be reported.

Let us assume that interindustry requirements, final demands, and valueadded payments are simultaneously becoming more "externalized" from the perspective of any given region over time. This means that intraregional propensities to purchase intermediate goods, final goods, and to make income payments are decreasing systematically, while compensatory increases are occurring in extraregional requirements or payments. The effect of such a process at work among all regions would be to spread requirements, to decrease intraregional interdependencies, and particularly to decrease intraregional multipliers in the $(I-S)^{-1}$ matrix. These decreases will be reflected complexly in increased requirements from nearby states, if the gravity-distribution embodied in these structural systems for intermediate and final demands are preserved. In general, the regions with the highest degrees of intraregional interdependence shown in Table 5 can be anticipated to lose some of this multiplier power to other regions as this process of structural adjustment occurs, and indirectly these changes should be reflected in a gradual evening of the proportion of output, income, and demand originating in each region. In effect, this process leads to a gradually more integrated national economic system, from a multiregional perspective.

Table 9 illustrates the results of a simulation of this type, showing the percentage of GNP accruing to various regions over time, when intraregional requirements in the $S, W$, and $F$ matrices decrease 18 per annum over twenty time periods from their initial values as shown or implied in Table 3 and the 
$-50-$

PERCENTAGE OF INCOME(V) ACCRUING TO EACH STATE OVER TIME

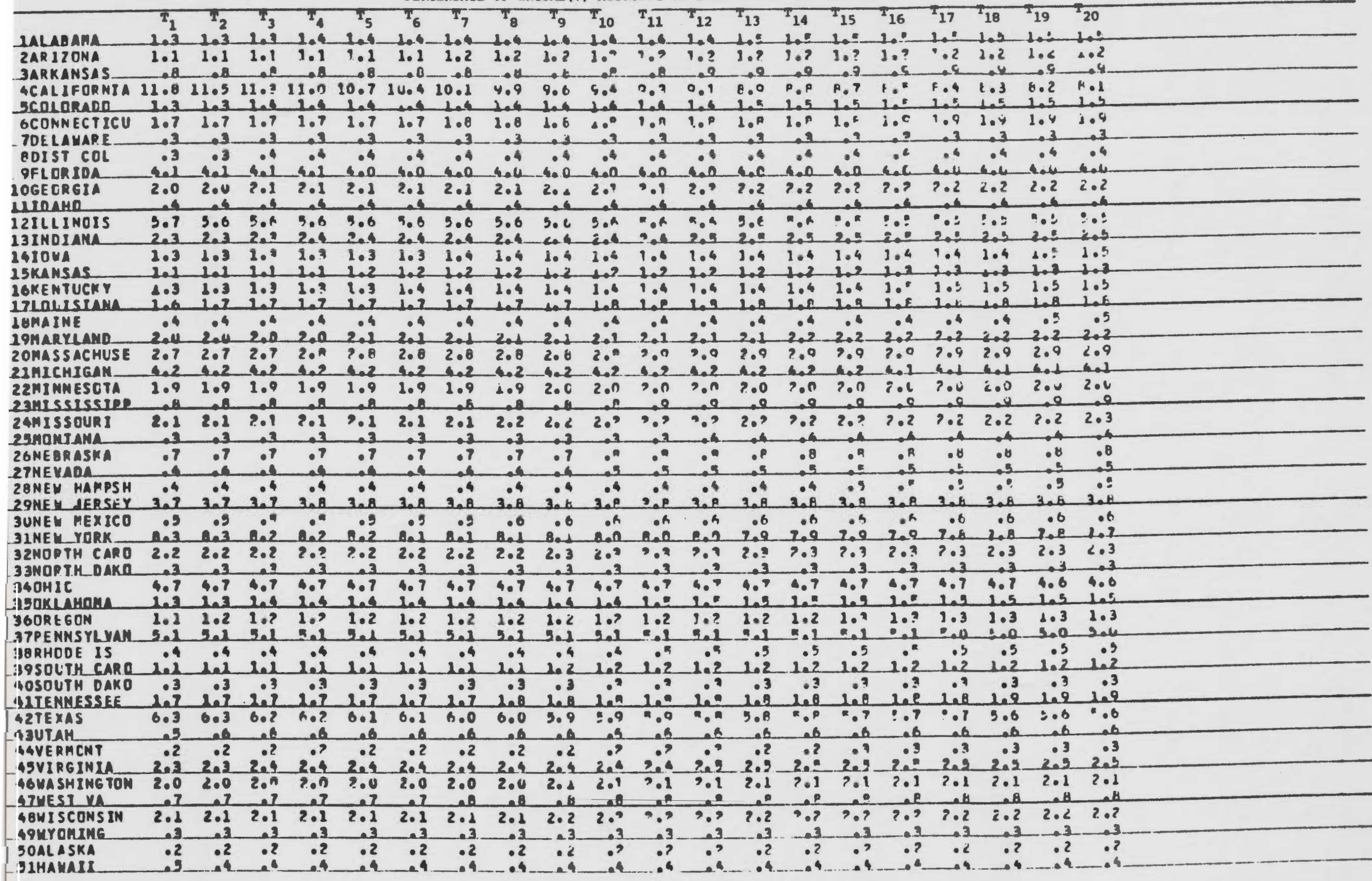

Woter Ech collus ane to 1000. 
appendix tables. In this particular simulation, the magnitudes of the decreases in the intraregional values were then spread proportionally over the appropriate vectors interregionally, given the initial distributions. It is recognized that this is a rather "pure" gravity-model approach to the redistribution question, and that the reality of industrial redistribution in our society has much more subtle spatial qualities, with forces favoring particular regions or clusters of regions over long periods of time, and simultaneously leading to relative decline in other regions.

The result of this simulation in terms of change in relative economic significance can be seen in Figures 9 and 10. Figure 9 shows ratios of the percentage of national income accruing to each state in time period twenty in Table 8 , relative to their initial values. The map is not a very good simulation of the trends shown in Figure 8 , driven as it is by the fact that relatively large regional economies tended to have relatively large intraregional coefficients in the S-matrix to begin with, which in turn lead to more of their intraregional output in absolute sense being spatially redistributed than was the case for smaller economic regions in this particular simulation. Yet the general decentralization of economic power is not unlike that actually occurring in the United States, even if the spatial pattern is unrealistic. A more realistic simulation probably would have induced a movement of mass in the redistribution process to those regions favored in Figure 8, meaning that they were recipients of relatively increased demands within the $S$, and $F$ matrices, and/or recipients of growth in the share of payments of income ( $W$ matrix). Alternatively, the simulation could mirror forecasts of interregional growth, such as those prepared by BEA. 37

Another view of the overall qualities of this modelling effort is portrayed in Figure 10, which shows in a fashion analogous to Figure 8 the percentage 
FI GURE 10

SIMULATED CHANGE IN U.S. PERSONAL INCOME

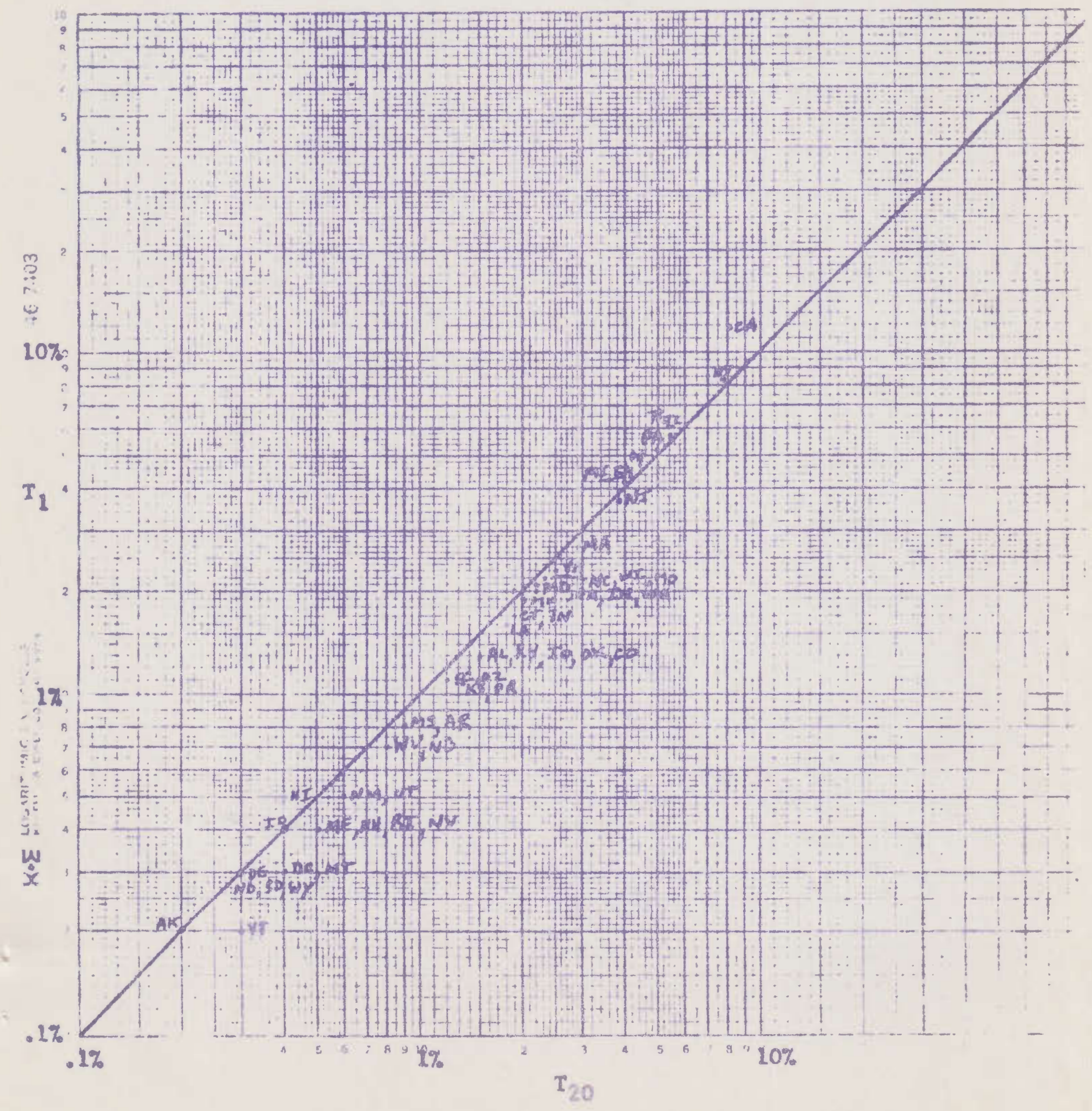


period 20. The overall redistribution process was not very dramatic istructurally if not spatially similar to that displayed in Figure 8.

This particular experiment in the change in the structure of this multiregional system could obviously be permuted in many different ways. It is offered as an illustration of the probable qualities of change which would be observed if we were fortunate enough to have observations of accounts of this type over time in disaggregate spatial models of economic systems.

v

\section{Concluding Comments}

A model of interaction among the states of the United States has been presented in this paper which was intended to be illustrative of the possible structure of interstate economic interdependence. The modelling framework used in this illustration is only one possible type of description of interregional interaction at the macro-scale, and it is clear that much larger multisectoral models could easily be conceptualized and much more elegant mathematical formulations for the structure of such models could be articulated. It remains to be seen if the general pattern of interaction found among Washington State producers is characteristic moneral of the macrospatial structure of purchases and sales of establishments located in other parts of the national economy. Washington's economy is relatively diverse in comparison to some smaller economies, such as Alaska or North Dakota, and these less diverse economies may have much more channelized interaction patterns. On the other hand, the Washington State economy is much less diverse than major industrial states such as Ohio or California, and these states' diverse economic base may be more integrated into the space economy than is the case for the smaller Washington economy. Transportation census data may help us to determine some characteristics of these interaction patterns, but they are of limited value since non-goods flows are not measured and it is difficult to relate 
measures of physical flow to product value. An ideal solution would be a series of surveys among the states to provide direct measures of interaction structures; such a survey effort would probably cost five to ten million dollars, but the resultant knowledge may be worth far more in a public policy context, when compared to the magnitude of differential regional effects of major changes in final demands.

The model outlined in this paper needs to be measured carefully in a national context, at several points in time. The stability of the flows needs to be carefully considered. Does the system have the relatively conservative allometric properties suggested by the intertemporal experiments described here because of the macrostructure identified in this paper, or is this quality the result of some other processes operating in the space-economy? Is the system of states a reasonable regionalization for studying interregional economic structure in advanced societies such as the United States, or is it either too detailed or too crude? Should accounts for such systems be developed annually or less frequently, and if less frequently at what time intervals? What dependencies with other driving forces in the spatial development of modern economic systems need to be captured more systematically in accounting models of this type? In this vein, should the ecodemographic modelling approaches be fully embraced, ${ }^{38}$ or even the more grandiose schemes pulling together much of Regional Science such as recently articulated by Walter Isard and colleagues? ${ }^{39}$

I do not have answers to these questions. Implicitly, this entire paper is a plea for investment in this topic, a call which is appropriate at a time like this when we take stock of the progress that has been made under the leadership of a scholar such as William Miernyk. Now as we look to the future, it seems to me that we must develop these more spatially and temporally powerful views of economic systems, and of the processes causing their restructuring in time. This paper has failed to account explicitly for the forces of change operating 
at the microscale which are manifested in the macroscale adjustments modelled here. Accomplishing that explanatory task is obviously a major agenda for research in this field if we are to develop a better understanding of the ongoing spatial path of development of economic systems and to understand the means by which we can influence this path of development.

These tasks are challenging from an empirical standpoint. Hopefully the type of exploration presented here will be developed further prior to embarking on a major measurement program to estimate more accurately macrospatial interaction models of the type suggested conceptually and empirically in this paper. In addition, considerable experimentation and debate needs to be undertaken on the functional form and level of spatial and sectoral detail which integrated economic and demographic models of this type should display, and on the frequency of their estimation over time. The considerable interest that such multiregional demoeconomic models have engendered in recent years suggests that we may in fact be on the verge of some major measurement efforts, which will not only help us to describe the spatial structure of our economic system and its evolution with more accuracy, but will ultimately allow regional scientists to evaluate meaningfully policy questions of the type discussed at the outset of this paper. 
POOTNOTES AND REFERENCES

1. W. Leontief, Academic Economics", Science, Vol. 217, No. 4555, July 9, 1982, pp. 104-107.

2. W. Miernyk, et al., Simulating Reglonal Economic Development, Lexington,

D. C. Heath co.., 1970, Virginia Press, 1967 .

- Inpact of the Space Program on a Local Economy. West

3. W. Isard, "Interreglonal and regional input-output analysis: A model of a space conomy", Review of Economics and Statistics, 33 (1951), Pp. 318-28;

w. Leontief, "Multiregional theory", in Leontlef, et al., Studies in the Structure of the American Econonry. Oxford, New York, 1953, pp. 93-115.

4. H. W. Richardson and P. Cordon, "A note on spatial multipliers", Economic Geography 54\& 309-13 (Oct. 1978).

5. P. J. Bourque and R. S. Conway, Jx., The 1972 Washington input-output study, Graduate School of Business Adrinistration, Univ. of Washington, June 1977,

W. A. Schaffer, et al., Introducing the Georgia Economic Model, Atlanta, Georgia Department of Industry and Trade, 1972,

Miernyk, 오. cit.;

Interindustry Study of the Hawailan Economy. Dept. of Planning and Economic Development, state of Hawali, 1972.

6. T. C. Koopmans (ed.). Activity Analysis of Production and Allocation, wiley, New York, 1951.

7. W. Isard, T. W. Lanford, Jr., and E. Romanoff, Philadelphia Region InputOutput Study (Working Papers, Regional science Research Institute, Philadelphia, 1966-68):

L. Moses, The stability of interregional trading patterns and input-output analysis", American Economic Review, 45 (1955) 803-32,

R. E. Millex, "Interreglonal ferdback effects in input-output models, some preliminary results", Papers, Regional sclence Association 17 (1966), 105-25:

G. J. Karaska, Manufacturing Inkages in the Philadelphia Economy: Som evidence of external agglomeration forces", Geographical Analys is 1 loct. 1969). pp. 254-69.

8. W. B. Beycrs, "On geographlcal properties of growth center ilnkage systems". Economic Geography 50 (July 1974), 203-218.

9. H. W. Richardson, Input-Output and Regional Economics, Willey, Hew York, 1972, Ch. 9. 
10. G. Micolis and 1. Prigogine, Self-organization in Noneyullibrium systems, From Dissipative Structures to Order Through Fluctuations, Wiley, New York, 1977,

P. M. Allen, "The evolutionary paradigm of dissipative structures", in E. Jantsch (ed.). The Evolutionary Vision, Toward a Unifying Paradigm of Physical, Blological, and Sociocultural Evolution, Westview, Boulder, 1981. pp. 25-74,

W. Isard and P. Llossatos, Spatial Dynadice and Optimal Space-Tíne Development, North-Holland, New York, 1979,

w. Miernyk, The Illusions of Conventional Economics, West Virginia Univexsity Press, Morgantown, 1982.

11. W. Beyers, "A fleld approach to spatial industrial dynamics", presented at the IGU Commission on Industrial Systens meetings, Chuo University, Japan, August 1980.

12. Hazar1, B., "Empirlcal identification of key sectors in the Indian economy", Review of Economics ard Statistics, 52: 301-05; -

Yotopoulos, P. A., and J. R. Nugent, "n balanced-growth varsion of the linkage hypothesis: a test", Quarterly Journal of Economi:s 87 (1973). pp. 157-77; and comments on this paper plus the reply by the authors ir. the same journal, 1976, esp. pp. 334-343.

13. W. Miernyk, "EDA and the objectives of reglonal development policy", Explorations in Economic Research, Simtier 1977.

14. See for example, A. Hawley and S. M. Mrie, eds.. Nonmetro:olitan America in Transition, Univ. Of North Carolina, Chapel Hil, 1981;

R. L. Lonsdale and H. L. Sayler, eds." Nonmetropolitan Industrialization, Winston, New York, 1979.

15. U. S. Department of Comwerce, Bureau of Economic Analysis, 1980 OBERS BEA Regional Projections, 1981.

16. It is recognized that this approximate ocuivalence may holk for the nation as a whole, but individual region may have large di ferentials between their levels of exports and imports from foreign rejions.

17. In this paper notation of the forr $z_{1}$, and $z_{. j}$ means a surr across the matrix or vector replaced with the dot. Thus, $z_{i}$. would be the s:um across the colums of a matrix with typ cal elements $z_{i j} \ldots$

18. Little evidence is available on changes in the structure of multirgional economic systems. At the national scale the work of Carter is the nost well known, while an excellent exaple of findings ragarding structural change at the regional scale is found in the work of Conway. See $\mathbf{A}$. 0 . Carter, Structural Change in the America Economy, Cambridge: Harvari University Press, 1970; R. S. Conway, Jx., "The stability of regionihl input-output multipllets", Bnvirorment and Planning A, Vol. 9, No.: pp. 197-214 (1977). 
19. Demoeconomic models of this type are currently proliferating. In a multiregional context see W. Beyars, Margration and the development of multiregional conowic syatems", Economic Geography, 56: 320-334 (October 1980), Peter Gordon and Jacques Iedent, "Towards an interregional demoeconomic model", Journal of Regional Science, 21: 79-88 (February 1981).

20. See P. J. Bourque and R. S. Conway, Jr, ge. clt.; W. A. Schafffer, et al.. op. cit.

21. W. Beyers, "On geographical properties..." op. cit.:

A. Pred, The interurban transwission of growth in advanced economias: enpixical findings versus regional planning assumptions", Regional studies $10: 151-71$.

22. Our current research has been focussing on surveying business establishments In both the manufacturing and service setors to ascertain geographical characteristics of their arkets and isput supplies. The project is leading to classifications of individual astablishment linkage patterns, - as well as to the aggregate patterns show in Figires 2 and 3 . We are also focussing on characteristics of tructural clange at the regional scale, using the central puget sound region as ou: case-study region.

23. Currently, we are extending thit sample to include a set of servicessector establishments which are reasonably presuned to be engaged in interregional business activities.

24. For the sales data, population, and distances expressed in logarithmic form, the multiple $x$ equals .81, with san Fotatistic of 45.6 . Similarly for the purchases data, the altiplier was .7\%, with an F, statistic of 24.6 .

25. E. L. UIlman, American Commodity Elow, Univ, if Washington, Seatile, 1957,

H. Sakal, "The center-pexiphery Clchotomy $; \eta_{\text {s }}$ the Japanese economy: a study in distance and spatial interaction", unpublished Ph.D. dissertation, Columbla Univ., 1972.

26. Estimates of state output for $\mathbf{1 9 6 3}$ wers derived from data found in $\mathbf{K}$. $\mathbf{R}$. Polenske, "A multiregional Input-output mod:I for the United status". Report No. 21, Harvard Economic Research Project, October 1970, p. 144.

27. Bureau of Economic Analysis, Survey of Curyent Business, 1963, 1910 , various monthly editions.

28. The constants .815 and .535 were the 1980 proportions of gross nat:onal product accounted for by persond income anl wages, salaries, and proprietors income, respectively.

29. Michael Bacharach, Biproportional Matrices an Input-Output Change University of Cambridge, Department of Applie! Economics, Monograph No. 16. Cambridge: Cambriage University Press, 190. 
30. Bourque and Conway, ge. cit.

31. 1980 estimates of personal incose wer triten from the Survey of Current Business. op. cit. Colum 2 is the ratlo of the state's location quotient for personal income in 1980 to the location quotient for 1933; this ratio entered equation 15 in the calculation of estimated 1980 output, which is shown in colum 3 . The personal incowe data were obtained from the Survey of Curxent Business.

32. See caxter, op. cit., for a discussion of this matter, pp. 33-34.

33. It would be interesting to evaluate this model through the use of methodology developed by Camploll in analyses of the intraregional structure of economic systera. Soe J. Campbe11, "Growth pole theory, digraph analysis, and interindustxy relationships". Tijdschrift voor Econ. en Soc. Geografie, 63: 79-87 (1972): -......., "Selected aspects of the interindustry structure of Washington State", Economic Geography 51: 35-46 (1974), ........., "Applications of graph theoretic analysis to interindustry relationships: The axample of Wawington State", Regional and Urban Economics, 5: 91-106 (1975).

34. R. E. Miller, "Intexregional reeâbacks in input-output models: Sowe preliminary results" Papers, Regional Science Association, 17: 105-25 (1966).

35. P. Rasmussen, Studies in Intersectoral Bajations, Amsterdam: North-Holland, 1956.

36. S. Mordback, "Uxban allometric grouth". Geografiska Annaler, 538, 53-67 (1971);

D. M. RaY, P. Y. Villeneuve, and R. A. Roberge, "Functional prerequisites, spatial diffusion, and allometxlc growth", Economic Geography 50: 341-51 (1974).

37. u. S. Department of Comerce, op. clt.

38. Beyers, "Migration and...", 으. 도.."

Goxdon and Ladent, op. cit. 


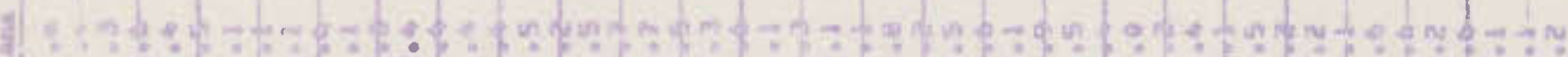

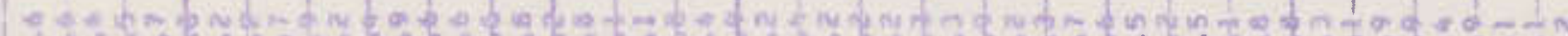

7. 5 .

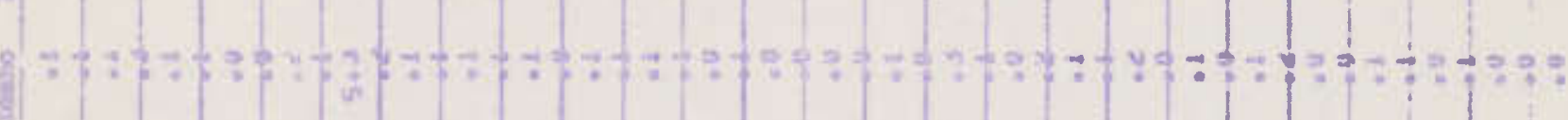

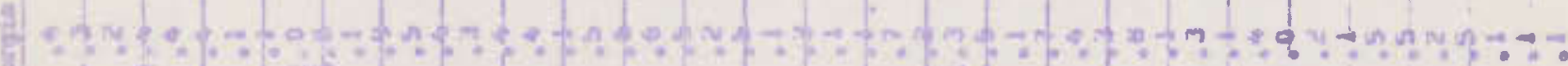

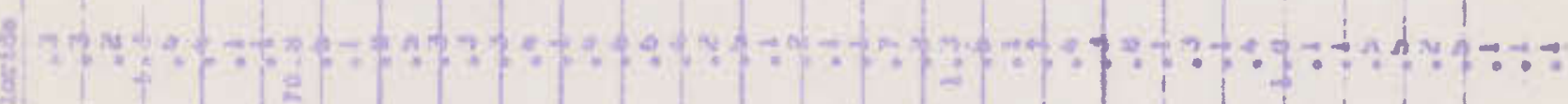
di

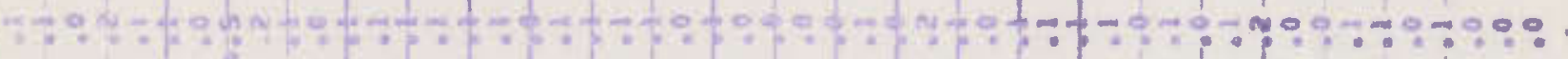




\section{(1)}

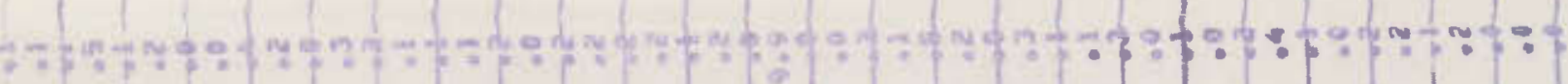
5

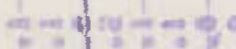

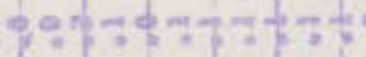

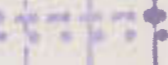

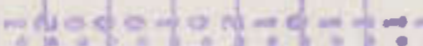

0 - $0-10:-1=00$

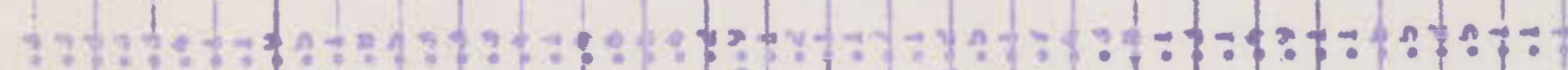
事

I.

(⿻) gั

$\frac{2}{2}$

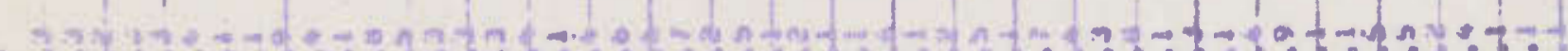

$\pm$

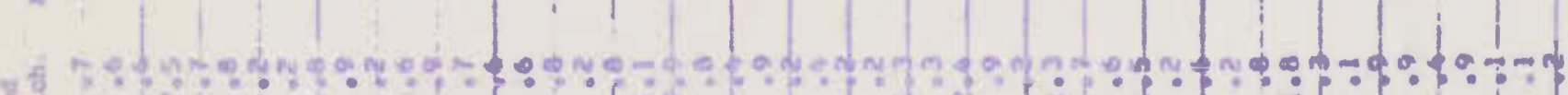
$\frac{3}{8}$

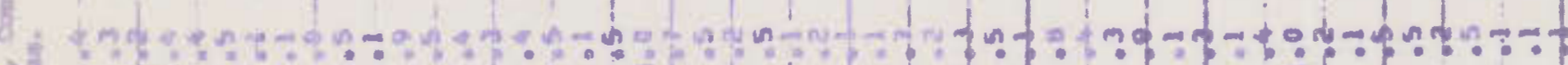
要

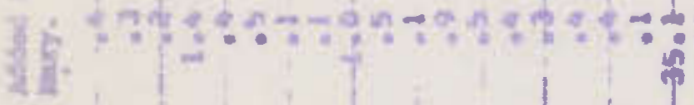
s.

इ. $1 \%$

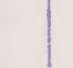

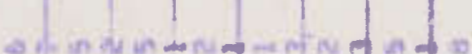

$\left.1\right|_{1} 1$

I

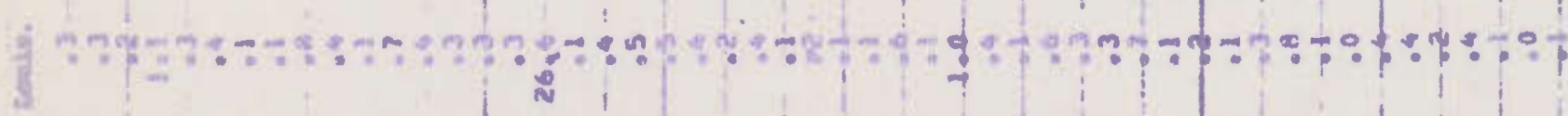

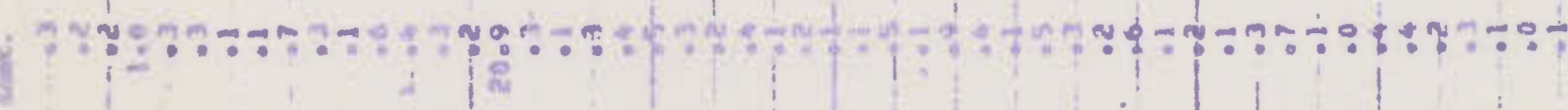

5.

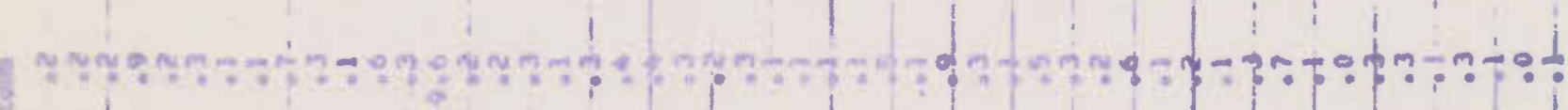
5 (

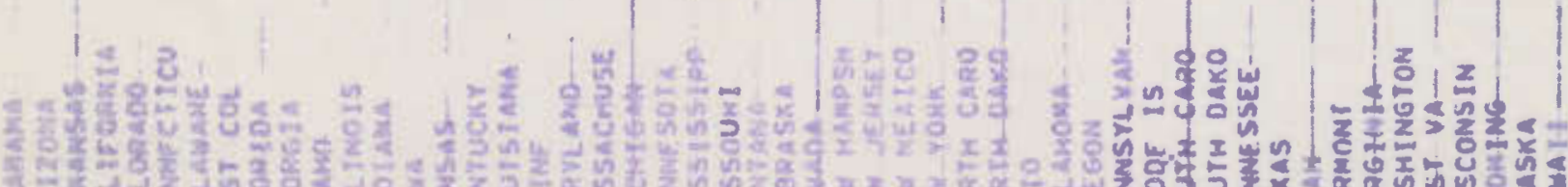
A2.

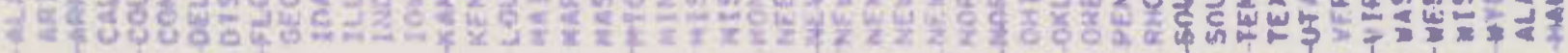
FN? 
14

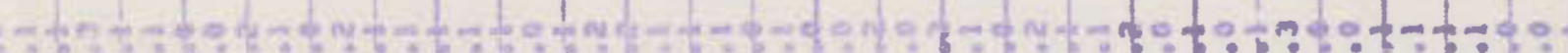

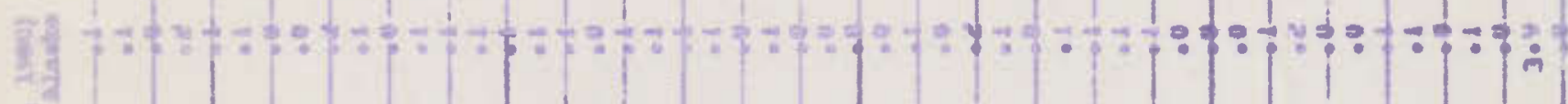

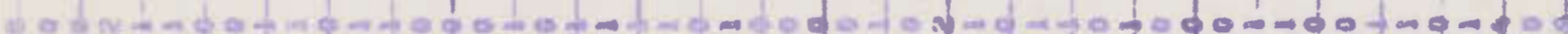

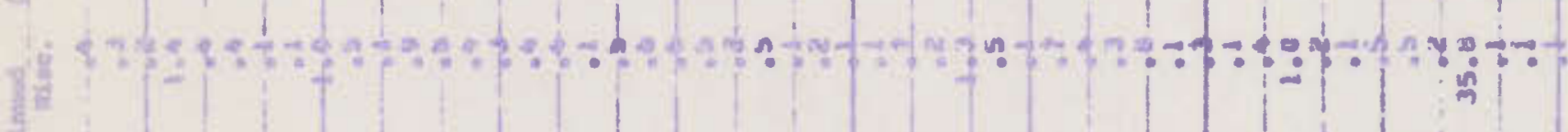

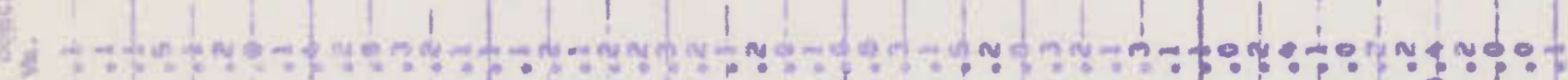
i.

I.

$\frac{1}{3}$

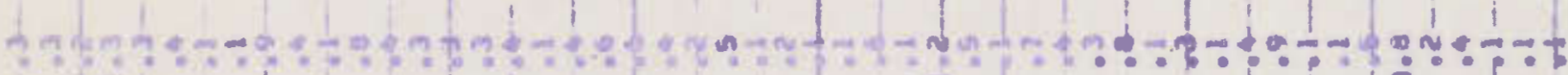

4

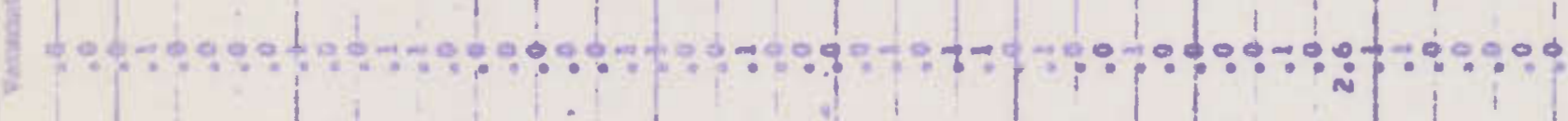

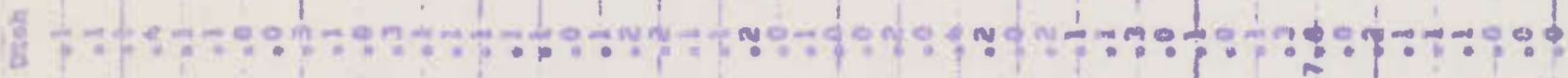

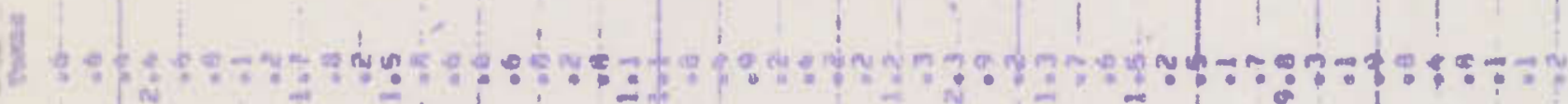
N

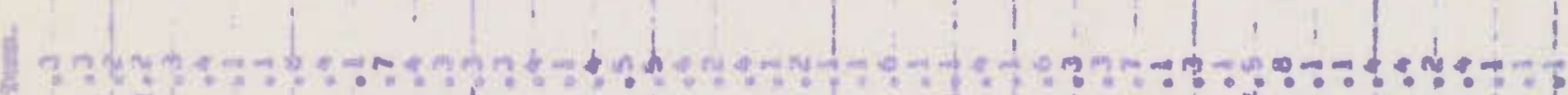

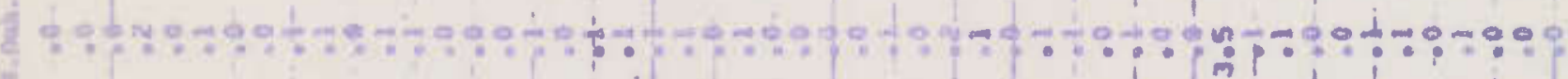

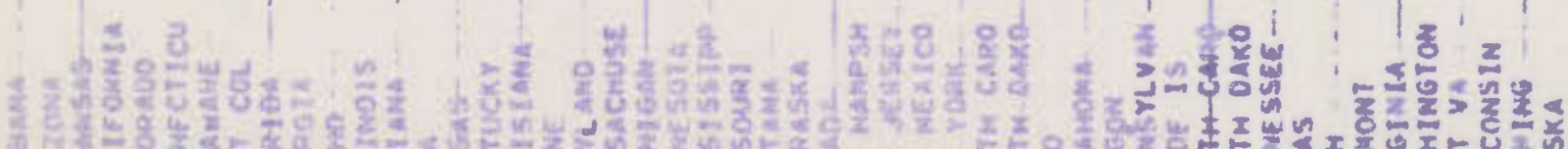

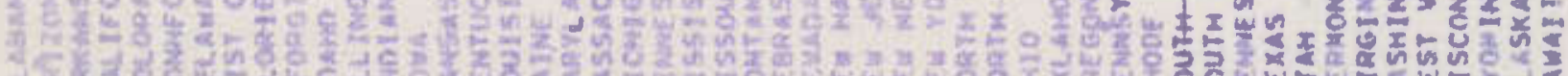

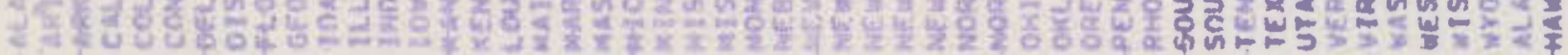
순 


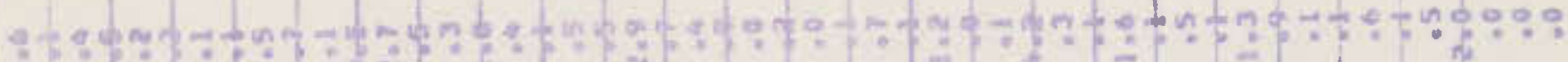

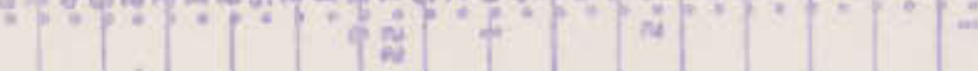

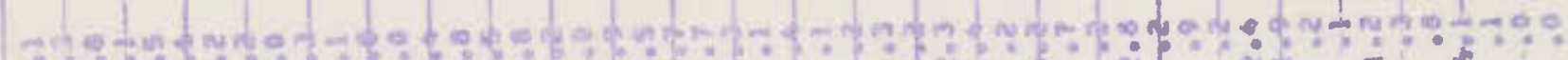

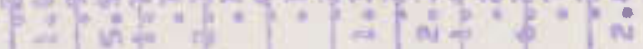

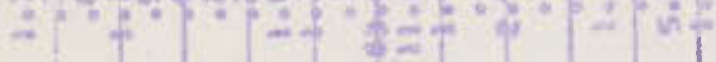

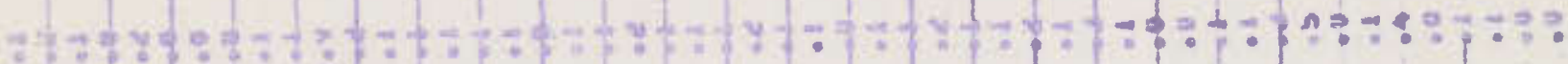
5.2

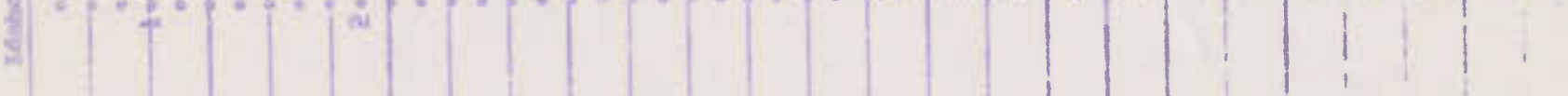

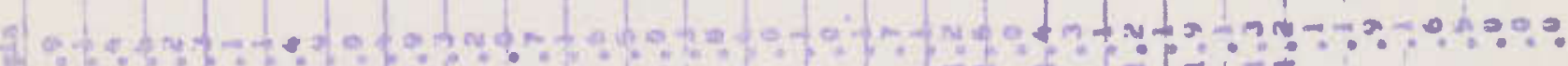
$=$ in

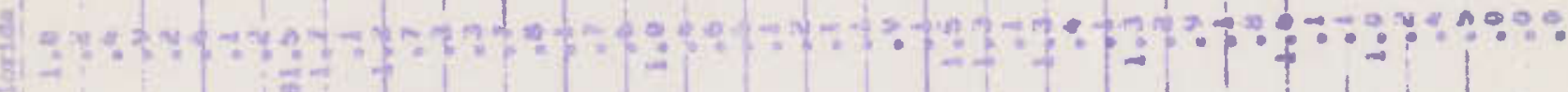

8

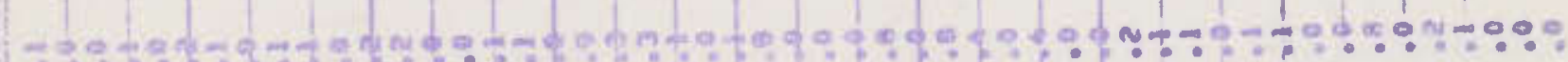
곤

$1-0$ -

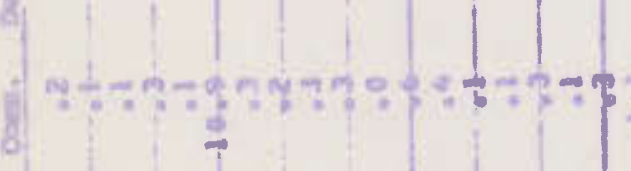

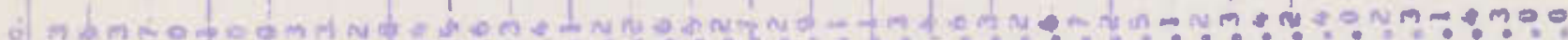
8

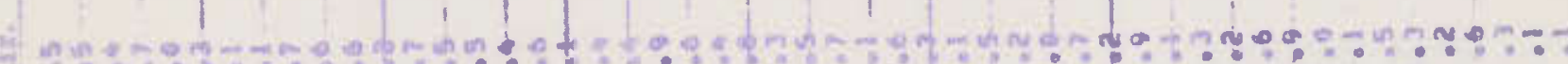

d

出

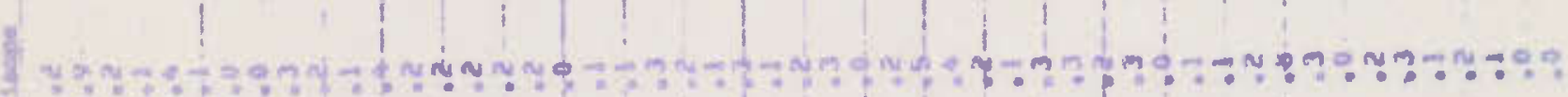
$z^{2}=t+i$

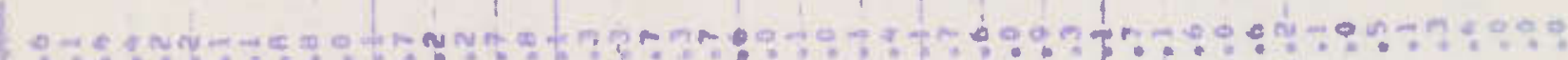
2.

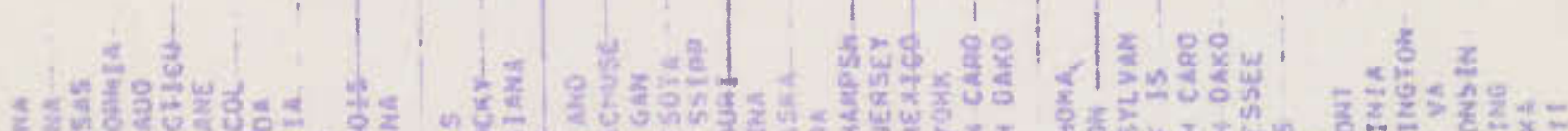
z

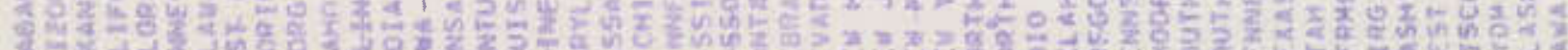

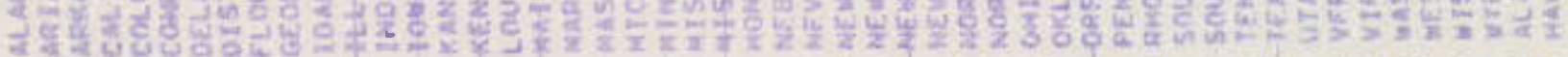

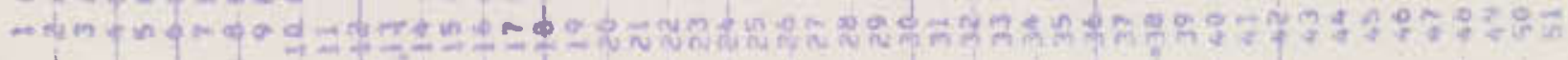


17. 4

the

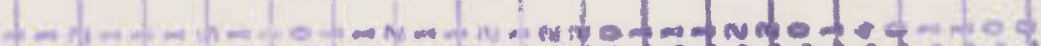

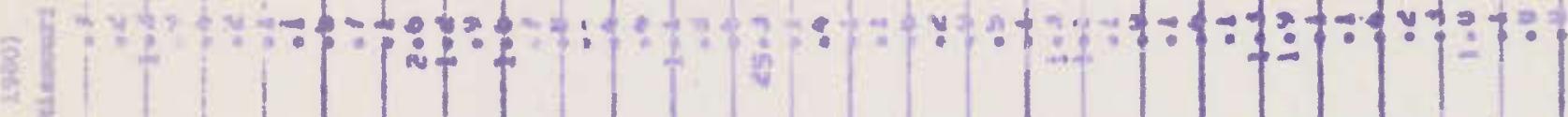

a'

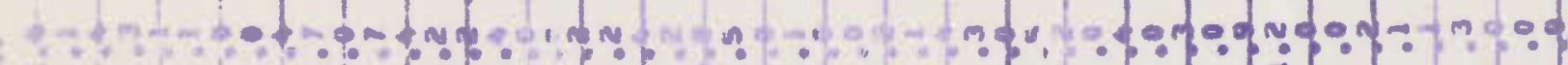

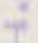

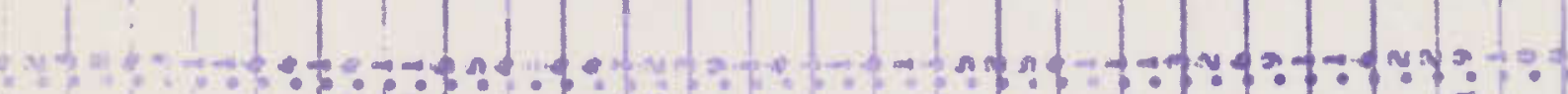

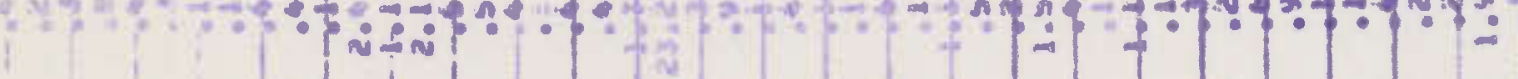

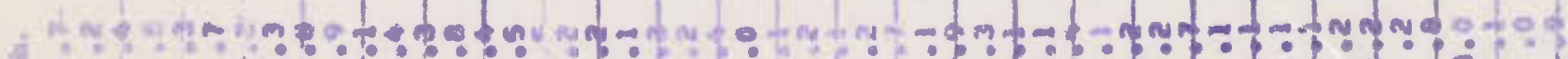

I 1 i

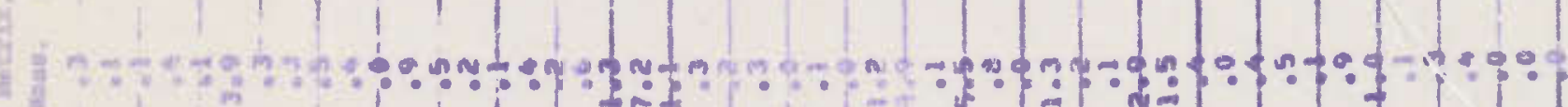

\section{E.}

8)

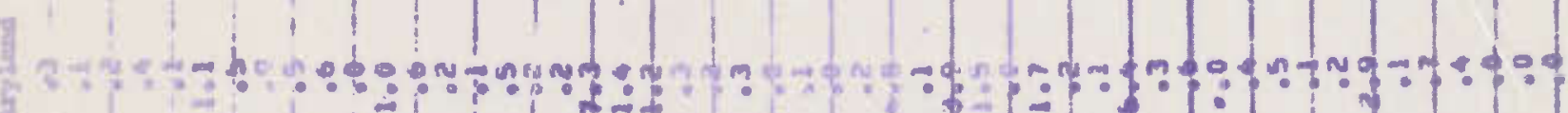

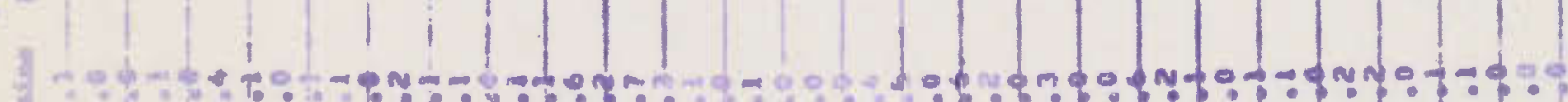

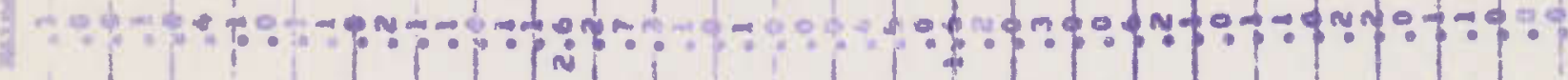

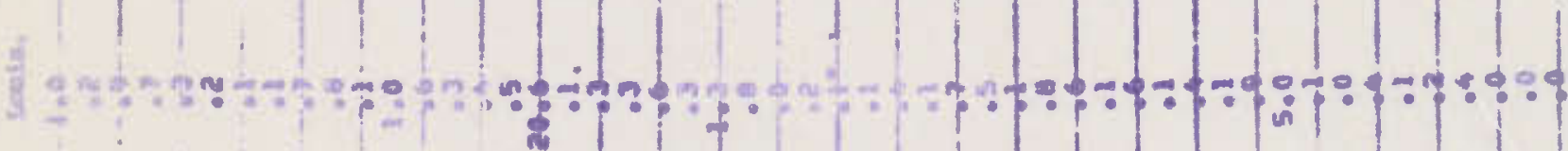

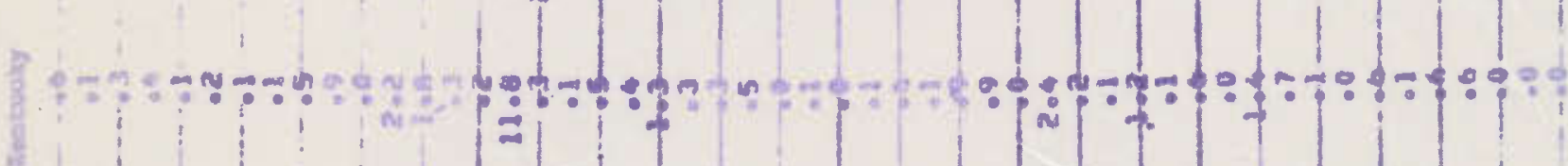

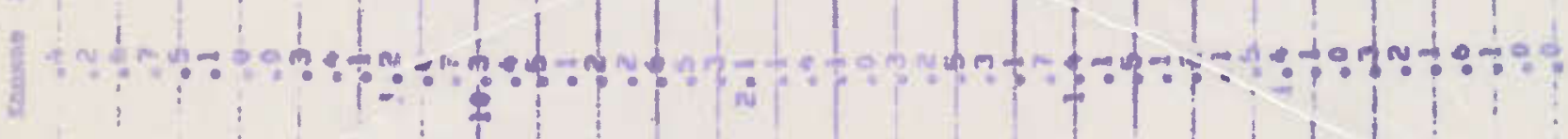

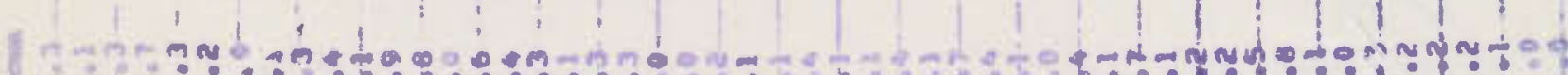
(1)

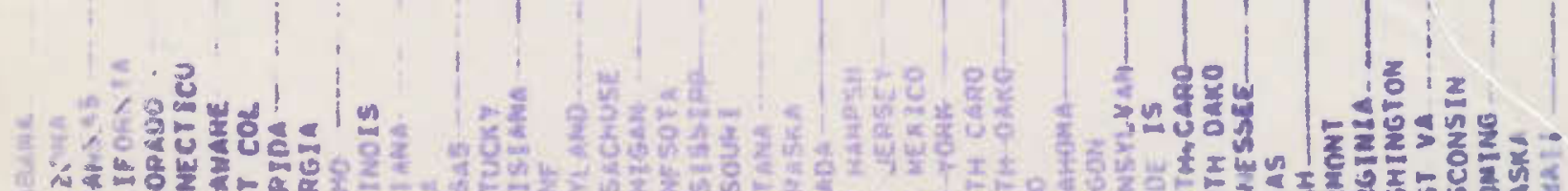
á

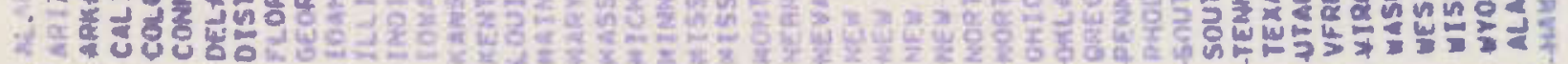

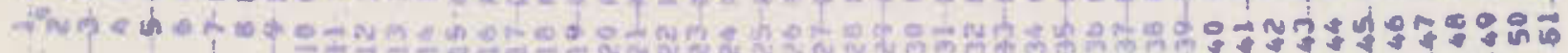




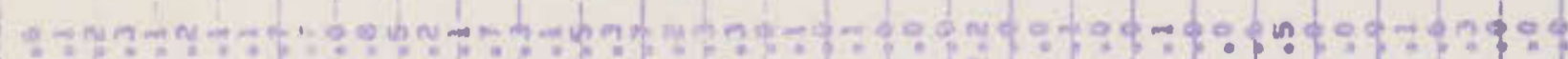
$5^{3}+4$

둘 at

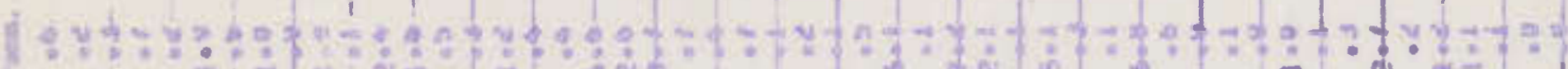
. 8

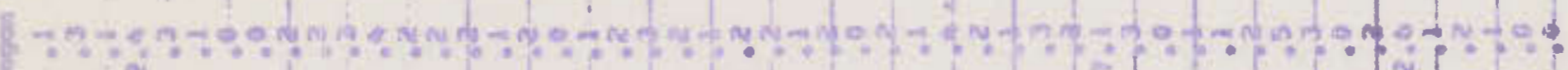
E

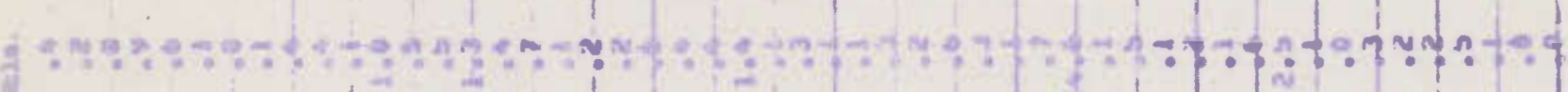

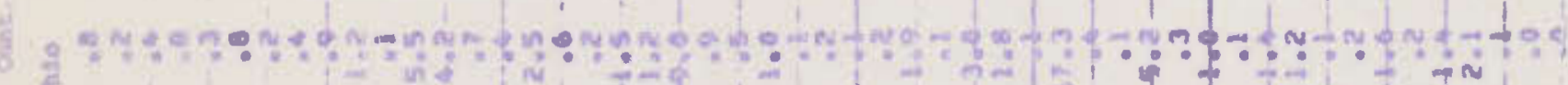
(1)

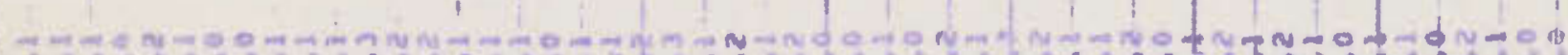
E $\frac{1}{8}$

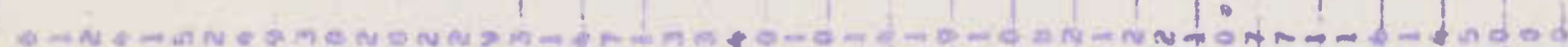

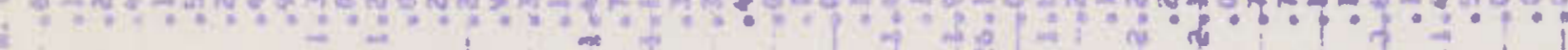
$\frac{16}{8}$

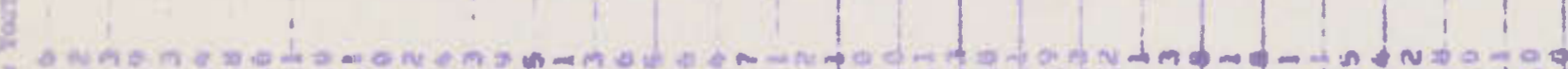
3.

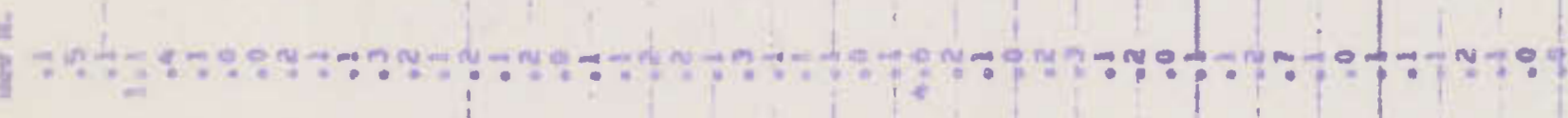

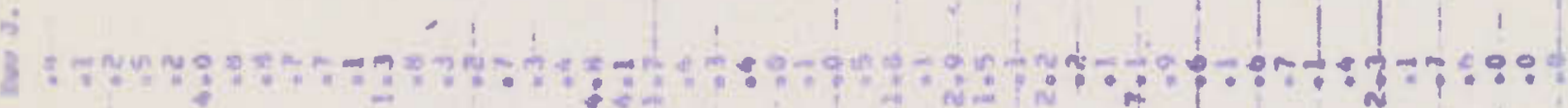

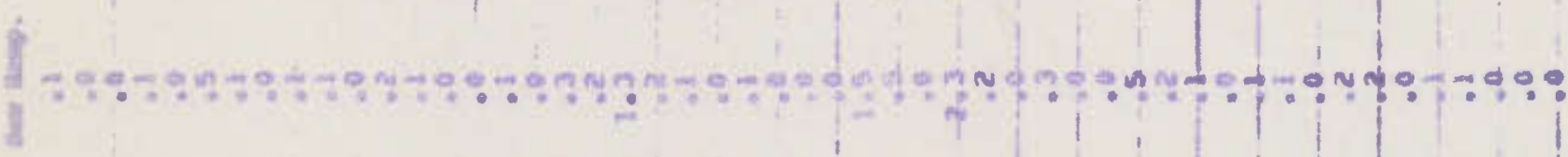

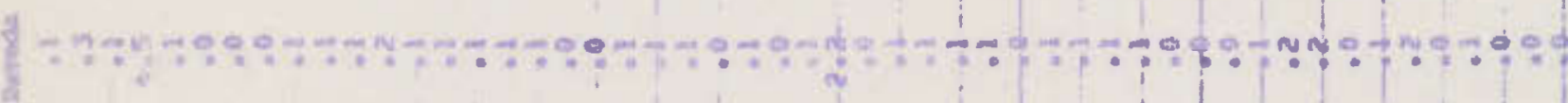

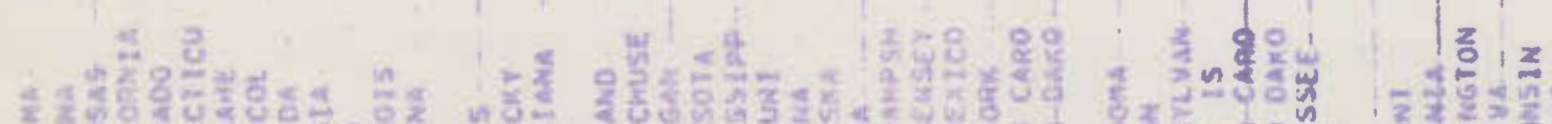

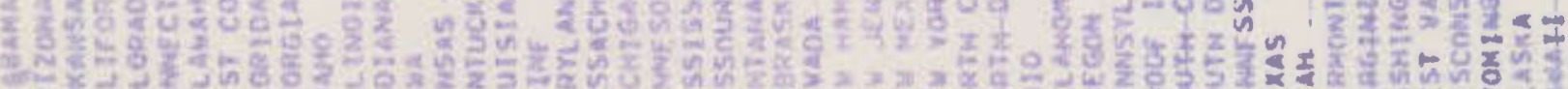

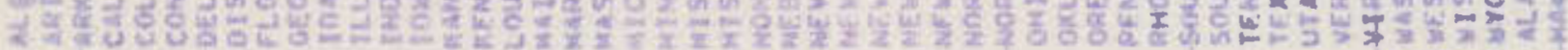

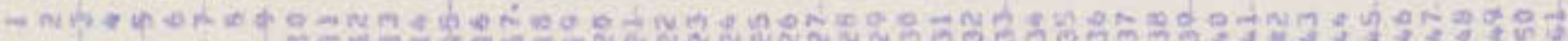


ist

1.

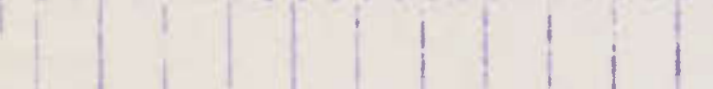

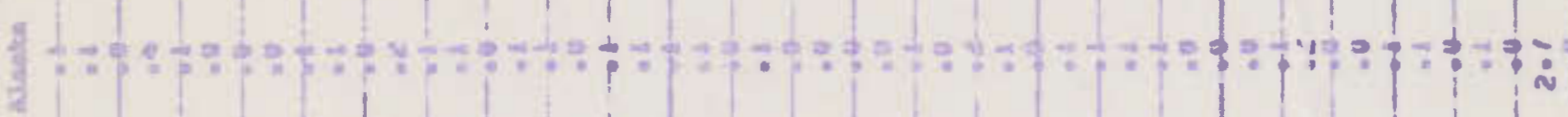

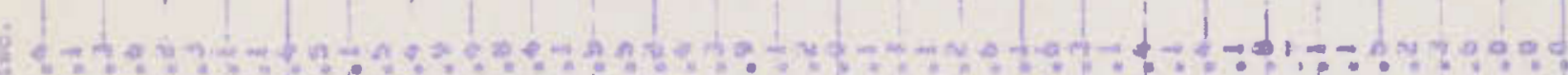
I moln-mmma ! m n

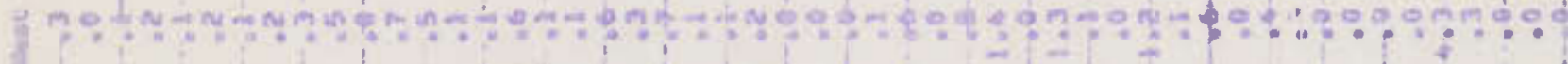

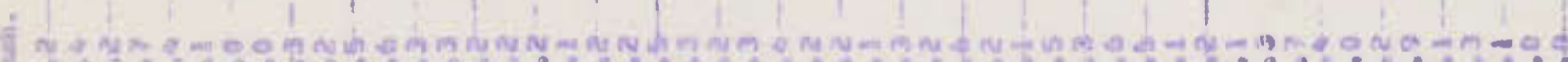
N

H

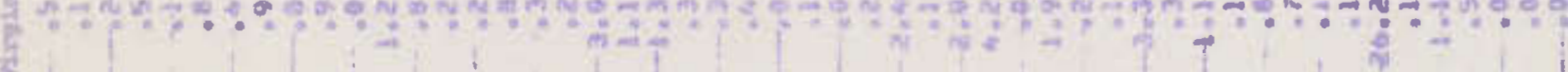
qog:omo: If

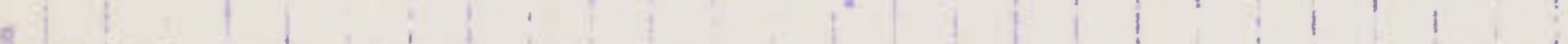

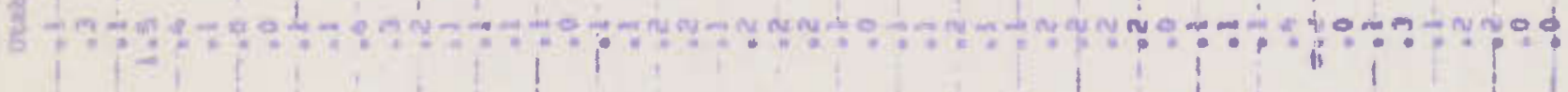

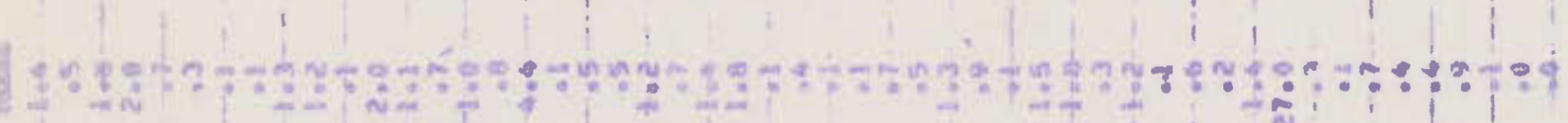

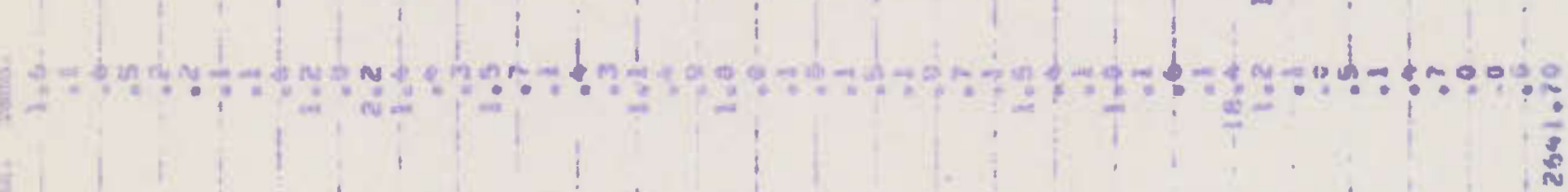

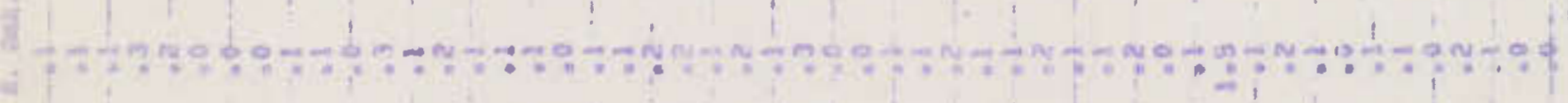

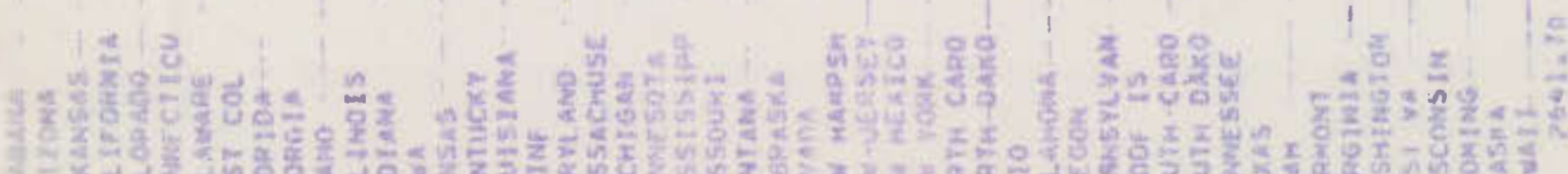

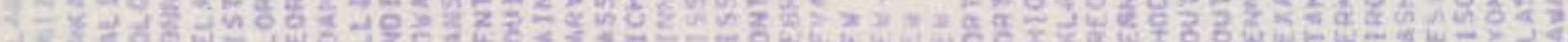

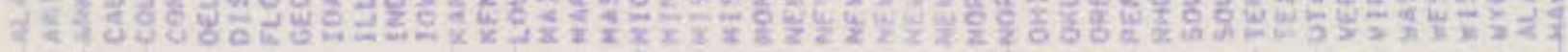
Nㅜ문 


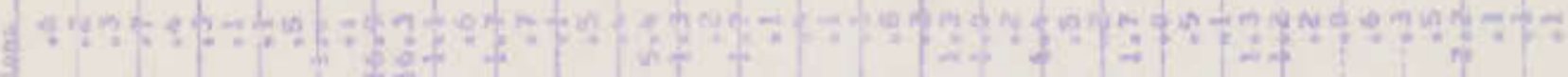

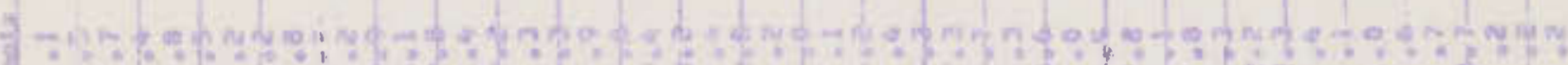

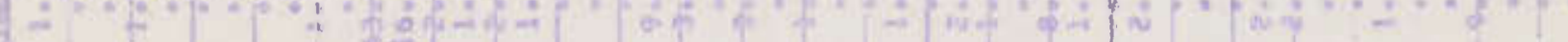
(1)

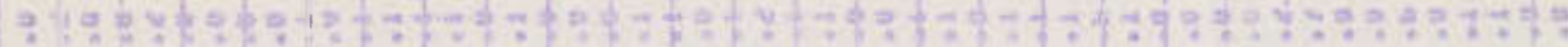

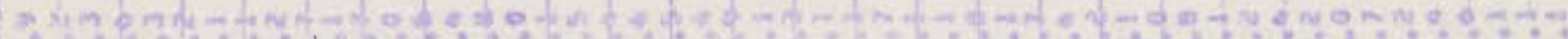

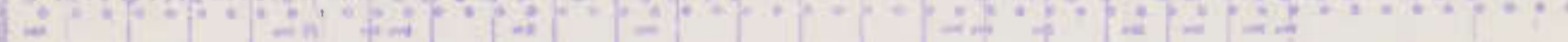
3.

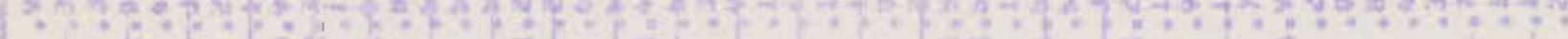
8 2-60-0 -

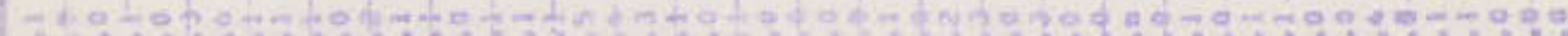
हf

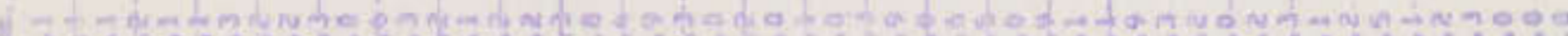
4
3
3
3
3

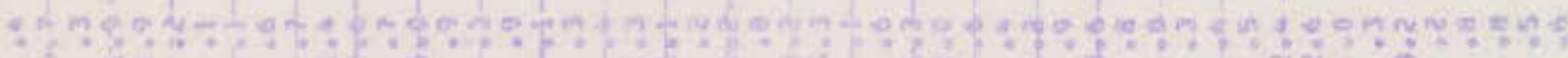

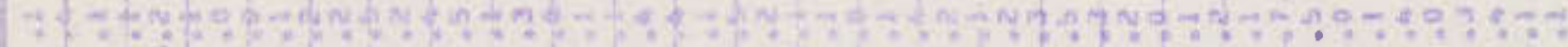
$\uparrow$

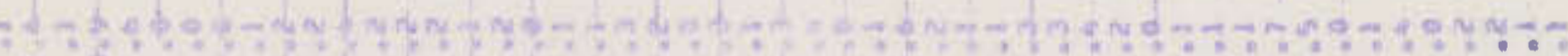

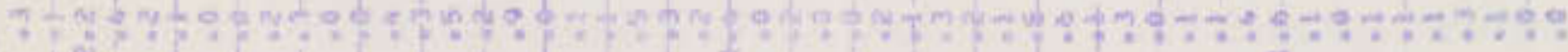
(1) 3 a $^{*}$

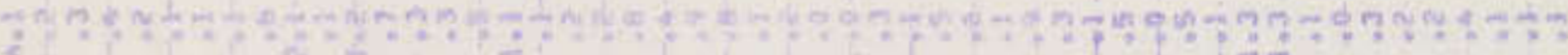

\section{$\leq 3$}

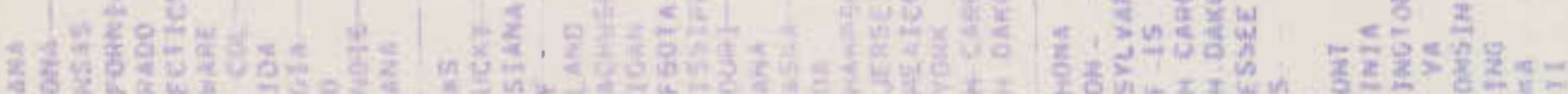

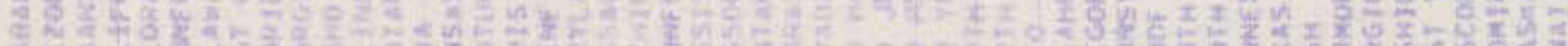

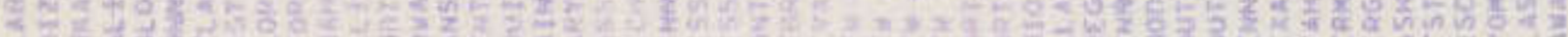

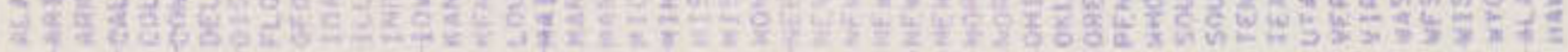
- wm 


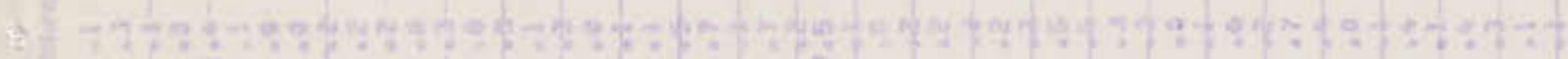
N

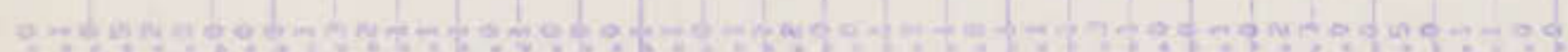

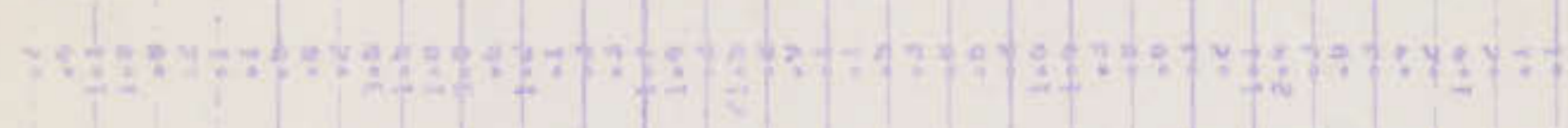

- - FM

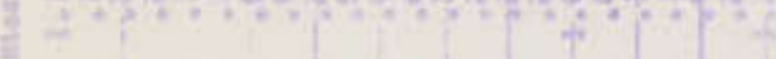

$y$ y $\frac{H}{2}$ nith

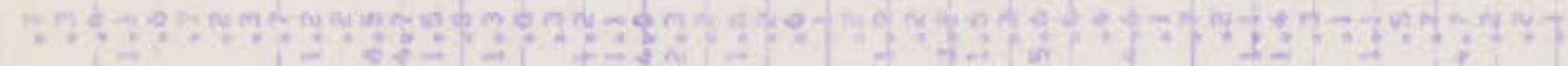

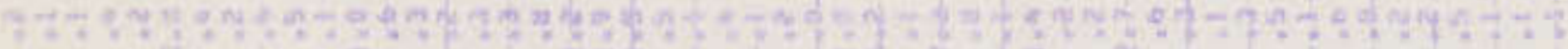

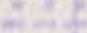

4

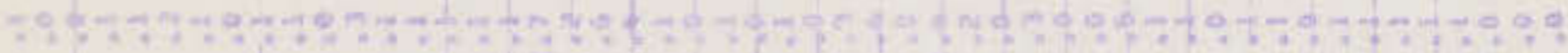

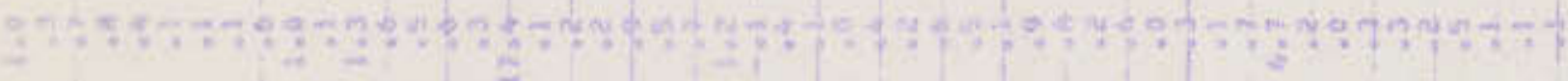

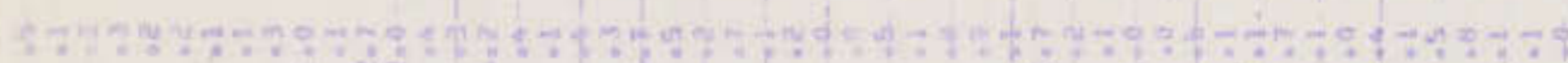
(

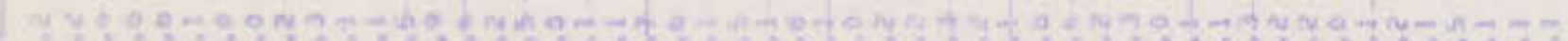

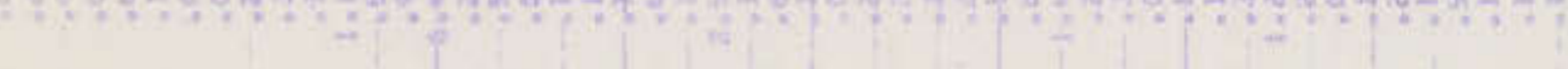

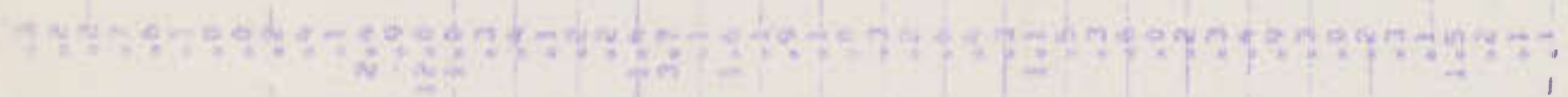

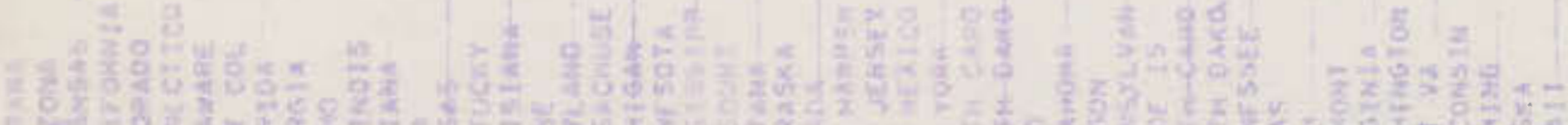

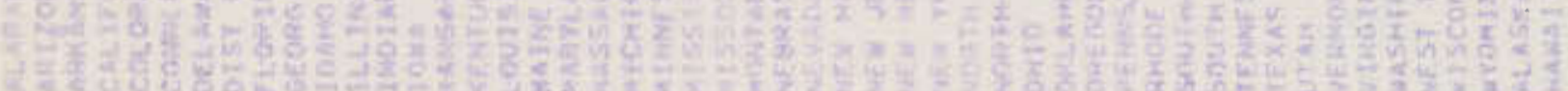
$-M m+M$ a 


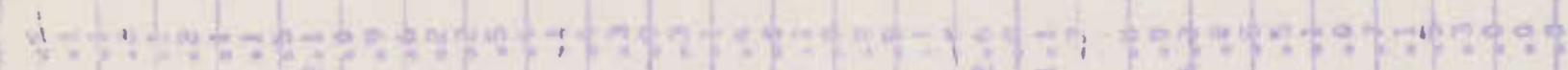

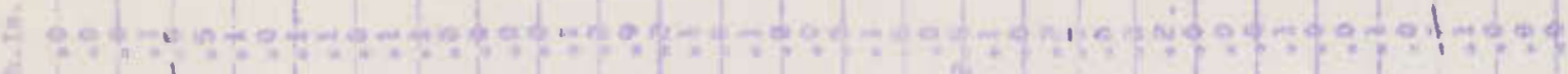

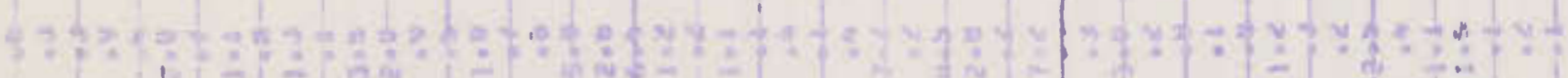
1. (1)

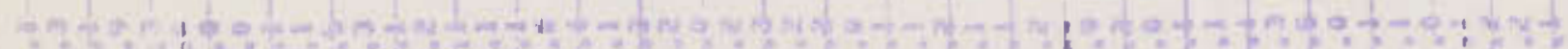
(3)

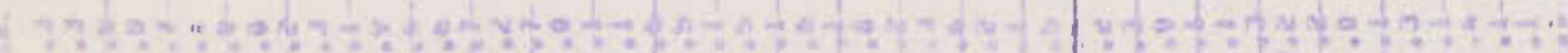
T.

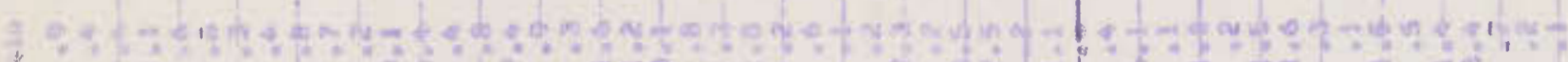

6.

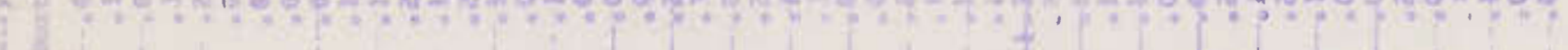

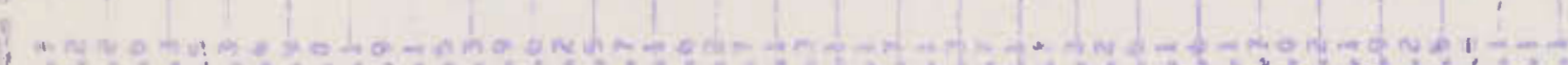

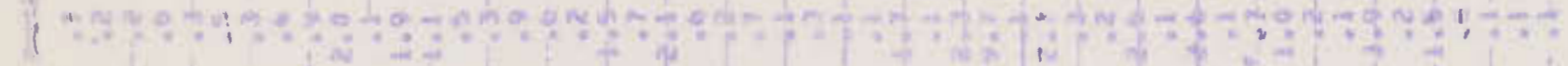
1
An

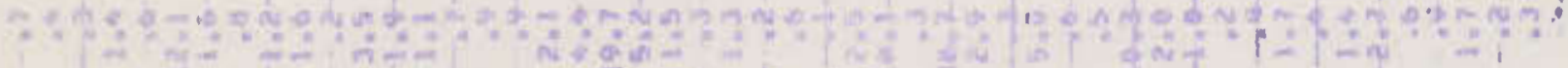

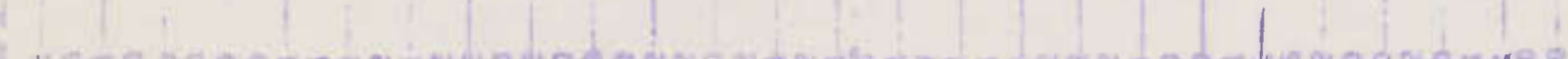

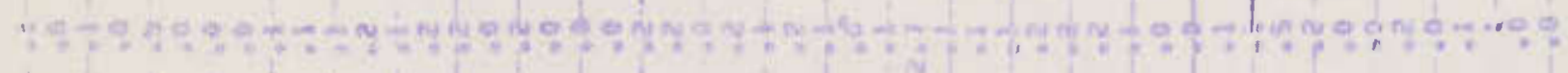

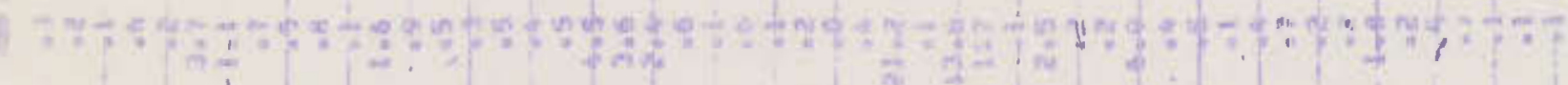

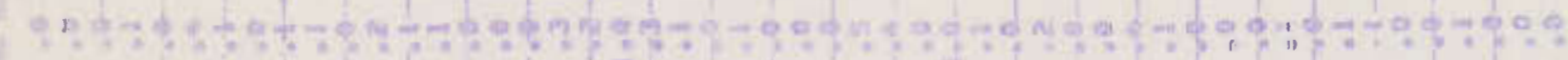

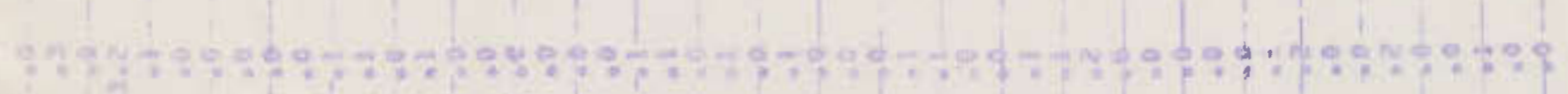

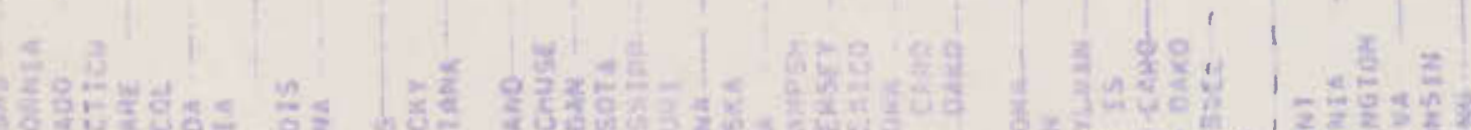

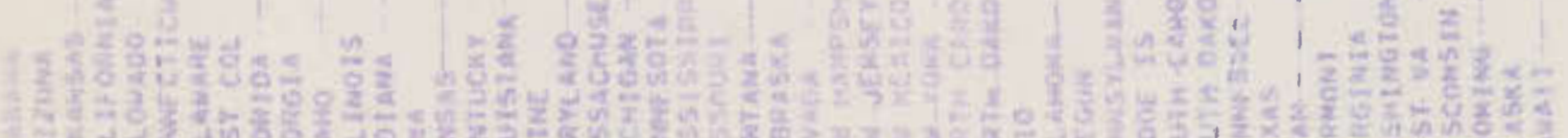

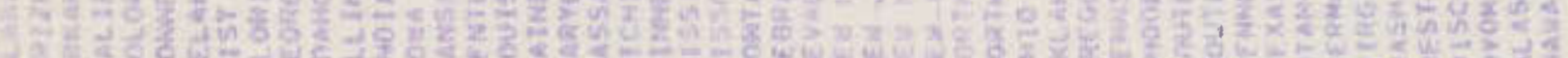
72. Ama 
1790 \% ?.

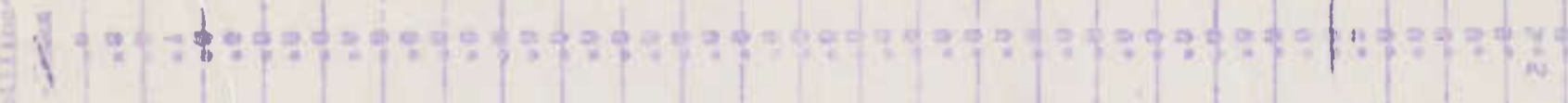

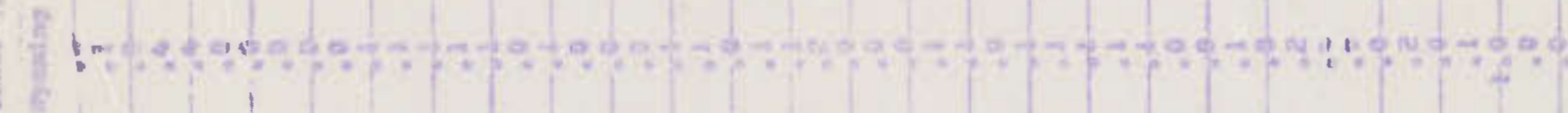

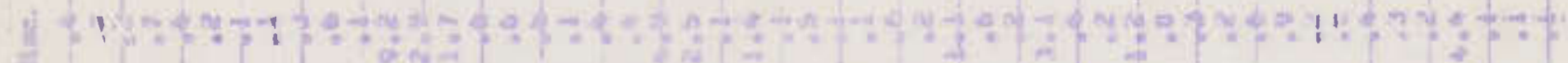

10

8.

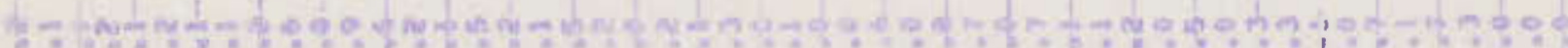

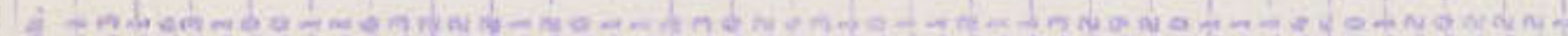
30 b.

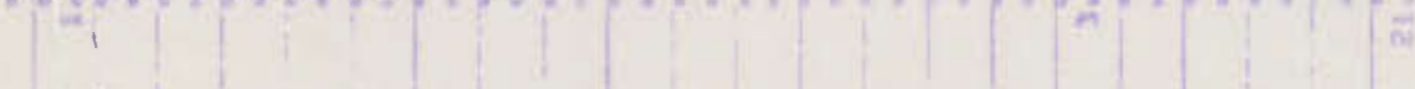

G 2. (15)

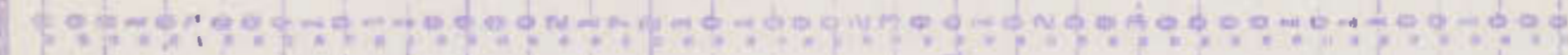

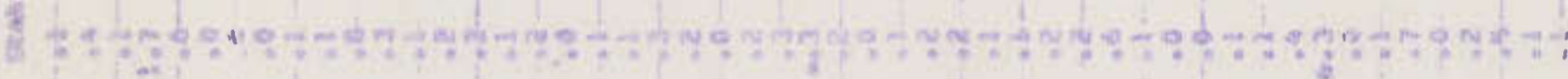

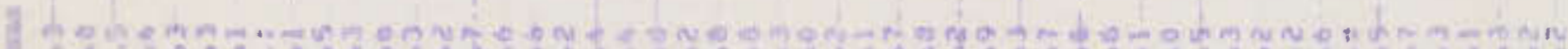

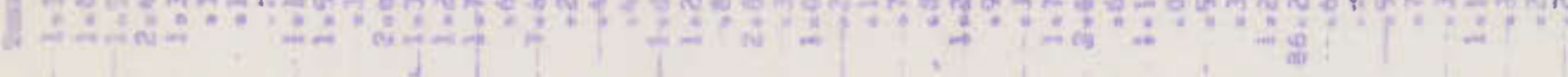

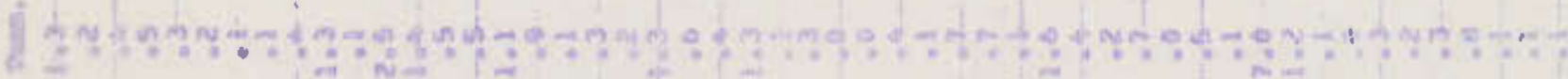

A -

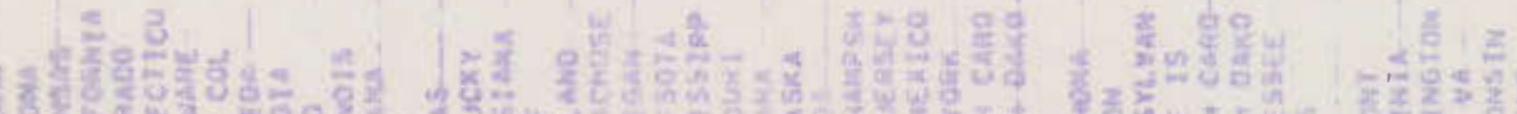

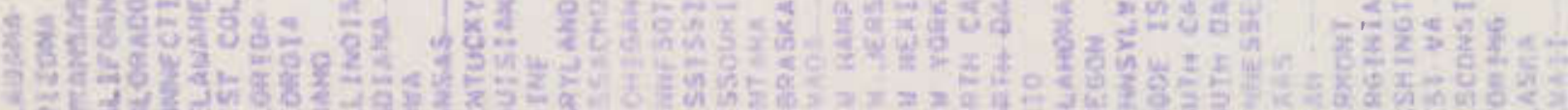

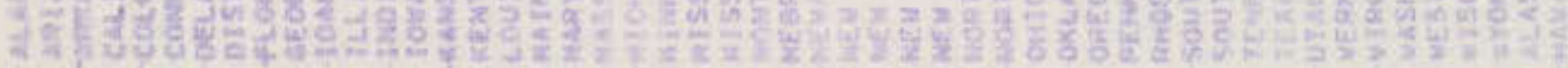

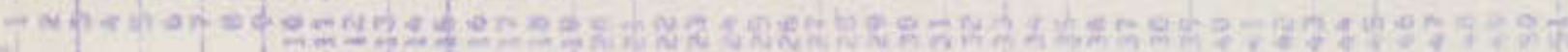

